University of Louisville

ThinkIR: The University of Louisville's Institutional Repository

Electronic Theses and Dissertations

$8-2020$

\title{
Modulation of inflammatory pathway by inflammatory inhibitor JSH-23 mitigates diabetic retinopathy.
}

Rubens Petit Homme
University of Louisville

Follow this and additional works at: https://ir.library.louisville.edu/etd

Part of the Endocrine System Diseases Commons, Eye Diseases Commons, and the Immune System Diseases Commons

\section{Recommended Citation}

Petit Homme, Rubens, "Modulation of inflammatory pathway by inflammatory inhibitor JSH-23 mitigates diabetic retinopathy." (2020). Electronic Theses and Dissertations. Paper 3479.

https://doi.org/10.18297/etd/3479

This Doctoral Dissertation is brought to you for free and open access by ThinkIR: The University of Louisville's Institutional Repository. It has been accepted for inclusion in Electronic Theses and Dissertations by an authorized administrator of ThinkIR: The University of Louisville's Institutional Repository. This title appears here courtesy of the author, who has retained all other copyrights. For more information, please contact thinkir@louisville.edu. 
MODULATION OF INFLAMMATORY PATHWAY BY INFLAMMATORY INHIBITOR

JSH-23 MITIGATES DIABETIC RETINOPATHY

\author{
By \\ Rubens Petit Homme \\ B.S., Florida Southern College, 2016 \\ M.S., University of Louisville, 2019
A Dissertation
Submitted to the University of Louisville School of Medicine In Partial Fulfillment of the Requirements
for the Degree of \\ Doctor of Philosophy \\ in Physiology and Biophysics \\ Department of Physiology \\ University of Louisville \\ Louisville, Kentucky
}

August 2020 



\title{
MODULATION OF INFLAMMATORY PATHWAY BY INFLAMMATORY INHIBITOR JSH-23 MITIGATES DIABETIC RETINOPATHY
}

\author{
By \\ Rubens Petit Homme \\ B.S., Florida Southern College, 2008 \\ M.S., University of Louisville, 2019
}

A Dissertation Approved on

May 18, 2020

By the following Dissertation Committee

Suresh C. Tyagi, Ph.D., Mentor

Mahavir Singh, Ph.D., Co-Mentor

Irving G. Joshua, Ph.D.

Neetu Tyagi, Ph.D.

Sandhu Harpal, M.D. 


\section{DEDICATION}

To my brothers Robens Manno \& Ferry Petit Homme, Juan Luis Garcia, my sisters Brindy, Luchandley, Guerlie, and Rose

My Parents, Mrs. Elicienne and Mr. Bienera Petit Homme, My best men \& women, Tervens, Clay, Senatus, Anne, \& Frederick The moms and dads that showed me my left foot from my right, aunt Clarine, Guerda, Ginette, Roseline, Mrs. Honors, Ms. Evon, Grandma Dada, Dr. Gauthier, Dr. Lee, Dr. Eubank, Dr. Crowe, Mr. Ferdinand, Coach Locke, and of course Dr. Adrienne Bratcher

To my city, La Pointe Des Palmistes, My guardian angels, Terancia, Aunt Paulna, \& Mrs. Serafin, My Church, First Baptist Church of Nazarene in Lakeland,

My alma matter, the Red Devils and the Moccasins

To those that want but never was as privileged as I am "Habacuc Milord."

To my family that has walked, continue to walk, and will always walk with me through all the paths of my life.

It's a great remorse that all your names cannot fit within one page.

All the cells and water in my body would like to say, "Thank you for sharing the love with me all the days of my life!"

My people continue to share the love, and I'm the living proof that your grace has no limit to the success it can bring to someone. 


\section{ACKNOWLEDGEMENTS}

I am truly blessed and privileged to have the opportunity to conduct my research with the best and the brightest people in the best University under the sky. It is with great pleasure that I would like to thank my mentor and my best soccer-mate, Dr. Suresh C. Tyagi for his support, encouragement, and guidance, for the past four years in his laboratory. His leadership and love for the scientific endeavors are incomparable. I would like to thank him not only for teaching me the know-how in the laboratory but also for sharing a soccer field with me. Soccer has been the remedy for my life, particularly under challenging days; it was a treasure to share the pitch with my mentor. As people say it is always better with a little humor; Dr. Mahavir Singh never ceases to amaze me with his sense of humor. He was there to support and guide me when things were well or not well in the lab. I am tremendously grateful for his mentorship. I would like to thank Dr. Joshua not only for his advice and guidance about my research but also for teaching me about the strategic career planning, something that I used not only for myself but also for my organization (BASSA). Further, I would like to thank Dr. Neetu Tyagi for serving on my committee, for her advice, support, and kindness over the years.

Additionally, I would also like to thank Dr. Sandhu for serving on my committee, arranging clinical samples, increasing my clinical knowledge on Diabetic Retinopathy, and encouragement over the years. I would also like to thank Dr. Bratcher who has always been there with me since my very first day in Louisville, mentored me as her from a summer student with the Summer Cardiovascular Research Programs to the Ph.D. application, qualification, and hopefully soon graduation. I would like to take this time to 
salute all the professors of the Department of Physiology for their guidance and knowledge during the last four years. I would also like to offer my utmost gratitude to Denise, Jennifer, and Carol for their constant love, support, help, and assistance for the last four years.

I would like to thank all our lab members for creating a supportive and inclusive work environment and years of friendship. Salute to Naira Metreveli, Irina Smolenkova, Anwesha Laha, Dr. Akash K. George, Dr. Papujohn, Dr. Thielen, and Dr. Majumder for their assistance, advice, teaching, and love during my studies. 


\begin{abstract}
MODULATION OF INFLAMMATORY PATHWAY BY INFLAMMATORY INHIBITOR (JSH-23) MITIGATES DIABETIC RETINOPATHY
\end{abstract}

\author{
Rubens Petit Homme
}

August 11, 2020

\begin{abstract}
Diabetic retinopathy (DR) is the most common microvascular complication of diabetes mellitus (DM). Its pathology is consisted of the breakdown of the blood-retinal barrier (BRB), particularly the inner blood-retinal barrier (iBRB). The exact mechanism that leads to the iBRB impairment and the development of DR has not been elucidated yet. However, chronic inflammation that is hallmark of the type I DM has recently become a key focus in DR study. Hyperglycemia causes dysregulation of nuclear factorkappa B (NF- $\mathrm{KB})$; and its constant activation increases the expression of inducible nitric oxide synthase (iNOS), cyclooxygenase-2 (COX-2), and intercellular adhesion molecule-1 (ICAM-1) in the retina and vitreous of DR patients and animal models. This increase in inflammatory mediators leads to the degradation of junctional molecules, occludin, connexin-43, death of retinal cells via pyroptosis, and thus disruption of the iBRB. Derailment of the iBRB induces fluid accumulation into the retina of DR patients, which eventually progresses into vision impairment. The purpose of this study


is to investigate whether chronic inflammation in DM induces disruption of iBRB; and whether inhibition of the expression and activity of NF- $\kappa$ B by Methyl- $\mathrm{N}^{1}-(3-$ phenyl propyl) benzene-1, 2-diamine (JSH-23) would mitigate this iBRB disruption.

Methods: Type 1 diabetic mouse model (Akita) on a C57BL/6J background along with non-diabetic littermate were used in the experiments. All mice were 22-24 weeks of age at the start of the experiments. The experimental and the control animals were treated for four weeks on alternate days with JSH-23 @ $5 \mathrm{mg} / \mathrm{Kg}$ body weight. The intraocular pressure (IOP), blood pressure, blood glucose, and body weights of all animals were measured before and after treatment. Fluorescence angiography (FA), optical coherence tomography (OCT), and dark-adapted electroretinogram were performed before and after the treatment. Also, intraperitoneal glucose tolerance test (GTT) were performed in the animals before and after the treatment. Then, the retinas and plasma were collected. Western blotting and real-time polymerase chain reaction were performed to analyze protein expression and the mRNA levels of NF- $\kappa$ B p65, iNOS, COX-2, ICAM-1, occludin, connexin-43, NLRP3, caspase-1, and IL-1 $\beta$. Additionally, plasma insulin levels were also analyzed via ELISA kit.

Results: The body weight of Akita mice was significantly lower than the C57BL/6J mice. The treatment with JSH-23 did not have any effect on body weight. The blood glucose of Akita mice was significantly higher than the blood glucose of non-diabetic littermate control mice. The treatment substantially decreased blood glucose in Akita mice. Also, the plasma insulin level for the Akita mice was significantly lower 
compared to non-diabetic littermate control mice. The intraperitoneal

GTT showed that the Akita mice were unable to lower their blood glucose levels.

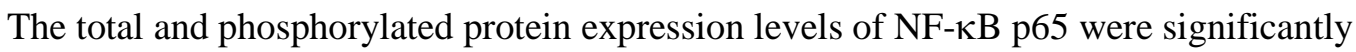
decreased after treatment with JSH-23 in Akita mice, and the gene expression of NF-кB p65 also reduced. The protein and gene expression levels of iNOS, COX-2, and ICAM-1 were reduced after treatment in Akita mice, and the treatment significantly lowered the expression of pyroptosis marker NLRP3. The gene expression of other proteins in the pyroptosis pathway were also reduced, including caspase- 1 and IL-1 $\beta$. On the other hand, the protein and gene expression levels of junctional molecules occludin, connexin-43 were significantly increased in Akita mice after treatment with JSH-23. The blood pressure of the animals was normal and the treatment did not have any effect on the blood pressure. FA depicted an increase in retinal capillary permeability in Akita mice, and the treatment significantly reduced that permeability. The OCT showed retinal layers thickening in the retina of Akita mice, and treatment increased the retinal layers thickness. Electroretinogram (ERG) showed an increase in the amplitude of the A-wave and the B-wave in Akita mice.

Conclusions: The results showed that inhibitor (JSH-23) improved visual function by decreasing the retinal vascular permeability, IOP, and the retinal inflammation in Akita mice. 


\section{TABLE OF CONTENTS}

PAGE

ACKNOWLEDGEMENTS ...................................................

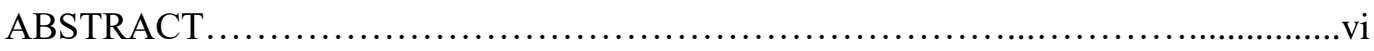

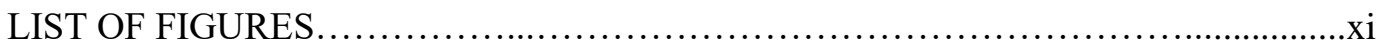

\section{CHAPTER I}

\section{GENERAL INTRODUCTION}

Retina...........................................................

Blood-Retinal Barrier...............................................11

Diabetic Retinopathy...........................................19

Inflammation................................................23

JSH-23...................................................42

\section{CHAPTER II}

HYPOTHESIS \& SPECIFIC AIMS .....................................51

\section{CHAPTER III}

JSH-23 DOWNREGULATED NF-кB AND INCREASED EXPRESION OF

JUNCTIONAL MOLECULES IN THE RETINA OF AKITA MICE

Introduction.................................................53

Methods............................................................55

Results...................................................62

Discussion................................................. 78 


\section{CHAPTER IV}

\section{EFFECT OF JSH-23 IN VISION OF AKITA MICE}

Introduction.................................................... 83

Methods........................................................ 84

Result......................................................... 86

Discussion......................................................101

\section{CHAPTER V}

CONCLUSION DISCUSSION ..........................................

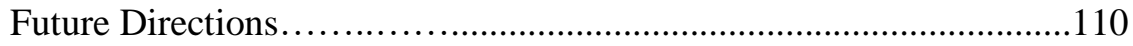

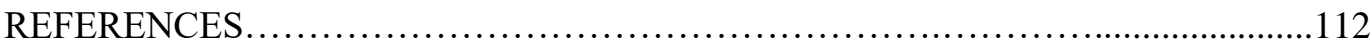

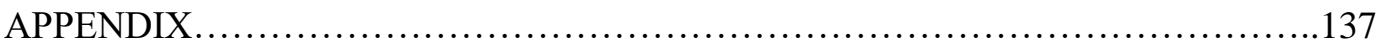

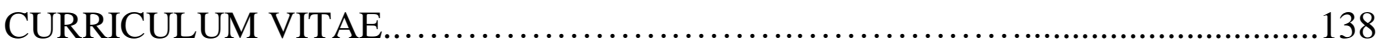




\section{LIST OF FIGURES}

FIGURE

PAGE

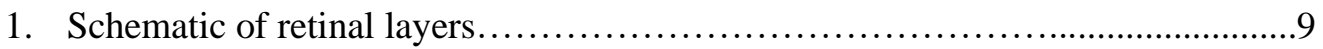

2. Brief schematic of the inner blood retinal barrier (iBRB) ...................... 16

3. Mechanism of diabetic retinopathy pathology .......................................24

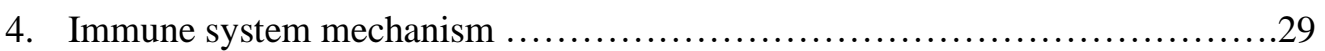

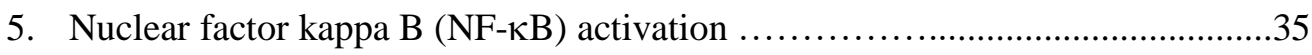

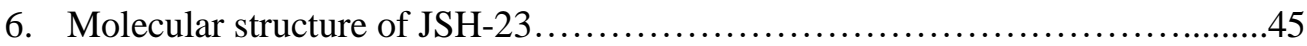

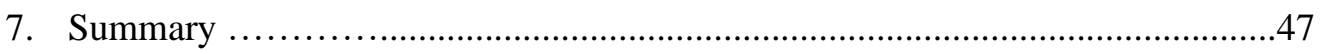

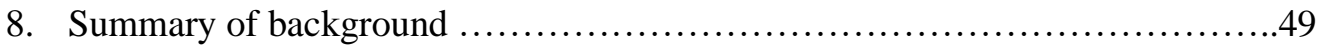

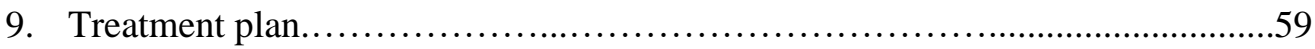

10. Genotyping and physiology parameters of Akita and non-diabetic littermate control mice............................................................65

11. Expression of NFאB p65 in the retina of Akita and non-diabetic littermate control mice after treatment with JSH-23...................................67

12. Expression levels of ICAM-1, iNOS, and COX-2 in the retina of Akita and nondiabetic littermate control mice after treatment with JSH-23...............69

13. Gene expression level of ICAM-1, INOS, and COX-2 in the retina of Akita mice and non-diabetic littermate control treated with JSH-23 ...................71

14. Pyroptosis marker in the retina of Akita and non-diabetic littermate control mice

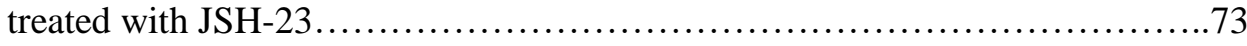

15. Expression of junctional molecules in the retina of Akita and non-diabetic littermate control mice treated with JSH-23 .............................75 
16. Systemic blood pressure and intraocular pressure (IOP) in Akita and non-diabetic littermate control mice.

17. Fundus imaging of Akita and non-diabetic littermate control treated with JSH-

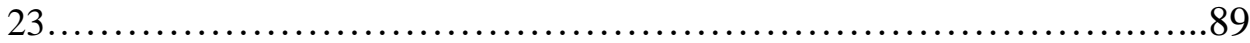

18. Fluorescence Angiography of Akita and non-diabetic littermate control treated with JSH-23.....................................................91

19. Optical coherence tomography of Akita and non-diabetic littermate control treated with JSH-23

20. Electroretinogram (ERG) of Akita and non-diabetic littermate control mice

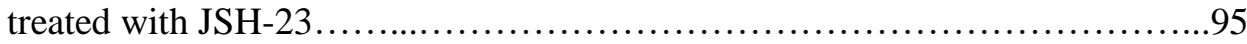

21. Light dark chamber movement....................................... 98

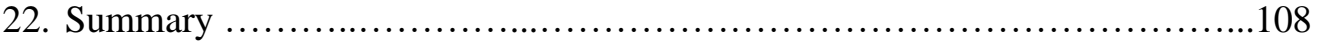




\section{CHAPTER I}

\section{GENERAL INTRODUCTION}

\section{$\underline{\text { Retina }}$}

Phototransduction carried out by retinal neuronal cells, supported by retinal glial cells (RGC), is the primary function of the retina [1-4]. Phototransduction is divided into three parts: a receptor (rhodopsin), G-protein (transducin), and an effector (cGMP phosphodiesterase or PDE/PDE6). It starts with 11-cis retinal absorption of a photon that leads to a conformational change in 11-cis retinal to 11-trans retinal. Rhodopsin is activated (metarhodopsin II), which then enables transducin $[3,5]$.

Transducin activate cGMP phosphodiesterase (PDE). PDE, hydrolyze cGMP, lead to the closing of a cGMP-gated ion channel in the membrane. PDE decreases cGMP concentration; as a result, the cGMP-dependent gated channels in the plasma membrane closed. Uptake of cation reduces in the photoreceptor outer segment (POS); the membrane hyperpolarizes. That decreases the secretion of glutamate. Termination of phototransduction involves inactivation of rhodopsin, transducin, PDE, and increasing concentration of cGMP. Rhodopsin kinase (GRK1) phosphorylated rhodopsin; protein arrestin (Arr1) complete the inactivation by binding to the receptor [6, 7]. G-PDE inactivated by RGS9-1- G-protein signaling protein [8]; Guanylyl cyclase restored the concentration of cGMP $[9,10]$.

The vision cycle is divided into dark and light periods. The dark period leads to a 
constant flow of $\mathrm{Na}^{+}$into the photoreceptor, thus depolarizing the plasma membrane. Depolarization triggers the release of glutamate however during the light cycle, the opposite happens, the flow of $\mathrm{Na}^{+}$stops, and thus the plasma membrane hyperpolarizes and the glutamate secretion stops [11-13].

Rods photoreceptors are sensitive to blue-green light (peak $~ 500 \mathrm{~nm}$ wavelengths). In fact, they are very sensitive and at the same time highly efficient in capturing a single photon [14]. Visual pigments in cones are the opsin molecules, and cones sensitivity depends on the molecular structure of opsin for the long wavelengths (red light), short-wavelength (blue light), and medium wavelength (green light).

\section{Anatomy and Physiology of the Retina}

The retina is a semi-circle with a diameter between 30 and $40 \mathrm{~mm}, 0.5 \mathrm{~mm}$ thickness, lining the posterior part of the eye. All the major blood vessels of the retina converge towards the center to form the optic nerve. The foveal (the center of the macula) contains no blood vessels and only cone photoreceptors are located to the left of the optic nerve. The retina is divided into two areas: the central (macula) and the peripheral retina. The central retina is the circular area with a $6 \mathrm{~mm}$ diameter from the fovea, while the peripheral retina is everything outside of the central retina [15].

The retina is further divided into ten different layers of cells and cell bodies such as outer nuclear layer (ONL), inner nuclear layer (INL), inner plexiform layer (IPL), outer plexiform layer (OPL), ganglion cell layer (GCL), outer limiting membrane (OLM), nerve fiber layers (NFL), inner limiting membrane (ILM), and the retinal pigment epithelium (RPE). The cell layers contain ganglion, photoreceptors, and epithelial cells. The ganglion cells (GCs) are closest to the retina and serves as the output of photoreceptors and input to the optic nerve. The photoreceptors capture and transduce 
light, while the epithelial performs many functions to maintain retinal homeostasis.

The cell bodies of first-order neurons (rods and cones photoreceptors) reside in the ONL. The INL houses the cell bodies of second-order neurons (bipolar, horizontal, and amacrine cells). First-order and second-order neurons synapse in the OPL. GCs and second-order neurons synapse in the IPL. The OLM contains adherens junctions between photoreceptors and Müller cells, while the ILM houses the Müller cells. The OLM forms a barrier between the outer retina and the subretinal space, while the ILM forms a barrier between the inner retina and the vitreous humor. All retinal cell layers are perfused mainly by the central retinal artery (CRA).

The retina has two main blood supplies: choroid (perfused photoreceptors) responsible for about $3 / 4$ of retinal blood supply, and the CRA (perfused inner retina), responsible for the last $1 / 4$ of the retinal blood supply [16]. The retinal layers are perfused via retinal capillaries. The retinal capillaries form a network throughout the retina, radial peripapillary capillaries (RPCs), inner and outer layer capillaries. The RPCs is located within the NFL and is alimented about $5 \mathrm{~mm}$ from the optic disc, inner capillaries alimented the GCL, while the outer capillary aliments the IPL, OPL, and the INL [16, 17].

Outer Plexiform Layer $(O P L)$. Second-order neurons synapses with photoreceptors in the OPL to propagate the signals. The OPL contains mainly two types of cells: bipolar and horizontal cells. The retina contains 11 different types of bipolar cells, all except one synapse with cones photoreceptors [18-21]. Bipolar cell bodies reside in the INL, with dendrites located in the OPL. Some photoreceptors synapse with one bipolar cell while other with many bipolar cells. There are also some bipolar cells that are photoreceptors specific, e.g., S-cone. Bipolar cells designated as either ON or OFF [19]. Bipolar cells 
responded differently to glutamate. Based on the receptor, it could lead to depolarization or hyperpolarization of the plasma membrane. Depolarization indicates an ON-bipolar cell, while hyperpolarization indicates an OFF-bipolar cell [22]. The ON-bipolar cell has mGluR6 glutamate receptors $[23,24]$ while OFF-bipolar cell has iGluR AMPA-kainate glutamate receptors [25]. The retina has only two distinct types of horizontal cells, which are layered horizontally in the OPL [21]. In the presence of glutamate, horizontal cells hyperpolarize. The IPL further carries the signal to amacrine and GCs.

Inner Plexiform Layer (IPL). Bipolar cells synapse with amacrine and GCs within the IPL. There are various types of amacrine cells $[19,26]$. They used serotonin, acetylcholine, and other neurotransmitters for further transducing phototransduction towards GCs [27-29]. They are various types of GCs as well [30, 31]. GCs are divided into alpha, beta, gamma, and G4 to G23 [31]. Beta GCs are the most prevalent, approximately half of all the GCs $[32,33]$. The IPL separates the ON-bipolar and OFFbipolar cells by dividing the GCs into two compartments below the amacrine cells. The ON-bipolar cells interact only with a compartment while the OFF-bipolar cells interact with the other compartment [34-39]. The optic nerve synapses with the GCs and sends the information to the brain.

Visual Responses of Ganglion Cells. Similar to bipolar cells, GCs are divided into ON, OFF, and ON-OFF centers cells based on their response to light. ON-GCs fires a burst of action potential (AP) upon stimulation then maintain the firing at a short interval. ONOFF-GCs fires AP when activated and then at the end of the stimulus, while OFF-GCs centers fire AP at the end of the stimulus [40, 41]. OFF-GCs cells synapse with axon terminal of OFF-bipolar cells in the proximity of the amacrine cell bodies, ON-GCs cells 
synapses with ON-bipolar cells, while ON-OFF cells do both [36, 42]. As stated earlier, GCs receive the final output of the signals, and they then send that output through the brain via the optic nerve for interpretation. Another structure critical to retinal function is the RPE.

Retinal Pigment Epithelium. The RPE located between the choroid and the POS. RPE apical side faces the POS, while its basolateral side faces the Bruch's Membrane. It has pigments granules in a single sheet of cell shape that resembles a hexagon that links together via tight junctions. The RPE contains organelles capable of digesting POS into phagosomes. The RPE functions to absorb light, buffer ion, phagocytoses, epithelial transport, secretion, and immune modulation.

Phototransduction results in a high amount of photo-oxidative energy within the retina $[63,110]$. The RPE located in the middle of the outer retinal blood flow (choroid) [117]. The choroid perfuses substantially higher than the kidney $[111,112]$, while the retina extraction of oxygen is significantly low, thus the choroidal venous blood is $90 \%$ saturated with oxygen. RPE also phagocytoses POS. These factors increase the free radicals levels in the RPE $[63,110]$. RPE uses pigmented granules to defend itself from the oxidative stress (OS) [113] that move to the apical side during light absorption [114, 115]. Aside from the pigmented granules, RPE uses antioxidants, and it has a high capacity to repaired macromolecules such as lipids, DNA, and proteins that damaged due to an increase of OS in the retina $[113,116]$.

The RPE separates the systemic and the subretinal flow, facilitates the transport of nutrients to the retina, balances the ion in the retinal space, and removes metabolic wastes from the retina. It also transports key phototransduction metabolites to the retina such as glucose, retinal (retinaldehyde; a form of vitamin A), and $\omega-3$ fatty acids. 
Apical and basolateral glucose transporter 1 (inducible to meet metabolic needs) and glucose transporter 3 facilitate glucose transport into the retina [118]. Retinal transportation initiates with retinal uptake and then induces in the visual cycle-

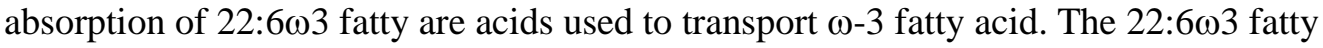
acids are also used to synthesize glycerophospholipids for incorporation into the membrane of photoreceptors [119].

The retina contains the highest cell density of any tissue in the human body and its cells have a substantial metabolic turn-over, which increases the production of water and thus its accumulation into the retina. Also, intraocular pressure (IOP) orient movement of water towards the retina, further contributing to its accumulation into the retina. There is also a substantial production of lactic acid in the retina $(19 \mathrm{mM})$ due to retinal metabolic activity [121]. RPE remove water via active transport through aquaporin-1 located both in the apical and basolateral membrane of the RPE [122, 123]. The energy for that transport is obtained via the ubiquitous $\mathrm{Na}^{+} / \mathrm{K}^{+}$pump located on the apical front of the RPE which is located on the basolateral membrane. Lactic acid is eliminated via mono-carboxylate transporter-1 (MCT1) (apical) and mono-carboxylate transporter-3 (MCT3) (basolateral). The $\mathrm{pH}$ regulation is mandatory for facilitating the transport. MCT1 and MCT3 use $\mathrm{H}^{+}$for the transport and is regulated via apical $\mathrm{Na}^{+} / \mathrm{H}^{+}-$ exchanger and $\mathrm{Na}^{+} / \mathrm{HCO}^{3-}(1: 2)$ co-transporter and basolateral $\mathrm{Cl} / \mathrm{HCO}^{3-}$ exchanger [124]. Through the transport of ions across its epithelial junctions, the RPE regulates the balance of ions in the subretinal space. Additionally, to maintain homeostasis, RPE needs to compensate for the fast change in ions in the subretinal space [125].

$\mathrm{K}^{+}$ions are the main ion concentration that must be in check. During the dark cycle, photoreceptors channels on the POS uptake $\mathrm{Na}^{+}$. The influx is balanced via the apical membrane of the membrane of the RPE by releasing $\mathrm{K}^{+}$ions into the subretinal 
space. During the light cycle, the cations channels are closed; thus, there is a decrease in the outflow of $\mathrm{K}^{+}$from the inner segment. Also, the $\mathrm{Na}^{+} / \mathrm{K}^{+}$-ATPase pump of the POS takes up $\mathrm{K}^{+}$. All these events combine to decrease the $\mathrm{K}^{+}$concentration in the subretinal space. RPE $\mathrm{K}^{+}$channels such as Kir7.1 in the apical membrane release $\mathrm{K}^{+}$into the subretinal space to maintain $\left[\mathrm{K}^{+}\right]$concentration $[125,126]$.

The RPE is responsible for the conversion of 11-trans to 11-cis retinal to maintain proper visual conduction [129]. First, the trans-retinal is transported through the POS from the intradiscal space via an ATP-driven flippase. Trans-retinal is converted to $\mathrm{N}$-retinylidinephosphatidylethanolamine by reacting with phosphatidylethanolamine. Then retinol-dehydrogenase reduces trans-retinal to trans-retinol in the membrane. Transretinol move to the subretinal space and the interphotoreceptor retinoid-binding protein (IRBP) carries the trans-retinol to the RPE. In the RPE, cellular retinol-binding protein transfers the trans-retinol to a protein complex. This complex contains three enzymes that mediate the conversion of trans-retinol to cis-retinal. Lecithin retinol transferase (LRAT) adds an acyl to the retinol. RPE65 (RPE protein with $63 \mathrm{kDa}$ ) catalyzes the reisomerization of acyl-retinol. And the 11-cis-retinol dehydrogenase oxidizes retinol to 11-cis retinal.

Photo-transduction destroys the POS, which is then replenished by the RPE via RPE shredding of the damaged part and phagocytosis [130]. This process is regulated by the circadian rhythm. It is a daily process that occurrs early in the day and activated by light [131]. The phagocytosis mechanism is regulated via three receptors: $\alpha \mathrm{V} \beta 5$ integrin, CD36, and receptor-tyrosine kinase c-mer (MerTK) [132]. The $\alpha \mathrm{V} \beta 5$ integrin mediates the binding of POS to the RPE, MerTK is phosphorylated via focal adhesion kinase [133]. That leads to the production of inositol-1, 4, 5-triphosphate leading to an increase 
in $\mathrm{Ca}^{2+}$ concentration inside the cells, and $\mathrm{CD} 36$, thus activating the phagocytosis. The blood-ocular barrier is another factor that plays a crucial role in the homeostasis of the retina. 
Figure 1. Schematic of Retinal Layers. The retina function to transmit light from the outside world to the brain via the photoreceptors and second-order neurons. The retina contains many different layers of cells and synapses, each played a distinct role in phototransduction. From the outer layer to the inner layers, OLM, RPE, ONL, OPL, INL, IPL, GCL, NFL, and the ILM. 
FIGURE 1

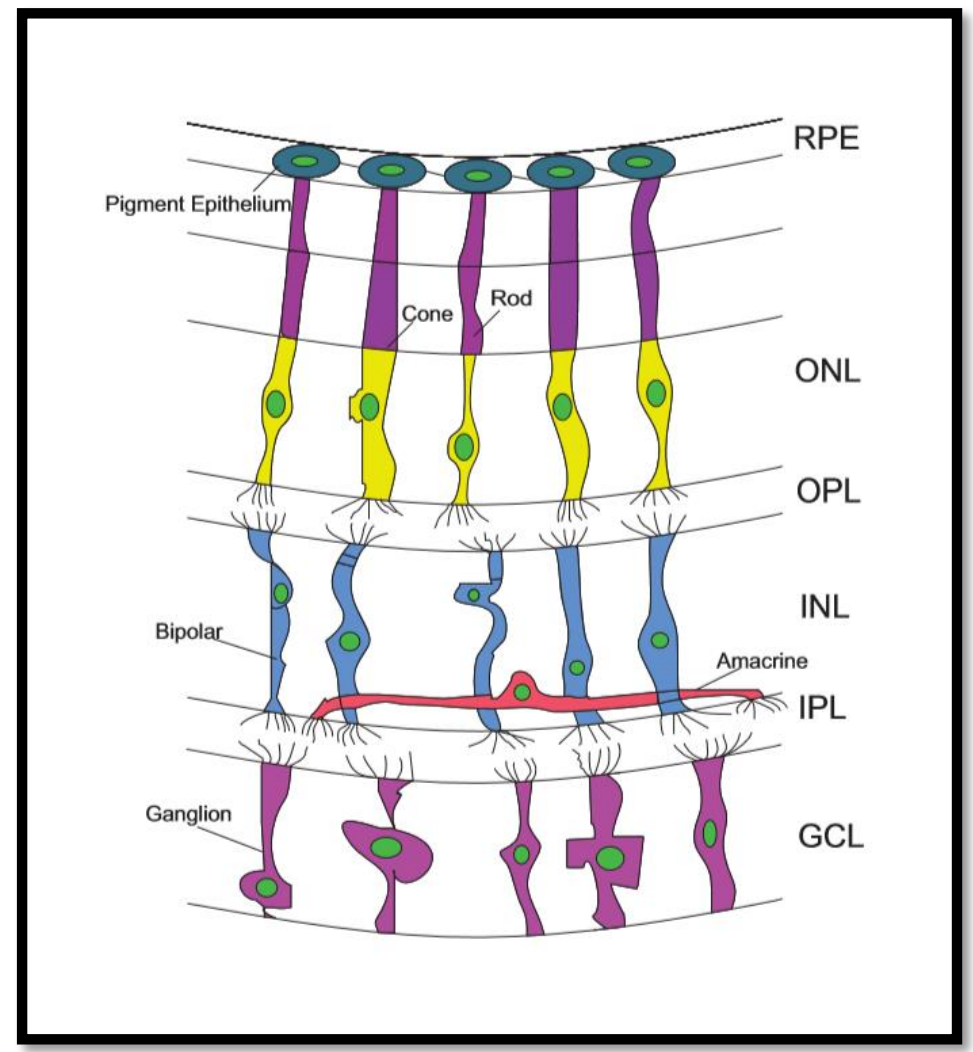




\section{$\underline{\text { Blood Ocular Barrier }}$}

The blood-ocular barrier (BOB) system is divided into two parts: blood-aqueous and blood-retinal barriers. BOB restricts the passage of ions and other blood-borne molecules from penetrating the retina through the aqueous humor and the vitreous [43]. Breakdown of the BOB allows molecules and other drugs to diffuse to the retina and induce inflammation. Another factor that contributes to retinal homeostasis is the downregulating immune environment (DIE) in the eye [44]. Degradation of the bloodretinal barrier (BRB) and loss of the DIE are hallmarks of retinal diseases [45]. The BOB system, along with the DIE, is critical in downregulating excessive inflammatory response and in maintaining the retinal homeostasis.

The BOB contributes to the eye being a privilege tissue; thus helping the eye abstains from variations in systemic circulations. The BOB maintains an ideal environment for the avascular tissues in the eye and regulates the diffusion of chemicals into the retina. Because once the molecules pass the ocular barriers, there is nothing that can prevent their dissemination to the retina [46]. The blood-aqueous barrier is formed by the ciliary body non-pigmented epithelium, Schelemm's canal endothelium, and the endothelium of the Iridal capillaries [47]. Whereas, the BRB consists of tight junctions that restricts the movement of molecules in and out of the retina.

\section{$\underline{\text { Blood Retinal Barrier }}$}

Blood Retinal Barrier. BRB consists of the inner and outer BRB. The inner BRB (iBRB) formed by tight junctions (e.g., Occludin) between the adjacent endothelial cells (ECs), and this endothelial layer rests on a basal lamina that is covered by pericytes and glial cells (astrocytes, and Müller cells) [48, 49]; whereas the outer BRB is maintained by tight junctions between adjacent RPE cells $[48,50]$. The BRB functions to control the 
movement of molecules and fluid into the retina also prevents leakage of macromolecules and harmful agents into the retina.

Endothelial Cells. The endothelial cells (ECs) provide the necessary nutrients and oxygen the retina needs to maintain its physiological functions while limiting other blood circulating agents from penetrating the retina. ECs mitigate transcellular and paracellular transport into the retina. Transcellular transport occurs through diffusion across the lipid bilayer for a host of small lipophilic molecules. The other mechanism of transportation is through receptor-mediated or constitutive transcytosis. Caveolin-1 contains receptors for many substances, including interleukin 1, vascular endothelial growth factor (VEGF), albumin, advanced glycation end-products (AGES), and protein kinase C (PKC). Vesicular transport under normal conditions is minimal [51]. Tight junctions restricted the paracellular traffic.

Pericytes. In the formation of retinal vasculature, ECs express a very high level of platelet-derived growth factor B (PDGF-B). It leads to the recruitment of pericyte cells, which then wrap ECs in a 1:1 to ratio. They also form cell-cell contact via Cx43, fibronectin adhesion plaques, and N-Cadherin. Pericytes also secrete angiopoietin-1 which acts via the Tie2 receptor on ECs to promote differentiation, remodeling, and maturation. Pericytes also secrete Angiopoietin-2 (Ang-2) which moves together with VEGF to promote angiogenesis. Overexpression of Ang-2 causes vascular regression, impairs barrier function in part by inducing degradation of TJ (Cadherin). Pericytes also secrete transforming growth factor-beta (TGF- $\beta$ ) which inhibits migration and proliferation of ECs [51]. 


\section{$\underline{\text { Junctional Molecules }}$}

ECs form a restricted lining of the vascular wall to regulate the passage of substances circulating in the blood and the interstitial space whereas, paracellular limit transport via adhesive cell-cell junctional proteins that include gap junction (GP) and tight-junction (TJ) [52].

Gap Junctions. GJ allowed cell-to-cell communication via hemichannels that are consisted of six connexins molecules. Each cell contributes a hemichannel to the connection, which opens the plasma membrane of each cell to the other. GJ allowed the transfer of small molecules $(<1 \mathrm{kDa})$ such as ions, glucose, amino acids, and neurotransmitters. Most cell types in the retina has GP, including photoreceptors [53], endothelial, and pericytes [54]. Connexin-43 (Cx43) is the most prevalent connexin molecule in the retina [55].

Cx43. Connexin generally localizes in the plasma membrane where it functions in intercellular communications via GJ. Cx43 has various phosphorylation sites in its carboxy-terminal for protein kinases, e.g., PKC. Cx43 is synthesized as a 40 to $42 \mathrm{kDa}$ protein which is then repeatedly phosphorylated through serine residues, and is assembled in the trans-Golgi network, and then transported and inserted through the plasma membrane. The phosphorylation usually functions in intercellular communications via various molecular mechanisms related to assembly, trafficking, and closing of the GJ channel $[56,57]$. Cx43 hemichannels open during low $\left[\mathrm{Ca}^{2+}\right]$ extracellularly, while PKC can block its opening.

Tight Junctions: TJ are formed in proximity between two adjacent cells. TJ restrict 
transports of blood circulating molecules paracellularly. TJ also regulates lipid flip flop across the lipid bilayer. They are consisted of more than 40 proteins that are generally divided into transmembrane proteins and cytoplasmic scaffolding proteins [51].

Occludin: Occludin is a part of the transmembrane class of TJ proteins and is a $60 \mathrm{kDa}$ tetraspan transmembrane component protein with two loops facing the extracellular space while both the amino and carboxy-termini in the cytoplasm. The amino terminus regulates occludin degradation via interaction with E3-ubiquitin ligase; while the carboxy terminus binds to one of the three Zona Occludentes proteins. Occludin functions more in regulating barrier properties rather than structural properties between ECs.

Overexpression of occludin leads to decrease flux into the interstitial space.

Downregulation of occludin increases paracellular permeability. Occludin knockout mice depicted that occludin is not required for barrier formation, but it does play a key role in TJ trafficking and stabilization [51]. Occludin and claudins are the two protein/protein family that link the ECs together [58].

\section{Glia cells and the BRB}

There are three different types of glial cells that populated the retina: Müller cells, astrocytes, and microglia. The macroglial cells (Müller and astrocytes) play significant roles by maintaining the function(s) of the iBRB.

Müller Cells. Müller cells are the primary macroglial cells in the retina and constitute $90 \%$ of the glial cells in the retina. Müller cells act as a linking cells for metabolites 
exchange between the neuronal cells and the blood vessels [59]. They function in neurotransmitters recycling, $\mathrm{K}^{+}$uptake, regulation of blood flow, metabolism control, nutrients supply to retinal neurons, anti-oxidative support [60], glycogen storage [61], sheath axons [59], and in maintaining the BRB. They can also interact closely with both retinal neurons and blood vessels due to their long shape [62]. Docosahexaenoic (DHA) protects photoreceptors disk membranes from oxidative damage. DHA also induces increased expressions of anti-apoptotic factors via the Bcl-2 family. Müller cells function in uptaking and delivering DHA to photoreceptors [59]. The depletion of Müller cells leads to the breakdown of the BRB [61]. These cells secreted anti-angiogenic factors to maintain pro and anti-angiogenic environment and thus BRB health.

Astrocytes. Astrocytes are non-prominent in avascularized area, generally located within the NFL. They are wrapped around blood vessels. Astrocytes primarily communicates via GJ [59]. Astrocytes are the primary producer of VEGF and thus play a key role in neovascularization. Other physiological functions of astrocytes include mechanical support for axons, neurotrophic support, and maintenance of the BRB. Astrocytes contained aquaporin 4 channels within their plasma membrane which help regulate the fluid in the extracellular space, buffering potassium, and clear the metabolic wastes [59]. 
Figure 2. A Brief Schematic of the iBRB. iBRB consists of TJ between adjacent ECs that are covered by pericytes. The capillary cells are wrapped by glial cells (astrocytes, and Müller cells). Although pericytes and glial cells are critical to the iBRB function, the transcellular and paracellular transport into the retina is regulated by the ECs and TJ together. 
FIGURE 2

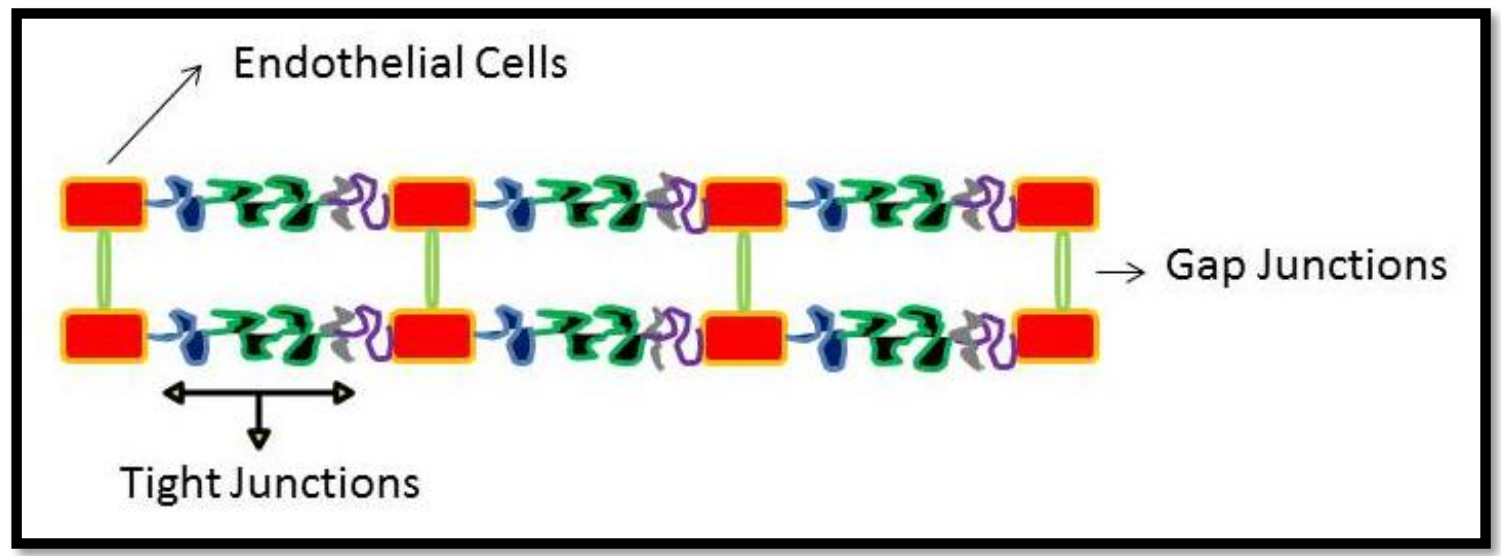


Downregulatory Immune Environment (DIE). The immune-privileged status of the eye is maintained by the BOB and DIE. Transportation of antigens and tissue drainage occurred via the blood route instead of the lymphatic pathway [63]. The inflammatory response in the eyes is particular to the eye. To protect the physiological functions, the eye regulates immune response strictly and manages its inflammation. The retina and choroid contain many immune cells that include choroidal macrophages, microglia, dendritic cells, and the mast cells population [64]. These cells introduce antigen to T cells and produce cytokines to non-specific stimuli such as bacterial liposaccharides (LPS). The presence of antigen-non-specific inflammation can be disastrous to host tissue. The BRB protects the retina from the aqueous chamber, and the vitreous body via immunosuppressive functions. Many factors played a crucial roles in maintaining the DIE state in the eye, including Müller cells, RPE, and the microglia. The normal retina has low major histocompatibility complex (MHC) molecules and there is an absence of the bone marrow-derived cells that function with tissues as Antigen Presenting Cells (APCs).

Anterior Chamber Associated Immune Deviation (ACAID). ACAID is the most studied immune privilege mechanism in the eye. It is unique to the anterior chamber, but there is evidence that the same mechanism exists in the vitreous and the subretinal space as well [65]. It contains TGF- $\beta_{2}$ which is capable of reprogramming the APCs to produce less IL2, less amount of CD-40 in the microenvironment of the eye, and also help produce more TGF- $\alpha$ which suppresses T cell activation [46].

$B R B$ and DR. DR is commonly defined as degeneration and occlusion of the microvessels, which caused fluid accumulation and abnormal neovascularization in the 
retina [66]. Loss of pericytes in retinal capillaries is one of the factors that leads to iBRB breakdown [67]. Hyperglycemia ( $\mathrm{HgA})$ causes retinal hypoxia and vasodilation increases retinal blood flow in response to the hypoxia temporarily. Exhaustion of autoregulation causes apoptosis of retinal capillary pericytes. The death of pericytes disrupts pericytesendothelial complex which then leads to an impairment in the endothelial TJ function. These events together caused the breakdown of the iBRB.

Retinal ECs in the iBRB are potential targets of the inflammatory markers such as eicosanoids, cytokines, and the growth factors. Chronic $\mathrm{HgA}$ upregulates inflammatory mediators which in turn induces leukocytes adhesion to ECs which further injures the $\mathrm{iBRB}[68-70]$. Breakdown of the $\mathrm{iBRB}$ as a result of cytokines release generate an inflammatory response which further increases the release of the inflammatory mediators, thus additionally exacerbating the situation. Leukocytes adhesion also induced retinal hypoxia, the retinal hypoxia also leads to abnormal blood vessel growth concurrently [71, 72].

\section{$\underline{\text { Diabetic Retinopathy }}$}

The earliest sign of DR is a dysfunctional iBRB. DR is characterized by loss of pericytes [73, 74], basement membrane thickening, microaneurysms [75], acellular capillary, and iBRB breakdown. The factors that contribute to capillaries degeneration are occlusion of the capillary's lumen by white blood cells or platelets, and death of capillaries cells due to hyperglycemia. There are many biochemical mechanisms proposed for the pathogenesis of DR, although the etiology is yet to be precise. Chronic $\mathrm{HgA}$ is the main factor contributing to the development of DR, and its complications. The earliest retinal changes due to $\mathrm{HgA}$ are biochemical, cellular, or hemodynamic in nature. Metabolic deregulation affects 
the neurons and the support cells of the retina. However, it is the microvessels that in fact are affected the most. They [capillaries] dominate clinical events of the disease and are also the focal point for the development of macular edema and neovascularization. In the early stages of DR, functional cells of the retina exhibit changes such as glial cell reactivity, alterations in glutamate metabolism, and neuronal cell death [76-78]. Until the development of retinopathy, vision is normal in diabetics patients if they don't have any other concurrent eye problems. DR is divided into two stages: Non-proliferative DR (NPDR) and Proliferative DR (PDR). After five years of living with diabetes, NPDR symptoms start to appear. NPDR is intraretinal microvascular derangement that could progress to diabetic macular edema (DME) (accumulation of fluid in the macula) or PDR (extraretinal neovascularization). Progressive retinal ischemia and the rise in local growth factors are the primary mechanisms outlined in the development of PDR. PDR is new growth of blood vessels in the retina or optic disc that extends along the retinal surface or into the vitreous cavity $[79,80]$. Pathogenesis of PDR involved hypoxia that results in low perfusion of retinal tissue, thus prompting neovascularization (directly related to VEGF). Initially, the new blood vessels are barely visible, then they gradually increase in size, and could become as large as a retinal vein. New blood vessels are usually asymptomatic $[81,82]$. The new growth of blood vessels is gradually accompanied by fibrous proliferation, and it is this contraction of the fibrous tissue that can can lead to retinal detachment and vitreous hemorrhage. These two traits more often than not lead to vision loss in PDR.

The cornerstone of NPDR treatment is glycemic control while managing PDR has the following aims: decrease the growth of blood vessels, contraction of vitreous, and fibrovascular proliferation. Photocoagulation is the gold standard for PDR treatment. However, photocoagulation comes with complications since high density/intensity laser 
may cause loss of night and colored vision [83] and reduced contrast sensitivity [84]. Other treatments for PDR include VEGF Inhibitors and Vitrectomy [85].

Many biochemical mechanisms have been put forward to explain the vascular pathology of DR. Among the proposed pathways are aldose reductase (AR), AGEs formation, reactive oxygen intermediates elevation, $\mathrm{PKC}$, and the inflammation.

\section{$\underline{\text { DR-Biomolecular Mechanisms }}$}

AR Pathway. Retinal capillary cells (endothelial, and pericytes), and glial cells expressed AR and thus are subjected to the polyol pathway [86]. The polyol pathway or the AR pathway is induced during high blood glucose levels [87]. First, AR reduces glucose into sorbitol (nicotinamide adenine dinucleotide phosphate hydrogen; NADPH serves as a cofactor). Next, sorbitol dehydrogenase (SD) reduces into fructose (nicotinamide adenine dinucleotide $\left(\mathrm{NAD}^{+}\right)$serves as a cofactor). Since sorbitol cannot cross across the cell membrane it accumulates intracellularly inducing an osmolality effect [87]. Next, as the substrates use NADPH and $\mathrm{NAD}^{+}$in this pathway, they are quickly depleted thus decreasing the body's capacity in responding to the OS. For example, the use of NADPH hinders its bioavailability for glutathione reductase [88]. NADH/NAD ${ }^{+}$ratio is increased due to the use of $\mathrm{NAD}^{+}$by SD. Further, NADH oxidase could also use NADH as a substrate to increase the generation of ROS [89]. Additionally, fructose can further metabolize into fructose-3-phosphate, and 3-deoxyglucosone, both of which can become the glycosylating agents $[90,91]$. This pathway generates osmolality effects, glycating agents, and OS. Studies have shown that inhibition of AR in diabetic animal models prevents retinal injuries [92]. Although clinical trials with AR inhibitor have not been significantly fruitful [93]. 
AGEs. Amine group modification of a protein by reducing sugars such as glyoxal, 3deoxyglucosone, and methylglyoxal, generate AGEs [94]. Retinal levels of AGEs increase in diabetic's rat model and humans [95]. The presence of AGEs on the basement membrane interferes with pericytes and ECs communication. AGEs bind to their receptors, activate $\mathrm{NF}-\kappa \mathrm{B}$, and generate ROS.

$P K C: \mathrm{PKC}$ is a serine/threonine-protein kinase that mediates many cellular signal transduction pathways [96]. The various isoforms of PKC are activated via diacylglycerol (DAG), calcium, and other substrates. HgA increases the expression level of DAG [97]. Studies reported that DAG levels have increase in the retina of the diabetics [98]. Activation of PKC increases albumin permeability across ECs $[99,100]$ and hinders vasodilation via depleting nitric oxide (NO) levels. PKC also caused the loss of pericytes [101].

OS: The retina is perfused 300 times more than both the heart and the cerebral cortex, thus making it more susceptible to OS; phototransduction, and shedding of POS by the RPE also contribute. ROS, free radicals in the form of hydroxyl radicals, and superoxide anion are very reactive, mainly due to the unpaired electrons in their valence shell [102]. Many factors lead to the generation of ROS including the mitochondria electron transport chain [103]. Under normal conditions, the mitochondria contribute the most to ROS levels. The process of aging, and inflammation can disrupt homeostasis by generating more ROS than the body can remove thus inducing the process called OS [104, 105]. The body uses antioxidant (vitamin $\mathrm{C}$ and $\mathrm{E}$, superoxide dismutase; SOD, and catalase) to neutralize ROS [102]. Once the body anti-oxidant system is overloard that create OS. $\mathrm{HgA}$ activates PKC, polyol flux, and AGEs that generate ROS [106]. 
Increased ROS injure ECs, activate NF-кB [107-110], and recruit neutrophils [111].

There is evidence that OS is the main factor that triggers the chronic inflammation response in the retina [112]. Inflammation increases expression of inflammatory mediators, promotes leukocyte adhesion to retinal capillary walls, and occludes retinal capillaries causing hypoxia. Eventually, breakdown of the iBRB happens.

\section{$\underline{\text { Inflammation }}$}

Basics Concept in Immunology. Immune privilege of the eye is maintained by the BOB, DIE, and the lack of direct lymphatic drainage from the eye [113]. The immune system consists of two parts: innate and adaptive. The innate immune pathway is immediate and nonspecific. Pattern recognition receptors (PRR) recognizes the conserved microbial patterns and triggered a nonspecific inflammatory reaction; for instance, toll-like receptors (TLR) recognize LPS of the gram-negative bacterial outer membrane [114] which activate immune cells, monocytes, macrophages, natural killer (NK) cells, polymorphonuclear cells, eosinophils, and basophils. The adaptive immune response, however, is more complicated and elaborated below.

Adaptive Immunity. The key components include B and T lymphocytes, which contain receptors (immunoglobulins; Igs) for recognizing antigenic epitopes [115]. Igs are expressed by B cells and T cells in the absence of exogenous stimulation. Igs contains unique configurations that recognize specific antigens. Each group of lymphocytes depicts the same cell surface receptors to identify multiple epitopes, and to accomplish this billions of lymphocytes are generated. 
Figure 3. Mechanism of Diabetic Retinopathy Pathology. Hyperglycemia during diabetes activates many pathways such as PKC, AGEs, and polyol. These pathways induce oxidative stress, and inflammation in the retina. Inflammation contributes to retinal vascular occlusion, and dysfunction of retinal capillary cells that lead to the development of DR. DR starts as NPDR, then gradually progress to PDR or DME or both. 
FIGURE 3

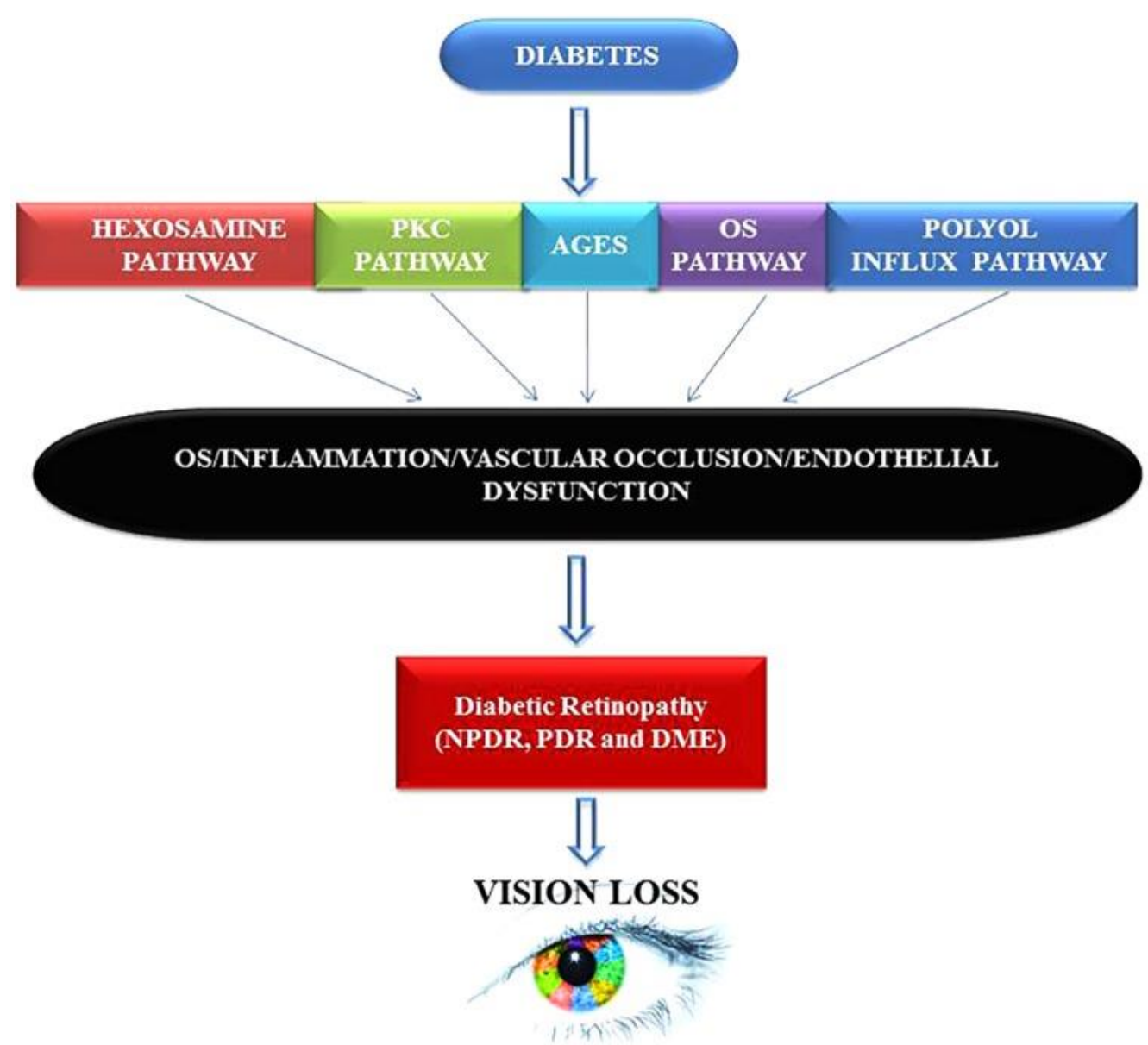


After maturation in the thymus (T cells) or bone marrow (B cells), lymphocytes remain in the dormant or G0 phase of the cell cycle until an antigen binds to its receptor (called naïve). Molecule binding to a B or T cells triggers an immune response to destroy the bound molecule or the antigens. If the molecule is pathogen-derived then it leads to the destruction of the pathogen. If it is a cell-derived then it leads to autoimmunity, and therefore occurrence of the tissue injury.

Activation of a naïve lymphocyte leads to the proliferation of that lymphocyte which recognizes a specific epitope. T cells $\left(\mathrm{CD} 4^{+}\right.$and $\left.\mathrm{CD} 8^{+}\right)$become cytotoxic once activated or differentiate into effector cells. $\mathrm{CD}^{+} \mathrm{T}$ cells become cytotoxic once activated. $\mathrm{CD}^{+} \mathrm{T}$ cells via interleukins (IL) differentiate into one of three effector $\mathrm{T}$ cells (Th1, Th2, and Th17). IL-4 leads to Th2, IL-12 leads to Th1 [116], whereas IL-1 and IL23 lead to Th17 differentiation [117]. Th1 and Th2 cells become memory cells that trigger the immune response if the antigens reappear. Th1 secretes cytokines that target macrophages, and other cells involved in the immune response. Th2 stimulates B cells proliferation to produce antibodies to kill the invader. Th17 cells produce IL-17 [118], and IL-23 to fight fungal and bacterial infections.

The adaptive immune response is divided into three parts: antigens recognition, transportation, and presentation to lymphocytes. Antigens are recognized, processed, and presented (through MHC) to lymphocytes by dendritic cells, and macrophages. There are differences in the process of antigen presentation. B cells can engage with naïve antigen directly but $\mathrm{T}$ cell receptor (TCR) can only recognize peptide fragments presented with MHC molecules (Class I or II). MHC Class I molecules (expressed in most cells) present peptides derived from protein degradation in the cytoplasm (intracellular antigens). MHC Class II molecules (expressed in APCs and lymphocytes) present peptides derived from phagocytic vesicles (extracellular antigens). APCs provide co-stimulation needed for 
lymphocytes activation [119]. APCs upregulates CD80, CD86, ICAM-1, and CD40 molecules to function as ligands for lymphocytes receptors. APCs also secrete soluble cytokines such as IL-12, IL-6, IL-10, and IL-1 $\alpha$ to stimulate lymphocytes further.

$\mathrm{CD} 4^{+} \mathrm{T}$-cell activation leads to $\mathrm{CD} 4^{+}$proliferation and cytokines secretion such as IL-2, IL-3, granulocyte-macrophage colony-stimulating factor, interferon-gamma (IFN- $\gamma$ ), and IL-4 which serves as growth and stimulation factors for lymphocytes and APCs. IL-2, IFN- $\gamma$, and IL-4 promote differentiation of $\mathrm{CD}^{+} \mathrm{T}$ lymphocytes to mature cytotoxic $\mathrm{T}$ lymphocytes. Cytokine production by $\mathrm{CD} 4^{+} \mathrm{T}$ cells also promotes activation and differentiation of B lymphocytes. IL-2, and IFN- $\gamma$ stimulate B cell to produce immunoglobulin g (IgG) while IL-4, 5, 6, and 10 stimulate the production of $\operatorname{IgG}, \operatorname{IgE}$, and $\operatorname{Ig} \mathrm{A}$ antibodies.

Final products of processing in the lymphoid tissues are activated effector $\mathrm{CD} 4^{+}$, $\mathrm{CD}^{+}$, and B cells. These cells travel through the blood to execute the response. Activated $\mathrm{B}$ cells secrete antigen-specific antibodies to kill the target directly. Activated CD4 ${ }^{+} \mathrm{T}$ cells secrete cytokines, and IFN- $\gamma$, which in turn recruit the cells of the innate immune system to the site of the antigen. Activated $\mathrm{CD}^{+}$lyse target cells and produce proinflammatory cytokines, especially IFN- $\gamma$. Cytokines involved in the response perpetuate a positive feedback loop at the target sites. Blood vessels become leaky, vascular endothelial cells display ligands that bind to immune cells receptors, and chemokines secreted by local inflammatory cells to attract more immune effector cells and the cascade continues [119].

\section{Inflammation in DR}

DR is regarded as an inflammatory disease due to the presence of inflammatory 
mediators that are found in the vitreous and the retina of diabetic animals models and the patients. The increase in expression of these markers is associated with a dysregulation in nuclear factor kappa-light-chain-enhancer of activated B cells (NF-кB) [120].

$N F K B . \mathrm{NF}-\kappa \mathrm{B}$ is a family of five transcription factors that has structurally related

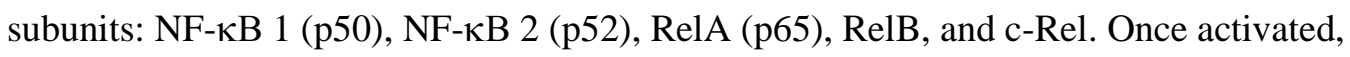
they form either hetero or homodimers and get translocated into the nucleus. In the nucleus, they bind to $\kappa \mathrm{B}$ DNA binding sites and increase the expression of NF- $\kappa \mathrm{B}$ targeted genes [121].

$\mathrm{NF}-\kappa \mathrm{B}$ regulates gene transcription that plays key roles in inflammation, immune cell development, cell cycle, proliferation, and cell death $[122,123]$. NF- $\kappa \mathrm{B}$ is pertinent for both innate and adaptive immune cell functions. It regulates survival, activation, and differentiation of both innate and adaptive immune systems cells. NF- $\kappa \mathrm{B}$ activation induces expressions of pro-inflammatory genes, cytokines, chemokines, immunoreceptors, apoptosis, proliferation, and inflammasome [120].

Stimuli that activate NF-אB include TLRs, antigen receptors, OS markers, genotoxic stress, cytokine, and growth factors. There are two types of NF- $\kappa$ B activation: specific and non-specific. Both are influential in regulating inflammation and immune response [124]. The NF- $\mathrm{B}$ subunits reside in the cytoplasm where they remain inactive via inhibitory proteins of the I $\mathrm{B} B(\mathrm{I} \kappa \mathrm{B} \alpha)$ family [125]. Activation of NF- $\kappa \mathrm{B}$ requires $\mathrm{I} \kappa \mathrm{B}$ kinase (e.g., IKK $\alpha$ ) to phosphorylate the IKB $\alpha$ which then is recognized by the E3 ligase to degrade the inhibitor. This process induces the translocation of NF- $\kappa \mathrm{B}$ heterodimers (e.g., p50/RelA) into the nucleus [126-128], where they bind to DNA sequences known as $\kappa \mathrm{B}$ sites [121]. 
Figure 4: Immune System Mechanism. The immune system consists of two parts: innate and adaptive. The innate system is the primitive and nonspecific one and uses dendritic cells, monocytes, macrophages, and other immune cells to destroy the invading pathogen(s). On the other hand, the adaptative system uses the bone marrow-derived (B cells) and thymus-derived Treg cells, innate immune cells, antibodies, and immune ligands (e.g., cytokines) to lyse antigens. 


\section{FIGURE 4}

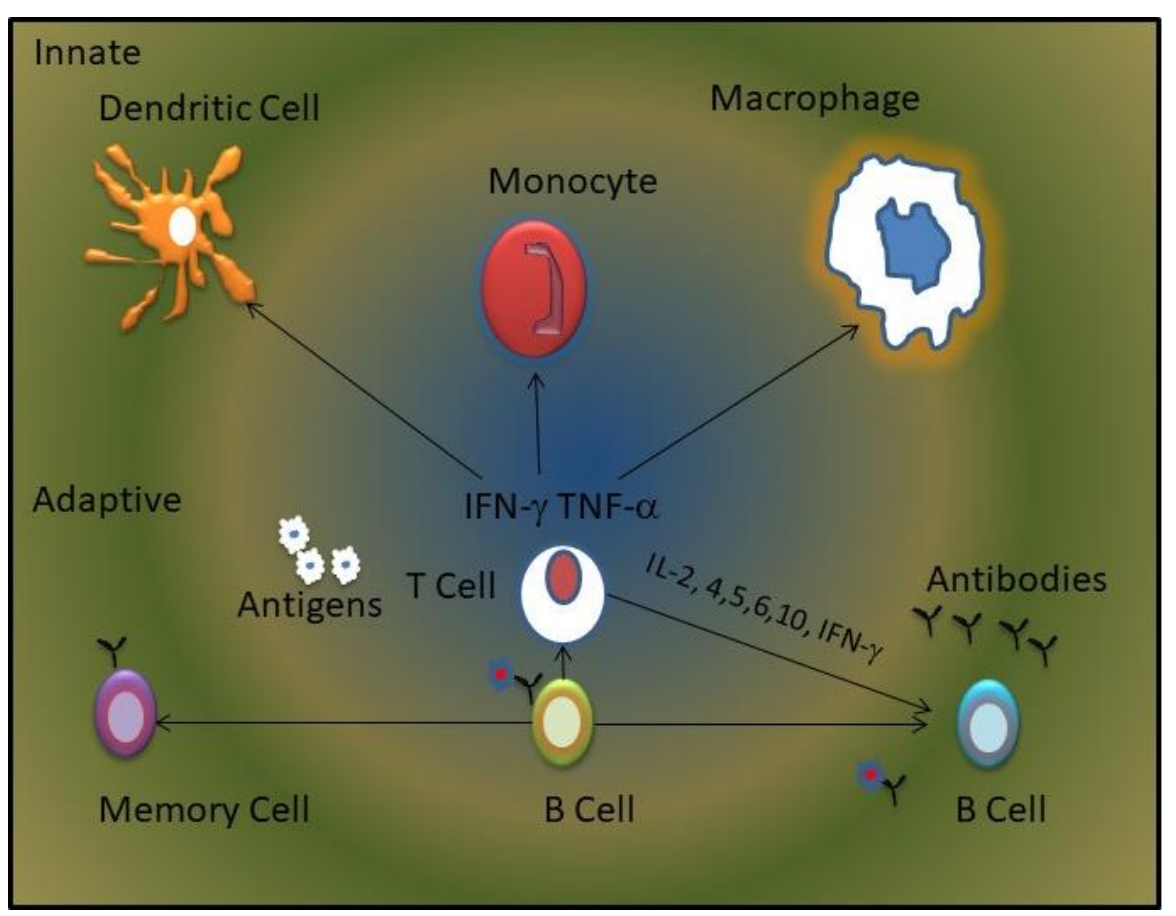


In contrast, the non-specific pathway responds to a specific set of stimuli, such as receptor-activated nuclear factor kappa B (RANK) $[129,130]$. The subunits activated in this pathway are RelB and p52 and require IKK $\alpha$ and cleavage of p100 to p52. First, processing of NF-кB 2 (p100) occurs [129] followed by translocation of p52/RelB into the nucleus $[129,131]$. The specific pathway is involved in all aspects of the immune system, and the non-specific is complementary to the adaptive immune system regulation [130]. NF- $\kappa \mathrm{B}$ is regulated primarily via a negative feedback loop wherein activation of $\mathrm{NF}-\kappa \mathrm{B}$ induces production of $\mathrm{I} \kappa \mathrm{B} \alpha$ [132]. Activation of NF- $\kappa \mathrm{B}$ mainly heterodimerizes into p50-p65 thus transcribing the pro-inflammatory proteins (iNOS, ICAM-1) [133]. Inflammation serves as a protective mechanism against tissue damages and infections under physiological conditions, however it may be detrimental in the long term. Deregulation of inflammatory responses causes damages to host tissues that could lead to the development of short or long-term inflammatory diseases. Chronic inflammatory conditions such as diabetes involve deregulation of NF- $\mathrm{KB}$ activation. Dysregulation of NF- $\kappa \mathrm{B}$ induces an excessive increase in inflammatory proteins. Recent studies have shown an increase in inflammatory mediators such as COX-2, and iNOS in the retina and vitreous of DR animal models and the patients, as stated earlier. These molecules are consistent with the innate immune pathway. Also, other studies have also shown that retinal inflammation is also associated with the activation of NF- $\mathrm{B}$ [134].

iNOS. Inducible Nitric Oxide Synthase (iNOS) meditates NO production from Larginine. Regular production of NO is generated via two NO synthases (neuronal and endothelial). While iNOS generation of NO involves solely in inflammation. An elevated level of NO is associated with many inflammatory diseases, e.g., inflammatory bowel 
disease [135-137]. iNOS has high expression in activated immune cells and low to no expression in most resting cells [135]. Activated NF- $\kappa \mathrm{B}$ induces transcription of iNOS [120]. Studies in the literature shows an increased iNOS levels in the retina of diabetic animals, which associated with apoptosis of retinal cells, leukostasis, and iBRB breakdown [138]. iNOS elevation is very well present in the retina of human patients [139-142]. iNOS has also been shown to mediate the production of oxygen radicals. iNOS generates superoxide anions in macrophages [143]. NO could react with superoxide anion to form peroxynitrite, and injure macromolecules inside the cells. Increase production of NO could also result in nitration and nitrosylation of the retinal proteins, which is also toxic. NO elevation generated by iNOS causes the loss of pericytes, and retinal thinning (GCL, IPL, and OPL). Studies of retinal cells exposed to high glucose (HG) demonstrated that NO (particularly iNOS generated) regulates prostaglandin $\mathrm{E}_{2}$ (inflammatory marker generated by COX-2) expressions. iNOS is also associated with GCs loss in Akita mice after 22 weeks of diabetes [144]. Inhibitor of iNOS (aminoguanidine) has shown to decrease vascular injuries associated with DR in rodents [145-147]. Studies of retinal cells exposed to HG demonstrated that NO (particularly iNOS generated) increases the expression of cyclooxygenases-2 (COX-2) [144].

COX-2. Eicosanoids are signaling molecules that are derived from arachidonic acids such as prostaglandin (PG), thromboxane, and leukotrienes. Cyclooxygenase enzymes mediate the first two steps of eicosanoids synthesis. Many isoforms have been identified, such as COX-1, and COX-2. COX-1 is expressed in most tissues and it functions to maintain PG production. PG is known to regulate renal blood flow, immune responses, and inflammation [148-152]. In the eye, it is involved in ocular inflammation [153], IOP 
[154], corneal neovascularization [155], corneal edema [156], retinal blood flow [157], iBRB, and BOB impairment [158].

COX-1 maintains physiological productions of eicosanoids, whereas COX-2 eicosanoid production occurs in the presence of inflammation. COX-2 is generally absent from most tissues, but its expression is increased in the presence of bacterial LPS and proinflammatory cytokines; thus, COX-2 has high expression in immune cells (monocytes, macrophages, and ECs) [159]. NF- $\kappa \mathrm{B}$ activation upregulates COX-2 gene expression in retinal cells [160]; and is associated with iBRB breakdown [161]. Interestingly, COX-2 expression is elevated in the retina of Akita mice [162]. Another inflammatory mediator that is positively regulated by NF- $\kappa \mathrm{B}$ and has high expressions in the retina of DR is the intercellular adhesion molecule-1 (ICAM-1).

ICAM-1. ICAM-1 is a membrane-bound glycoprotein and serve an important function in immune responses, e.g., leukocyte trafficking [163]. ICAM-1 is consisted of five Ig domains, a transmembrane domain, and a linker in the cytoplasm that interacts with actin molecules [164]. It is expressed in ECs, leukocytes, platelets, epithelial cells, and glial cells. Its expression is low when inflammation is not present. It performs functions in immune cells such as adhesion, migration, and aggregation [165]. Leukocytes adhesions (leukostasis) to retinal endothelium is associated with iBRB breakdown [166].

Leukostasis is elevated in the retina during hyperglycemic conditions [166]. Leukostasis in retinal vessels is mediated by elevation of ICAM-1. Activation of NF- $\kappa B$ increases ICAM-1 expression [167]. Leukostasis elevation is linked with an increase in vascular permeability [168]. Inhibition of ICAM-1 reduces leakage and leukocytes adhesion in the retina of diabetic rats [169]. 
Leukostasis in retinal vessels is mediated by elevation in ICAM-1 and CD18 leucocytes integrin [170]. Streptozotocin (STZ) induced diabetes in mice that are deficient in ICAM-1 shown less leukostasis in retinal vessels [171]. STZ induced WT C57BL/6 J mice exhibited increased expression of ICAM-1 in their retina [169]. Activated leucocytes injected into the retina of healthy mice show increased leukostasis via ICAM-1 [172] and inhibition of ICAM-1 decreases leukostasis in the retina of diabetic rats [173].

\section{Pyroptosis}

Pyroptosis is a cell death pathway due to inflammation. It involves the assembly of an inflammasome, activation of caspase 1 (Casp-1), IL-1 $\beta$, and IL-18. Pathogenassociated molecular patterns (PAMPs) and danger-associated molecular patterns (DAMPs) induce inflammasome assembly [174]. Inflammasome contains a nod-like receptors protein (NLRP) family receptors (e.g., NLRP3), adaptor protein ASC (apoptosis-associated spec-like protein containing CARD) and pro-caspase 1. Inflammasome plays a vital role in the innate immune system against infections, but its deregulation could lead to the development of autoimmune and inflammatory diseases also [175]. NF- $\kappa \mathrm{B}$ regulate inflammasome assembly [175]. NF- $\kappa \mathrm{B}$ is a known activator of nod-like receptor pyrin domain 3 (NLRP3) [176, 177]. NF-кB induces pyroptosis through activation of NLRP3 [178].

NLRP3. Nod-like receptors (NLRs) are PRR and generally located in the cytoplasm, thus making it possible to detect pathogenic invaders inside the cell [179]. Most NLRs are 
Figure 5. Nuclear Factor Kappa B Activation. NF- $\kappa B$ homo/heterodimerizes and translocate into the nucleus once activated. They bind to $\kappa \mathrm{B}$ DNA binding sites and induce the transcriptions of inflammatory mediators such as iNOS, COX-2, and ICAM-1. 
FIGURE 5

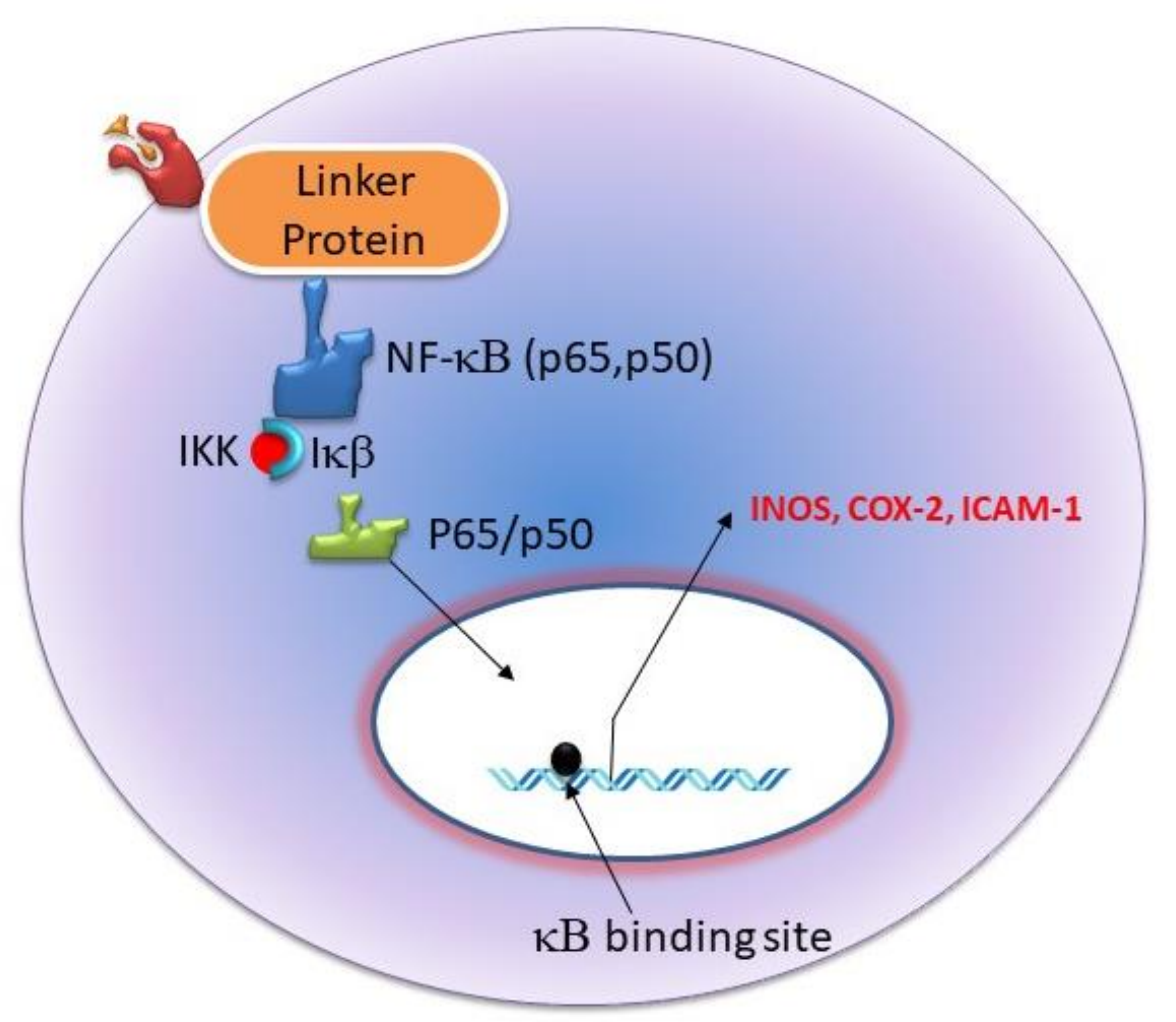


active during the innate immune responses, and are activated via PAMPs, DAMPs, cell stress, or ROS. NLRs family have 14 distinct members, named NLRP1 to NLRP14 [180]. NLRP3 can also be activated by extracellular ATP, and UVB radiation [180]. NLRs form complexes known as inflammasomes, which cleave casp-1, and casp-1 cleaves interleukins-1 beta (IL-1 $\beta$ ), and interleukins 18 (IL-18) [181]. NLRP3 is the most studied NLRs and various stimuli could trigger its activation. It is involved in multiple pathologies, e.g., type II diabetes, and obesity [182]. NLRP3 structure has three distinct domains: pyrin domain (PYD), leucine-rich repeat (LRR) domain, and a nucleotidebinding domain (NBD) [183]. NLRP3 inflammasome is consisted of NLRP3, ASC, and Casp-1. Stimuli activate NLRP3 via interaction with the LRR, then the PYD and the NBD are free to interact with other entities. Through the NBD domain, NLRP3 oligomerizes and then recruit ASC to form the NLRP3-ASC complex [184]. ASC then recruits casp-1, casp-1 auto processed, and cleaved pro-IL-1 $\beta$ to IL-1 $\beta$ and IL-18 [185, 186]. The NLRP3 activation mechanism is yet to be defined though. A common mechanism has been suggested that the extracellular ATP stimulates purinergic P2X7 ATP-gated ion channel leading to the efflux of $\mathrm{K}^{+}$ions. Pannexin-1 membrane pore protein is recruited into the target cell and that can lead to the activation of the assembly of the NLRP3 inflammasome [180].

HgA can upregulate NLRP3 expression in cultured Müller cells [180]. The role NLRP3 and inflammasomes play in DR is still under intense investigation. Hui Chen et al. reported a high level of NLRP3 expression in the blood from diabetic patients. They speculated that its activation could be due to elevation in ROS that could presumably be a byproduct of other molecular mechanisms, e.g., polyol pathway [187]. 
Casp-1. Casp-1 is part of the caspase family of cysteine proteases that involve either (a) an increase activation of proinflammatory cytokines or (b) cellular death by apoptosis. However, casp-1 can participate in both cytokines activation and apoptotic cell death. Casp-1 resides in the cytoplasm until activation by NLRP3, and then it heterodimerizes into two subunits (10 \& $20 \mathrm{kDa})$ [180]. Casp-1 activation induces expression of both IL$1 \beta$ and IL-18 [188]. HgA has been shown to activate casp-1 in the retina of diabetic mice, patients, and Müller cells [188]. Inhibition of casp-1 by minocycline prevents the degeneration of retinal capillaries cells induced by the development of diabetes [188]. Casp-1 activation induces expression of both IL-1 $\beta$ and IL-18 [188].

$I L-1 \beta$ IL-1 $\beta$ is part of the IL- 1 family which is consisted of 11 different ligands and receptors. These ligands function to induce inflammation or anti-inflammation independently in the blood or tissues. IL- $1 \beta$ is one of the first ILs discovered. IL-1 $\beta$ is synthesized as pro- IL-1 $\beta$, which remains inactive until it is cleaved via casp-1 to produce mature IL-1 [180]. IL-1 $\beta$ binds to its receptor (IL-1 receptor type 1; IL-1R). IL$1 \beta$ action is regulated via IL-1R antagonist, which competes for the same receptor. IL$1 \beta$ functions in the extracellular milieu where it resides within the cytosol and is secreted upon stimulation or cell death. Many different retinal cells produced IL-1 $\beta$, including microglia, and the astrocytes [189]. IL-1 $\beta$ played a crucial role in innate immune response, helps fighting pathogens, and tissue repair. IL-1 $\beta$ induces the activation of microglia and other retinal glial cells along with proinflammatory mediators. Thus, prolonged exposure or overexpression of IL-1 $\beta$ can lead to tissue damage. Elevation of IL-1 $\beta$ expression was reported in the retina of diabetic rodents experimental models as early as eight weeks after the onset of $\mathrm{HgA}$. IL-1 $\beta$ has also been reported in the 
vitreous of patients with DR. IL-1 $\beta$ administration in the vitreous of nondiabetic rats led to apoptosis of retinal capillary cells via activation of NF-kB $[189,190]$. Susana Vallejo et. al reported that anakinra (inhibitor of IL-1R) prevented impairment of ECs in STZ induced diabetic rats via NF- $\kappa \mathrm{B}$ activation and subsequent increase in iNOS production [191]. Literature also reported that constant exposure to IL-1 $\beta$ led to ECs impairments and degeneration of blood vessels [188]. Other studies reported that HG increased the expression of IL-1 $\beta$ in Müller cells [192]. In the retina of diabetic mice, casp-1 and IL-1 $\beta$ have been detected as well [193]. These markers have also been shown to be implicated in the death of microglia and Müller cells [194]. Furthermore, IL-1 $\beta$ increases the expression of COX-2 and adhesion molecules in ECs [180].

\section{$\underline{\text { iBRB and DR }}$}

Recent studies reported existence of reduced gap junction intercellular communication (GJIC) thus highlighting the iBRB dysfunction. $\mathrm{Cx} 43$ expression in numerous retinal cells is downregulated during HG environment [195]. Studies have shown that $\mathrm{HG}$ downregulates $\mathrm{Cx} 43$ expression levels in the mitochondria, potentially promoting endothelial and pericytes cell death $[196,197]$. HgA showed to impair Cx43 expression, thus decreasing the activity of GJ, and the decrease in expression of the $\mathrm{TJ}$ molecules in ECs, and a subsequent cell death phenotype [55].

Studies in astrocytes depicted that activation of NF- $\mathrm{KB}$ by TLR-3 protein leads to a decrease in the expression of Cx43, thus reducing GJIC [198]. Kunihiko Nagasawa et al. reported that $\mathrm{Cx} 43$ is associated with $\mathrm{TJ}$ proteins in the blood-brain barrier (BBB) [199]. Studies in rat retinal ECs depicted that HG decreased Cx43 expression, and this decrease in $\mathrm{Cx} 43$ expression downregulated $\mathrm{TJ}$ protein, particularly occludin, thus 
impairing cell permeability but the mechanism(s) is yet to be discovered [200].

$\mathrm{HgA}$ decreases expression and redistribution of occludin [58, 201]. Ermelindo Leal et al. found that increased expression of NO generated by iNOS reduced the expression level of occludin in STZ induced diabetic rats, therefore leading to the breakdown of the iBRB [201]. NF- $\kappa$ B activation induced by TNF- $\alpha$ can internalize occludin which may disrupts the TJ barrier between epithelial cells in inflammatory bowel disease [202].

Loss of pericytes occurs during $\mathrm{HgA}$ in part due to a reduction in PDGF-B levels. Additionally, a concomitant loss of both the pericytes and ECs could result in acellular capillaries (no ECs or pericytes). This particular aspect increases the likelihood of microaneurysm formation and bleeding in the retina which would indicate iBRB breakdown. In the presence of IL-1 $\beta$, activated pericytes secrete various cytokines and chemokines, including IL-1 $\beta$. It secretes these factors to attract immune cells to the sites of inflammation. Pericytes increase the expression of ICAM-1, other adhesion molecules, and at the same time downregulate the TJ molecules [203] thus facilitating immune cell passage through the endothelium.

HG leads to the death of Müller cells via activation of casp-1 and IL-1 $\beta$ [192]. $\mathrm{HgA}$ increased the expression of IL-1 $\beta$ in Müller cells [61] and its secretion. IL-1 $\beta$ then bound to IL-R1 on ECs and increased the expression of ICAM-1 [60]. Studies have shown that $\mathrm{HgA}$ impaired Müller cells uptake of glutamate, which could lead to glutamate toxicity in diabetic rats. $\mathrm{HgA}$ also reduced potassium uptake, further exacerbating the glutamate toxicity by increasing the neuronal excitation [61]. Diabetes impairs Müller cells function via decreasing expression of glutamine synthase, and the activity of the glutamate transporters [204]. Selective ablation of Müller cells 
results in BRB in Rlbp-LacZ mice which also impairs the A-wave and B-wave responses of the mice [204]. HgA significantly impaired communication between astrocytes by reducing Cx43 expressions and other GJ as early as four weeks post STZ treatment in rats. These animals also depicted the death of astrocytes after six weeks of $\mathrm{HgA}$ [205].

\section{Inflammation and Intraocular Pressure}

The aqueous humor is secreted by the ciliary body $(\mathrm{CB})$ epithelium and it is the key factor that determines the dynamics of intraocular pressure (IOP). It is the plasma components of the $\mathrm{CB}$ that help secrete the aqueous humor into the posterior chamber (PC) which then circulate into the anterior chamber (AC). From there the aqueous humor drains into the trabecular meshwork and Schlemm's canal. The cells in the CB synthesized the aqueous humor in three steps. First, when the blood flows through the CB the plasma in form an ultrafiltrate is made due to the pressure gradient between blood flow and the interstitial of the ciliary body. Last, the epithelium of the CB transports the aqueous humor from its basal end to its apical surface actively (and selectively) and then pumping it into the PC. Systemic blood pressure has very little to do with aqueous humor synthesis, although the first step has to do with blood flow, only about $4 \%$ of plasma is being filtered [206].

Circulation of the aqueous humor generates the IOP within the AC. IOP plays a crucial role in the pathophysiology of glaucoma. An increase in IOP is a key risk factor for glaucoma, although some patients with normal IOP may have glaucoma, while others with high IOP may not have glaucoma. One factor that is associated with an increase in IOP is increased resistance in outflow [206].

$H g A$ and IOP. Multiple demographics studies concluded that there is an increase 
in IOP in diabetic patients than nondiabetic patients, and that an increase in IOP is independent of open-angle glaucoma. The mechanism has not yet been determined though. It is speculated that $\mathrm{HgA}$ causes an osmotic gradient that shifts fluid between plasma and intraocular fluids thus elevating the IOP [207]. A Japanese study found a significant correlation with IOP and $\mathrm{HBA}_{1 c}$ levels in patients with DR [207]. Similarly, a Chinese population study found an association between DM with high IOP (>21 mmHg) [208]. Demographic study in Singapore also found an association between elevated IOP and DM. Even after accounting for the difference in central corneal thickness, which is higher in diabetics individuals, the increase in IOP was independent of the development of glaucoma.

\section{$\underline{\text { JSH-23 Mechanism }}$}

4-methyl-N1-(3-phenyl propyl)-1, 2-benzenediamine (JSH-23) is a selective

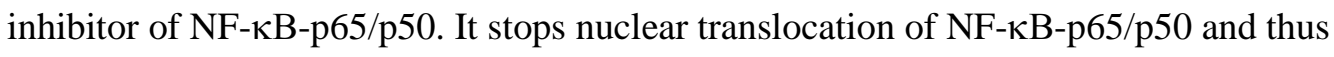
helps stop the transcription of its target genes [209]. JSH-23 has an $\mathrm{IC}_{50}$ of $7.1 \mu \mathrm{M}$ for NF- $\kappa \mathrm{B}$ nuclear translocation and transcriptional activity on macrophages RAW 264.7

stimulated by LPS. Kumar et al. showed that oral administration JSH-23 inhibits NF-кB in STZ induced male Sprague Dawley rats, and was able to decrease the expression of COX-2, iNOS in the sciatic nerve and improve nerve function [210]. When JSH-23 was used in a chronic mild stress model to inhibit the effect of NF- $\kappa \mathrm{B}$, it was able to decrease inflammatory mediators and increase anti-oxidant defense in the hippocampus [211]. After sepsis, LPS induced cardiac injury through differentiation of M1 macrophages. JSH-23 inhibits LPS induced cardiac injury in a sepsis animal model [212]. Transition metal ions activate NF- $\kappa \mathrm{B}$ and NLRP3 in bone marrow-derived macrophages, thus 
pyroptosis and again JSH-23 was shown to inhibit NLRP3 activation via inhibiting phosphorylation of NF- $\mathrm{BB}$ in macrophages after transition metal activation [213].

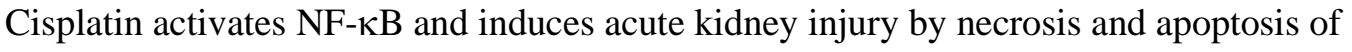
proximal tubular epithelial cells. JSH-23 reduced many of the response genes of the NF$\kappa \mathrm{B}$ activation, including casp-1 in C57BL6J mice treated with cisplatin [214]. To our knowledge, JSH-23 has not yet been used to decrease NF- $\kappa$ B activation in DR or Akita Mice. Therefore, to test our hypothesis, we used the Ins $2^{\text {Akita }}$ mouse (Akita) that has been well-characterized as an excellent model system to study T1D. Akita harbors a missense mutation in the Insulin 2 gene, which leads to a conformational change in insulin protein, causing it to accumulate in pancreatic $\beta$-cells. Accumulation causes loss of cellular function, decreased cell density, and, finally, cell-death leading to $\mathrm{HgA}$ because of insulin deficiency [144, 215-217]. These mice become hyperglycemic after four weeks of age. HgA-induced retinal pathology ensues after 12 weeks, starting with appearance of acellular capillaries, and infiltration of the leukocytes into vascular walls [144, 218, 219], increased in vascular permeability, degeneration of astrocytes and microglia, thinning of the IPL, INL, and loss of RGCs [219]. The Akita model has many vital advantages. It has an autosomal dominant mutation with stable hypoinsulinemia, and lacks systemic immunologic alterations. It is fertile, and its background does not contain the rd (pde6) variations; such modification are responsible for photoreceptors degeneration [144].

Summary. $\mathrm{HgA}$ in Type I Diabetes (T1D) induces retinal inflammation via NF-кB activation. Retinal capillary cells such as endothelial, pericytes, and glial cells are critical parts of the iBRB but remain potential targets of inflammatory mediators. Inflammatory mediators also targeted junctional molecules thus impairing the cell-cell 
communication and the paracellular transport. NF- $\kappa \mathrm{B}$ increased the pro-inflammatory genes, which induced iBRB breakdown. Thus, we proposed that the inhibition of NF- $\kappa \mathrm{B}$ p65 subunit with JSH-23 to prevent retinal microvascular impairment in the retina of Akita mice. 
Figure 6. Molecular Structure of JSH-23. JSH-23 inhibits the nuclear translocation of $\mathrm{NF}-\kappa \mathrm{B}$ p65 subunit and its transcriptional activity. 


\section{FIGURE 6}<smiles>Cc1ccc(NCCCc2ccccc2)c(N)c1</smiles>

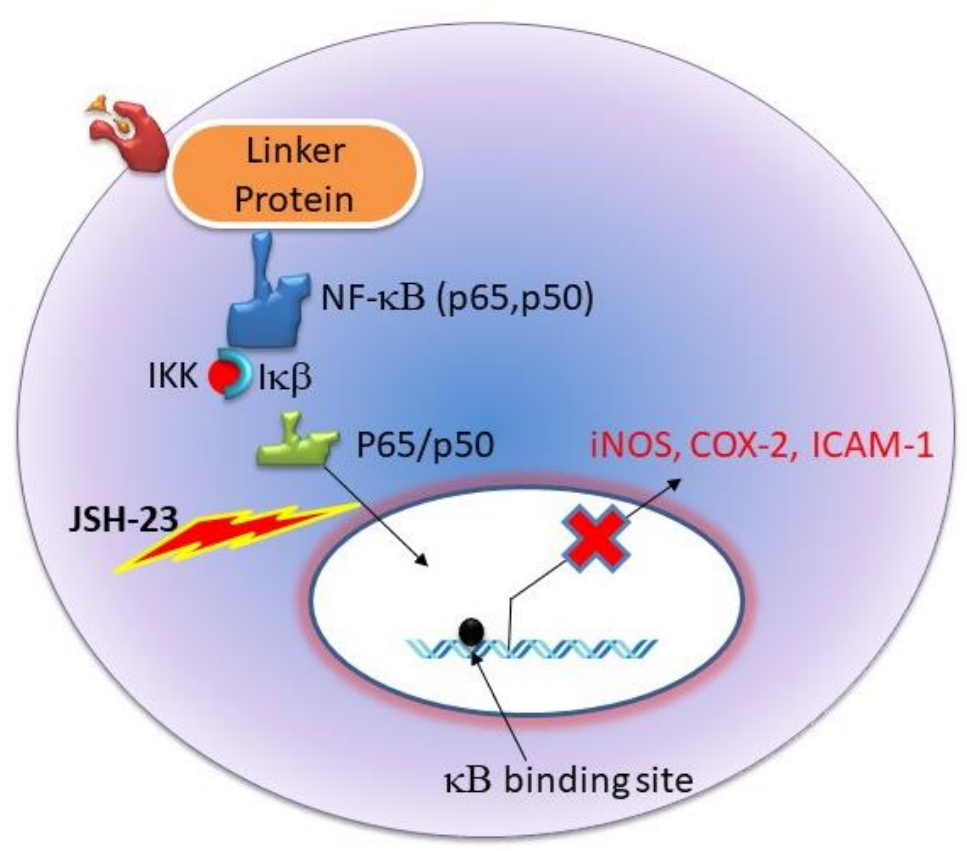


Figure 7. Summary. iBRB is consisted of endothelial, pericytes, and glial cells. The ECs and their TJ regulate transcellular and paracellular transport into the retina. $\mathrm{HgA}$ activates NF- $\kappa \mathrm{B}$, which then increases the expression of inflammatory mediators thus causing leukostasis, vascular occlusion, and the iBRB breakdown. 
FIGURE 7

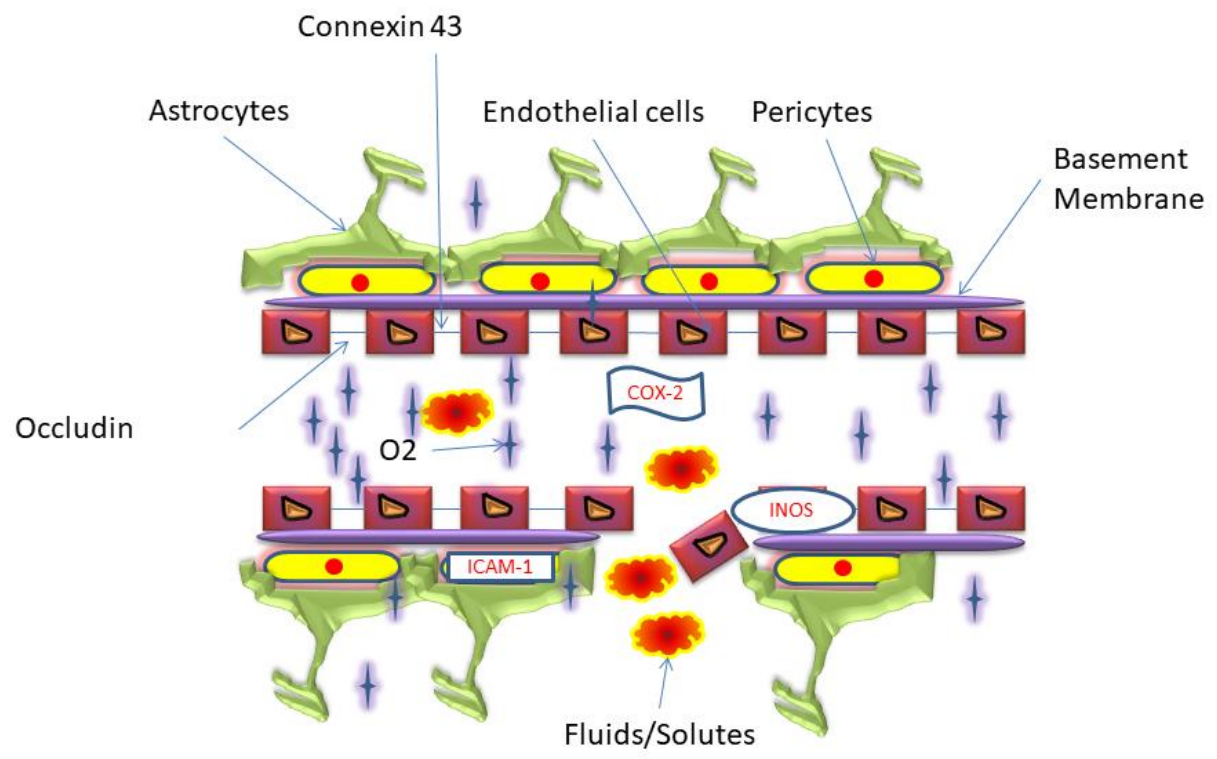


Figure 8. Summary of Background. $\mathrm{HgA}$ (in T1D Akita mouse model) dysregulates NF-кB. $\mathrm{NF}-\kappa \mathrm{B}$ overexpression increases the production of pro-inflammatory molecules from its target genes that lead to degradation of the junctional molecules in the affected retinae. As a result, the iBRB is impaired, which eventually results in the vision loss or even blindness in the susceptible diabetic patients. 
FIGURE 8

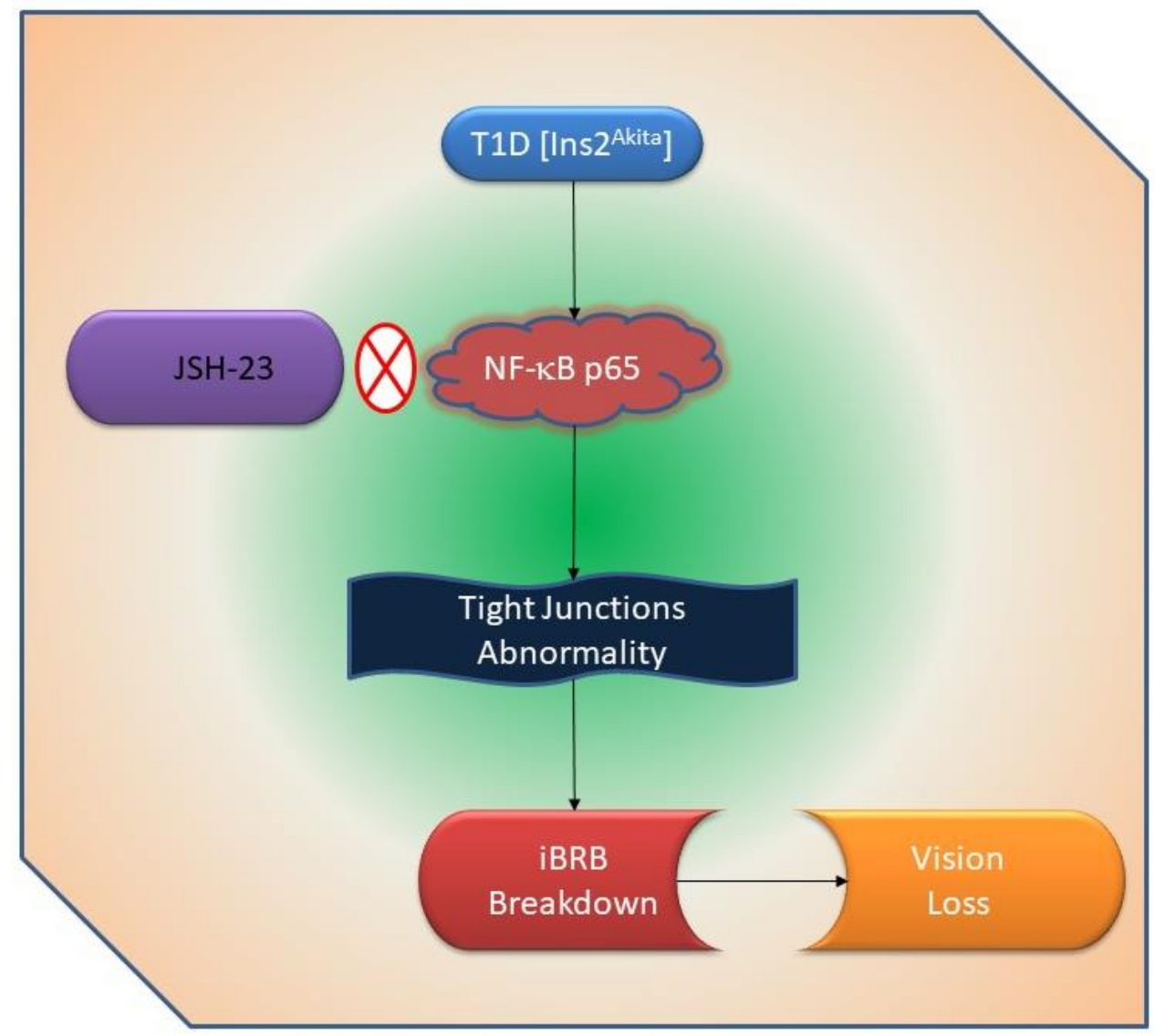




\section{CHAPTER II}

\section{HYPOTHESIS AND SPECIFIC AIMS}

Key Objective

The goal of this study is to determine the effects of chronic inflammation in impairing retinal capillary vessel in Akita (T1D model) and to investigate whether JSH23 can inhibit these injuries.

Hypothesis

During Diabetes (T1D), vision loss is due to retinal vascular leakage by an increase in inflammatory mediators (NF- $\kappa$ B p65, COX-2, INOS, and ICAM-1) which lead to an increase in retinal vascular permeability, intraocular pressure, and vision loss. Therefore, treatment with inflammatory inhibitor (JSH-23) will mitigate this vision loss.

Specific Aims

Specific Aim 1: To determine whether there is an increase in inflammatory mediators (NF- $\kappa \mathrm{B}$ p65, COX-2, INOS, ICAM-1) in Retina of T1D mice and 
whether inflammatory inhibitor, JSH-23, mitigate this increase in inflammatory mediators. (Chapter 3)

Specific Aim 2: To determine whether T1D increases retinal vascular permeability by decreasing expression of junctional molecules (Occludin, Connexin 43) and whether treatment with JSH-23 mitigate this increase in retinal vascular permeability. (Chapter 3)

Specific Aim 3: To determine whether T1D leads to vision loss in part by increase retinal vascular permeability and ocular pressure and whether treatment with JSH-23 mitigate this vision loss and retinal vascular permeability. (Chapter 4) 


\section{CHAPTER III}

\section{JSH-23 DOWNREGULATES NF- $\kappa B$ AND INCREASE EXPRESION OF JUNCTIONAL MOLECULES IN THE RETINA OF AKITA MICE}

\section{$\underline{\text { Introduction }}$}

T1D is a chronic illness that is diagnosed during childhood. It occurs in $~ 1: 400$ 600 American children [220]. A recent disturbing trend is a $15-20 \%$ increase in new diagnoses of T1D under age $5[221,222]$. The reason for this alarming increase in youths is debatable. Clinically, diabetes management has proven challenging for a variety of reasons, including physiological factors such as increased insulin sensitivity, especially in children [223]. T1D microvascular complications included DR which is divided into NPDR and PDR. DME can develop in either of the two stages [224]. Other serious complications include retinal detachment, and blindness.

DR is a leading cause of blindness in the working age adults. In its advanced form, DR can lead to blindness due to the development of DME, and cataract. Current clinical interventions vary depending on the extent of disease progression. Tight bloodglucose control and dietary measures may help slow down the disease progression in some people however; glucose control does not stop disease progression to DME or PDR. Patients may require laser surgery to seal the leaking blood vessels in their eyes or to discourage other vessels from leaking further. VEGF inhibitor injection into the eye may also be needed to decrease unabetted underlying inflammation or to stop the formation of 
abnormal vessels. Leakage from retinal vessels leads to a fresh wave of inflammatory swelling that invariably results in a cloudy or blurred vision. Even worse, a surgical procedure may be warranted to repair a detached retina. If left untreated, DR causes permanent blindness $[225,226]$.

Current interventions do not adequately address the "retino-vascular" signature pathology that underlies the initiation, progression, and maintenance of the DR phenotype. Furthermore, they fail to restore loss vision in the majority of patients. The etiology of DR is not fully understood although many pathways have been proposed for the development of DR pathology such as polyol flux, hexosamine, AGEs, and OS. DR is regarded as an inflammatory disease due to the presence of various inflammatory mediators found in the vitreous and the retinas of diabetic animals and humans [227]. An increase in the expression of inflammatory mediators is directly associated with NF- $\kappa \mathrm{B}$ activation [120]. NF- $\kappa \mathrm{B}$ is a dynamic transcription factor that orchestrates complex biological processes, including the inflammatory response itself [228]. Owing to its upstream role in cell-signaling, $\mathrm{NF}-\kappa \mathrm{B}$ is considered a central component in the inflammatory response, directing the elaboration of cytokines, and responses to stress, free radicals, heavy metals, ultraviolet irradiation, oxidized LDL, and bacterial, and viral antigens.

$\mathrm{NF}-\kappa \mathrm{B}$ is the first responder to harmful stimuli for cells/tissues. It shuttles between cytoplasm and nucleus to initiate and then help execute a robust genetranscription program. It consists of a family of structurally related transcription factors viz. NF-кB1(p50), and RelA (p65) that can form hetero- and homodimers and translocate to the nucleus upon activation $[121,209,229,230]$. There is a presence of a chronic inflammation in diabetics individuals, which could be mediated by dysregulations in NF- 
$\kappa \mathrm{B}$ signaling [120]. It has been shown that NF- $\kappa \mathrm{B}$ increased the pro-inflammatory genes in the retina of both diabetic animal models and patients [231]. It also induced the activation of pyroptosis [194]. It seems that the sustained inflammation could lead to degradation of the $\mathrm{iBRB}$. The $\mathrm{BRB}$ consists of the $\mathrm{iBRB}$ and $\mathrm{OBRB}$ which regulates the movement of ions, and solutes into the retina. The iBRB maintains harmony between TJ molecules, and retinal ECs and any kind of impairments can lead to fluid accumulation in the retina [232]. In diabetes, there is a decrease in expression in junctional molecules in the presence of sustained inflammation [233].

As DR is a significant complication of an underlying autoimmune disease, we tested our hypothesis that systemic inhibition of NK- $\mathrm{B}$ activity in a T1D model could help mitigate inflammation-induced microvascular changes in the retina that we believe are responsible for vision problems. And we know that the inflammatory mediators are elevated in the retina of DR; and are associated with iBRB breakdown [234]. Therefore, we hypothesized that pre-empting inflammation by inhibiting NK- $\kappa \mathrm{B}$ activity with JSH23 would certainly help mitigate the microvascular alterations in the diabetic retina. Moreover, JSH-23 has been demonstrated to inhibit the nuclear translocation of NF- $\kappa \mathrm{B}-$ p65 and thus inhibit its transcriptional activity [209]. The objective of this study is to investigate the effect of how suppressing inflammation could potentially prevent the development of DR in the Akita mouse model.

\section{$\underline{\text { Methods }}$}

Animal Genotyping and Maintenance of the Animals. Male C57BL/6J (WT) and Ins $2^{\text {Akita }+-}$ mice (Akita) were purchased from the Jackson Laboratory (Bar Harbor, ME). All animals were $\sim 24-26$ weeks old and were maintained in a 12:12 hour light-dark cycle 
with a regular mouse diet at the University of Louisville School of Medicine animal facility. Mice were cared according to ARVO guidelines, as approved by the Institutional Animal Care and Use Committee (IACUC) of the University of Louisville, Louisville, KY. The experimental protocols were performed following the National Institute of Health guidelines (NIH Pub. No. 86-23, revised 1985). Genotyping of the mice was carried out by collecting the tail biopsy. DNA was isolated using the DNeasy Blood and tissue kit (Qiagen, Germantown, MD). The cross-breeding yielded Ins2 $2^{\text {Akita }}$ with high and low glucose levels, as measured by blood glucose meter Ultra Touch 2 (Life Scan, USA). The high glucose level category consists of mice with blood glucose levels that were greater than or equal to $300 \mathrm{mg} / \mathrm{dL}$, and the low glucose levels were animals exhibiting less than or equal to $250 \mathrm{mg} / \mathrm{dL}$. Only mice with high glucose levels used in the experiments.

Mice were divided into four different groups: (a) WT, (b) WT + JSH-23, (c) Ins2 ${ }^{\text {Akita, }}$ and (d) Ins $2^{\text {Akita }}+$ JSH-23. JSH-23 purchased from Sigma (Sigma Aldrich, St. Louis, MO; CAS\# 749886-87-1). A stock solution of JSH-23 was prepared by diluting $25 \mathrm{mg}$ in 1000 microliter ( $\mu \mathrm{L}$ ) of 200 proofs ethanol (Decon Labs, King of Prussia, PA; CAS\# 6417-5) and stored at -70 degrees Celsius. A $100 \mu \mathrm{L}$ of the stock solution diluted with 4900 $\mu \mathrm{L}$ of $1 \mathrm{X}$ sterile phosphate-buffered saline (PBS). The control solution prepared with $4900 \mathrm{~mL}$ of $1 \mathrm{X}$ PBS and $100 \mathrm{~mL}$ of 200 proofs ethanol. Akita and wild type (WT) C57BL/6J mice strains were treated with or without a specific and selective inhibitor for the translocation of the NF-kB (i.e. with JSH-23) intraperitoneally (IP) @ 5mg/Kg body weight on alternate days for a total of 4 weeks. Blood pressure (CODA Instrument), blood glucose (Ultra Touch 2), body weights (OHAUS, CS-2000 Balance), and intraocular pressure (iCare, Tonolab) were measured before and after the injections of the 
NF-кB inhibitor (Fig. 9).

Measurement of body weight, blood glucose, blood insulin, and glucose tolerance test. Body weights of all the animals recorded using an electronic weighing balance (OHAUS, CS-2000). ELISA. Mouse INSULIN ELISA kit (EMINS) from Thermo Fischer Scientific (Waltham, MA) was used to analyze plasma insulin levels. The test performed according to manufacture instructions.

Intraperitoneal Glucose Tolerance Test. The glucose tolerance test used to measure the clearance of an IP injected glucose load from the body and to detect disturbances in glucose metabolism that linked to diabetes or metabolic syndrome. Glucose $(200 \mathrm{mg} / \mathrm{ml})$ was injected IP (@ 2g per kg body weight after 6 hours of fasting. Blood glucose was measured (tail vein) at $0,30,60,90$, and 120 minutes after the injection using Ultra Touch 2 [235].

Reagents and Antibodies. Antibodies and chemicals were purchased from trusted sources such as Sigma-Aldrich, Abcam, Cell Signaling Technology, or Santa Cruz Biotechnology. Details for the antibodies are; iNOS (ab15323) and NLRP3 (ab214185) purchased from Abcam (Cambridge, MA, USA). COX-2 (4842S), Total NF-кB p65 (8242S), and p-NF-кB p65 (3033S) purchased from Cell Signaling Technology (Danvers, MA, USA). ICAM-1 (sc-107) purchased from Santa Cruz Biotechnology (Dallas, TX). The secondary antibodies also purchased from Santa Cruz Biotechnology, namely rabbit anti-mouse (sc-358914), mouse anti-rabbit (sc-2357), and mouse anti-goat (sc-2354). GAPDH (MAB374) was purchased from EMD Millipore (Burlington, MA). All reagents/antibodies were used for Western Blotting following the manufacturers' 
recommended protocols. 
Figure 9. Treatment plan. The blood glucose, blood pressure, IOP, and body weight of the animals were measured before and after treatment with JSH-23. The treatment was carried on alternate days for four weeks. 
FIGURE 9

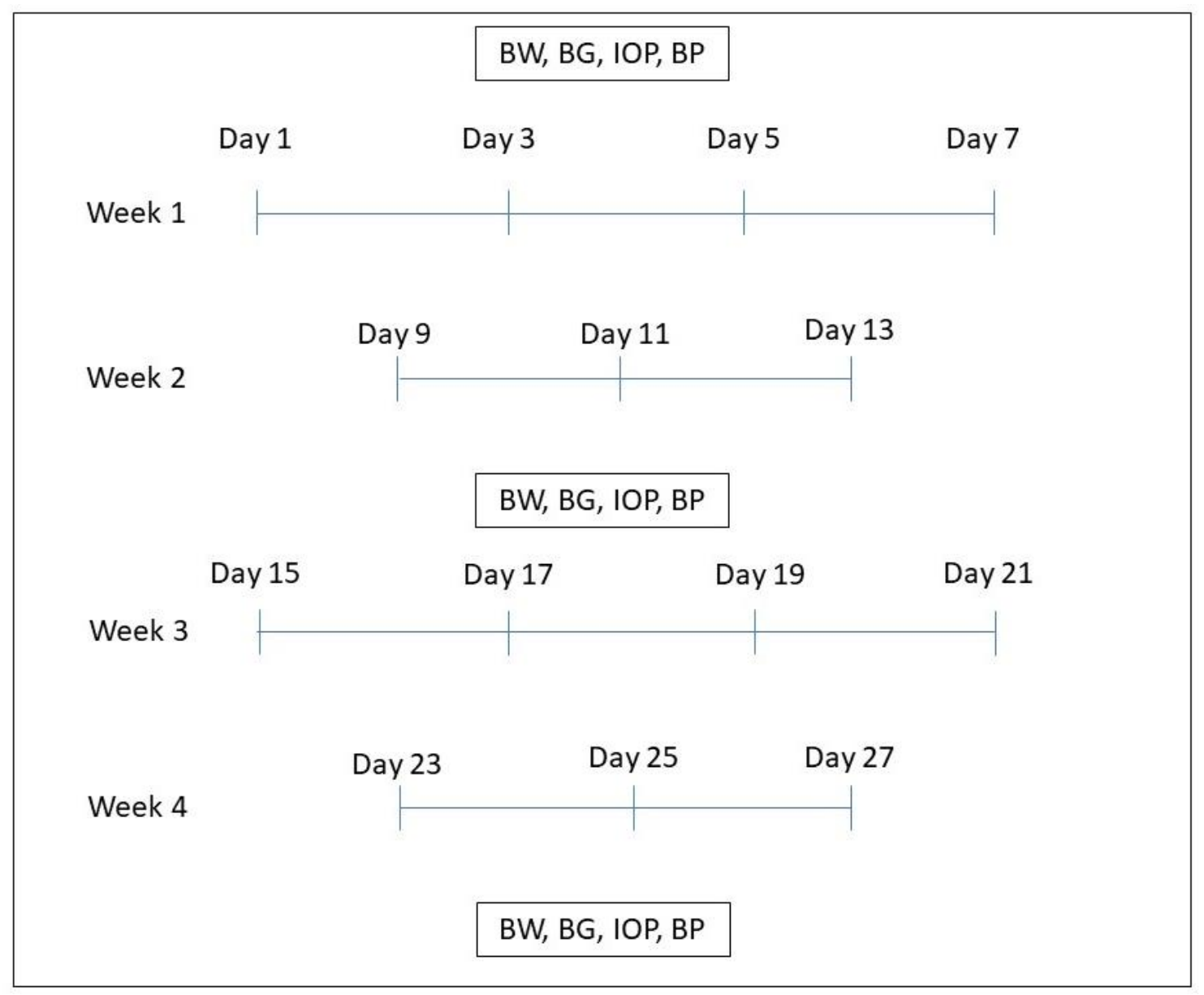


Western Blotting. Protein expression profiles were performed via Western blots analyses. Retinas were separated from enucleated globes from the euthanized mice, and the retinal protein lysates were used immediately or snap-frozen in liquid nitrogen and stored at $80^{\circ} \mathrm{C}$ until further use. Protein were extracted via homogenizing in RIPA buffer (Boston BioProducts, Worcester, MA). These cocktails were added to the RIPA buffer; a cocktail of $1 \mathrm{mmol} / \mathrm{L}$ phenylmethylsulfonyl fluoride (Sigma, Saint Louis, MO), 1\% protease inhibitors cocktail (Sigma). Then the samples were sonicated with the Sonifier 450 (Branson Ultrasonics, Danbury, CT). The homogenates were centrifuged at 15,000 rpm for $15 \mathrm{~min}$ at $4^{\circ} \mathrm{C}$, and the resultant supernatants were collected and stored at $-80^{\circ} \mathrm{C}$. Bradford assay was used to estimate the total protein contents. Per sample, $40 \mu \mathrm{g}$ of total protein amount resolved on a $10 \%$ SDS-PAGE and then transferred to polyvinylidene difluoride (PVDF) membrane. The membranes were incubated with primary antibodies overnight and then with the secondary antibodies were added the next day for 3 hours before visualization with ECL Luminata Forte (Millipore, Temecula, CA) via a Bio-Rad ChemiDoc system (BioRad Laboratories, Des Plains, IL, USA). Band intensities were normalized to GAPDH for all the target proteins analyzed, and their respective quantifications were performed through Image Lab ${ }^{\mathrm{TM}}$ Software (Bio-Rad, Hercules, CA).

Quantitative PCR. RNA was isolated with TRIzol ${ }^{\circ}$ reagent (Life Technologies, Carlsbad, CA, USA) based on the instruction of the manufacturer. Nanodrop-1000 (Thermo Scientific, Waltham, Ma) was used to analyze RNA quantification and purity. Im Prom-II ${ }^{\mathrm{TM}}$ Reverse Transcription System (A300, Promega, Madison, WI) was used to reverse-transcribe the total RNA into cDNA per instructions of the manufacturer. Quantitative PCR (qPCR) was performed for different transcripts 
(RelA, iNOS, COX-2, ICAM-1, Cx43, Occludin, NLRP3, Casp-1, IL-1 $\beta$ ). The final reaction included $10 \mu \mathrm{l}$ of nuclease-free water, $8 \mu \mathrm{l}$ of Bullseye EvaGreen qPCR Mastermix (BEQPCR-S, MIDSCI, Valley Park, MO), 50 picomoles of forward and reverse primers, and $1 \mu \mathrm{l}$ of cDNA (Table 1). The data were normalized with housekeeping gene GAPDH.

Statistical Analyses. All values are reported as mean \pm SEM. One-way ANOVA was used to analyze the difference between the groups, including a Tukey's post hoc analysis for groups' comparisons. The tests were performed with $\mathrm{p}<0.05$ and a total number of mice $(n)=5-20$ were subjected toanalysis depending upon particular experiments from each group. GraphPad Prism (Ver 8.1, GraphPad Software) used during analyses.

\section{$\underline{\text { Results }}$}

Confirmation of Ins2 ${ }^{\text {Akita }}$ Mutation in the Expanded Mouse Colony and Effect of JSH-23 on Glucose Metabolism. Mice tail DNA samples were analyzed using PCR employing specific primers to determine the mice genotype. Genotyping revealed the mutated version of the insulin gene exhibiting two discrete bands: 280 and 140 bp representing the heterozygous status while wild-type (WT) mice showed one $140 \mathrm{bp}$ band (Fig. 10A). To generate mice for the study, Akita female with low blood glucose (LG) were cross-breed with male Akita mice with high glucose (HG). Cross-breeding yielded Akita progeny with HG and LG levels as measured by blood glucose (BG) meter Ultra Touch 2 (Life Scan, USA). Only Akita mice with a BG level $<300 \mathrm{mg} / \mathrm{dL}$ were used in this study. Akita mice have a mean BG level of $596.47 \mathrm{mg} / \mathrm{dL}$, significantly higher than C57BL/6 J BG of $173.47 \mathrm{mg} / \mathrm{dL}$ ( $\mathrm{p}<0.0001, \mathrm{n}=15$ per group). JSH-23 significantly decreased 
Table 1. Nucleotide sequence. Forward and reverse primers gene sequences for each gene analyzed. 
TABLE 1

\begin{tabular}{|l|l|l|}
\hline \multicolumn{1}{|c|}{ Gene } & \multicolumn{1}{|c|}{ Forward Sequence } & \multicolumn{1}{c|}{ Reverse Sequence } \\
\hline Rel A[236] & 5'- GCCCAGACCGCAGTATCC & 5'- GTCCCGCACTGTCACCTG \\
\hline iNOS [237] & 5'- CAGCTGGGCTGTACAAACCTT & 5'- CATTGGAAGTGAAGCGGTTCG \\
\hline COX-2 [238] & 5'- CAGAACCGCATTGCCTCTG & 5'- TTGTAACTTCTGGTCCTCATGTCGA \\
\hline ICAM-1[239] & 5'- TTCACACTGAATGCCAGCTC & 5'- GTCTGCTGAGACCCCTCTTG \\
\hline Cx43 [240] & 5'- CCAAGGAGTTCCACCACTTTG & 5'- CCATGTCTGGGCACCTCTCT \\
\hline Occludin[241] & 5'- AGACCCAAGAGCAGCCAAAG & 5'- GGAAGCGATGAAGCAGAAGG \\
\hline NLRP3 [242] & 5'- CTTCTAGCTTCTGCCGTGGTCTCT & 5'- CGAAGCAGCATTGATGGGACA \\
\hline Casp-1[242] & 5'-GTACACGTCTTGCCCTCATTATCTG & 5'- TTTCACCTCTTTCACCATCTCCAG \\
\hline IL-1 $\boldsymbol{\beta}$ [242] & 5'-CAACCAACAAGTGATATTCTCCATG & 5'- GATCCACACTCTCCAGCTGCA \\
\hline
\end{tabular}


Figure 10. Genotyping and Physiological Parameters of Akita, and C57BL/6J Mice.

A. Genotyping of Akita, and C57BL/6J mice. B. Body weight of the Akita, and the C57BL/6J, Akita mice body weights were significantly lower than the body weights of the C57BL/6J mice ( $p<0.0001, n=19$ per group). C. The blood glucose level of Akita, and C57BL/6J mice the blood glucose levels of Akita mice were significantly higher than C57BL/6J mice ( $\mathrm{p}<0.0001, \mathrm{n}=15$ per group). JSH-23 significantly decreased blood glucose levels in Akita mice ( $\mathrm{p}<0.0001)$. D. Plasma insulin levels of Akita mice were substantially lower ( $\mathrm{p}<0.0001, \mathrm{n}=19$ per group). E. Intraperitoneal glucose tolerance test depicted the inability of the Akita mice to lower their blood glucose levels $(\mathrm{p}<0.009, \mathrm{n}=5$ per group). 
FIGURE 10

A. Genotyping

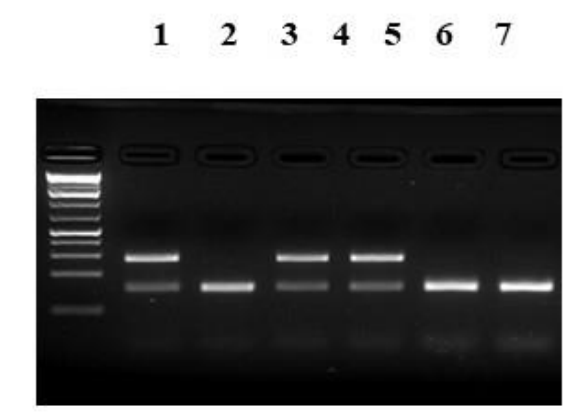

C. Blood Glucose Level for C57BL6J and
Akita Mice Treated with JSH-23
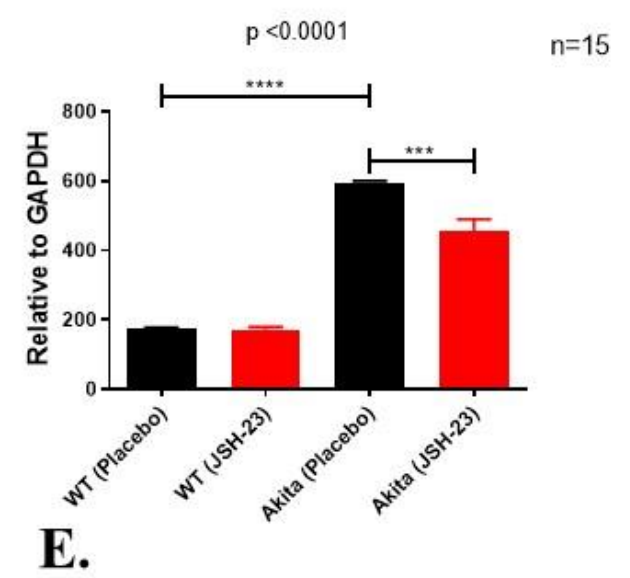

Intraperitoneal Glucose Tolerance Test $p<0.0090$

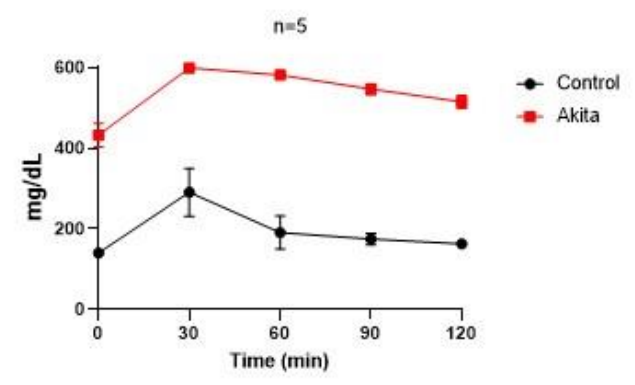

B.

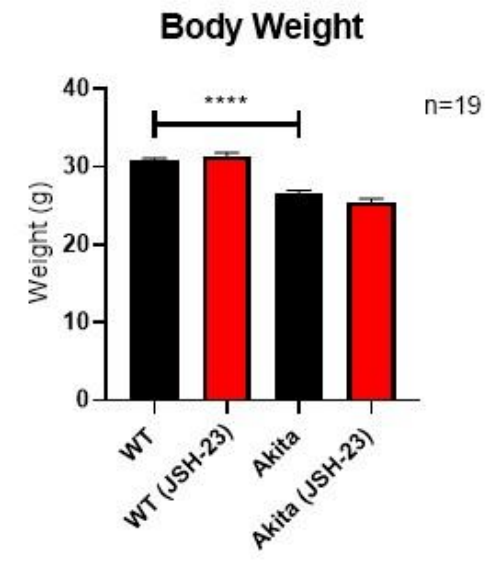

D.

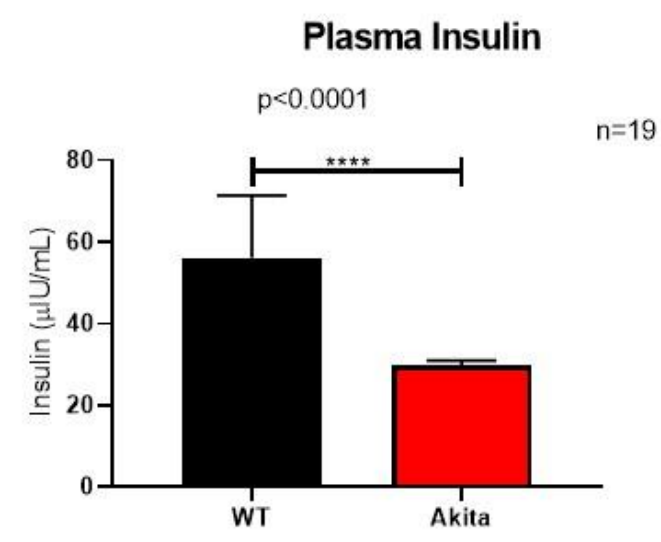


Figure 11. Expression of NF-kB p65 in the retinae of Akita, and C57BL/6J mice after treatment with JSH-23. A. Immunoblotting image of total and phosphorylated

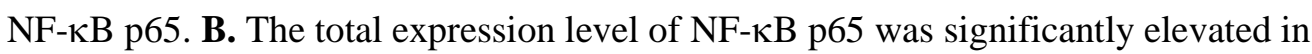
Akita mice ( $\mathrm{p}<0.05, \mathrm{n}=7$ per group). JSH-23 significantly decreased the total expression of NF- $\kappa$ B p65 in Akita mice $(\mathrm{p}<0.005)$. C. The phosphorylated expression level of NF$\kappa B$ p65 significantly elevated in Akita mice ( $\mathrm{p}<0.05, \mathrm{n}=7$ per group). JSH-23 could significantly decreased the phosphorylated expression level of NF- $\kappa$ B p65 (p<0.05). D.

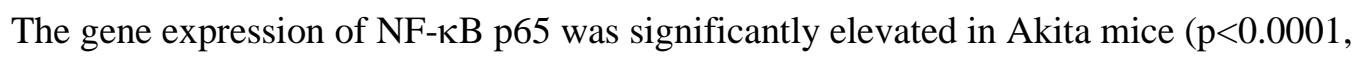
$\mathrm{n}=7$ ). JSH-23 significantly decreased the gene expression of NF- $\mathrm{BB}$ p65 in Akita mice $(\mathrm{p}<0.0002)$. 
A.

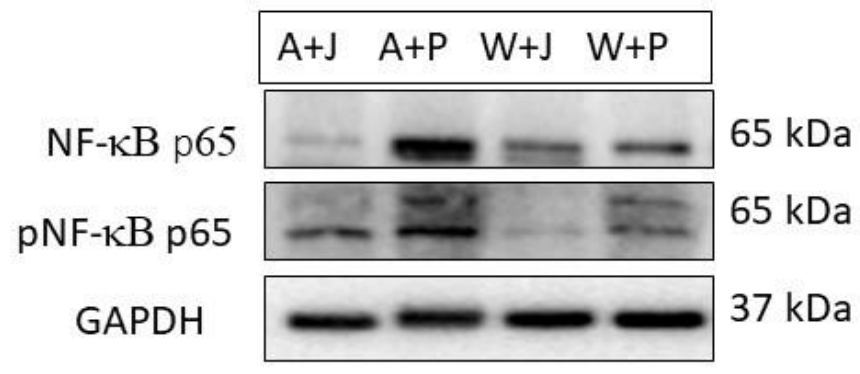

B.

Total NF-kB p65 Expression $p<0.0039$

$\mathrm{n}=7$



NF-кB p65 Gene Expression

D.

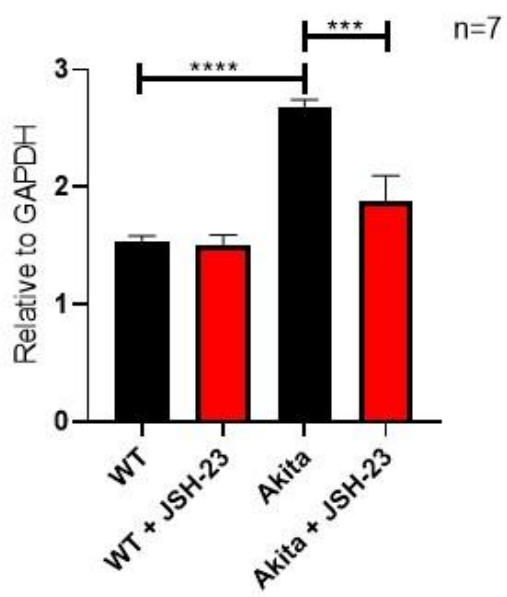

C. p-NF-kB p65 Expression

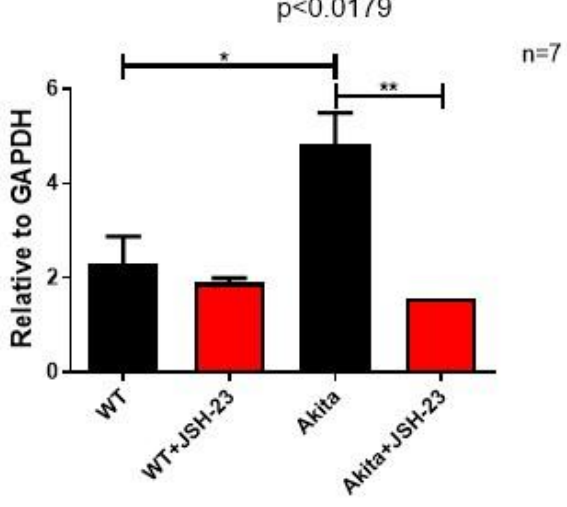


Figure 12. Expression levels of ICAM-1, iNOS, and COX-2 in the retinae of Akita, and C57BL/6J mice after treatment with JSH-23. A. Immunoblotting image of ICAM1, iNOS, and COX-2. B. The expression level of ICAM-1 was significantly elevated in Akita mice ( $\mathrm{p}<0.0218, \mathrm{n}=6$ per group). JSH-23 significantly decreased the expression of ICAM-1 in Akita mice $(\mathrm{p}<0.0028)$. C. The expression level of iNOS was significantly elevated in Akita mice ( $\mathrm{p}<0.0001, \mathrm{n}=6$ per group). $\mathrm{JSH}-23$ significantly decreased the expression of iNOS in Akita mice $(\mathrm{p}<0.0001)$. D. The expression level of COX-2 was significantly elevated in Akita mice ( $\mathrm{p}<0.0001, \mathrm{n}=6$ per group). JSH-23 significantly decreased the expression of COX-2 in Akita mice $(\mathrm{p}<0.0001)$. 
FIGURE 12

A.

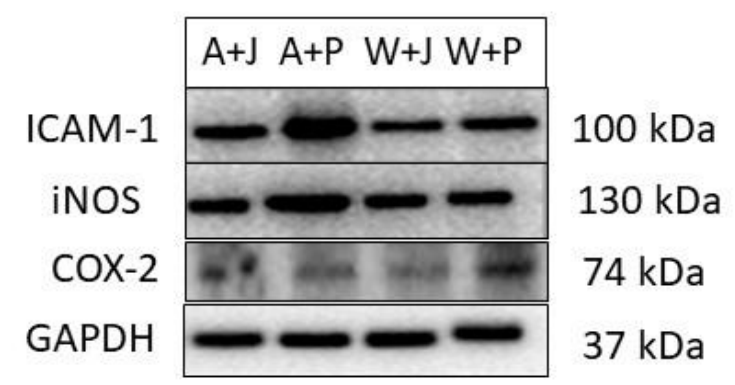

B.

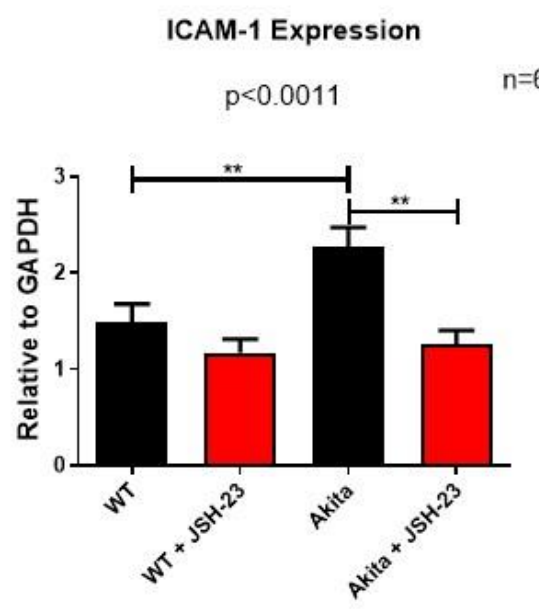

D.

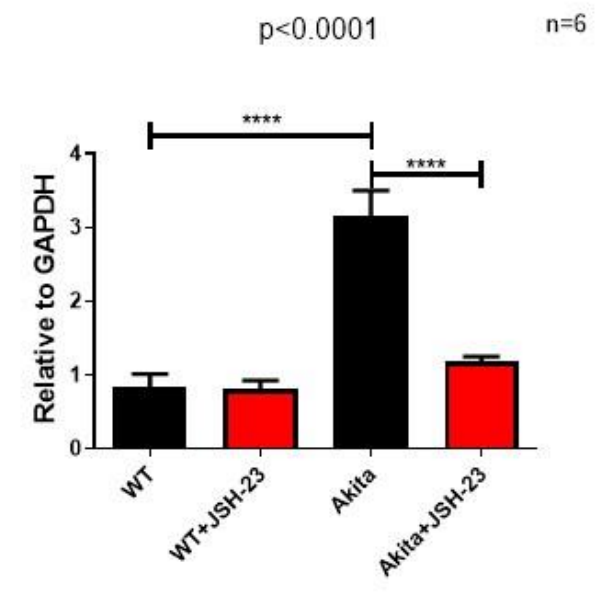

C.

iNOS Expression

$p<0.013 \quad n=6$

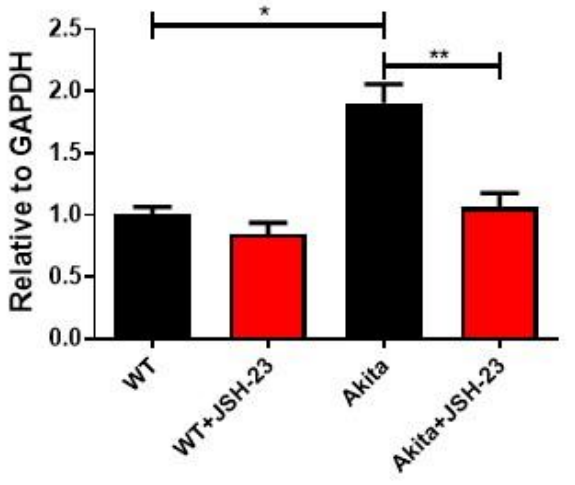


Figure 13. Gene expression level of ICAM-1, iNOS, and COX-2 in the retinae of Akita mice, and C57BL/6J treated with JSH-23. A. ICAM-1 gene expression was elevated in Akita mice ( $<<0.0003, n=5$ per group). JSH-23 decreased the gene expression in Akita mice $(\mathrm{p}<0.0001)$. The iNOS gene expression was elevated in Akita mice $(\mathrm{p}<0.0012, \mathrm{n}=5$ per group). JSH-23 decreased iNOS gene expression levels in Akita mice $(\mathrm{p}<0.0031)$. COX-2 gene expression was increased in Akita mice $(\mathrm{p}<0.0004, \mathrm{n}=5$ per group). JSH-23 reduced the expression of COX-2 in Akita mice $(\mathrm{p}<0.0001)$. 
FIGURE 13

A.

ICAM-1 Gene Expression $p<0.0001$

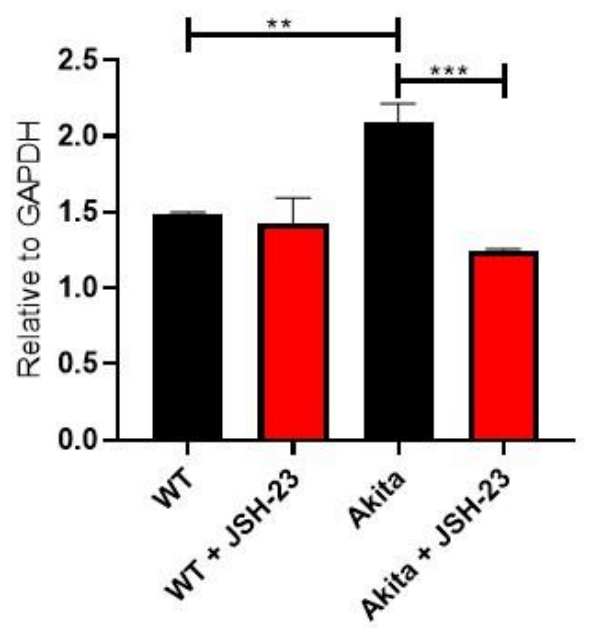

C. COX-2 Gene Expression



B.

INOS Gene Expression $p<0.0007$ $n=6$

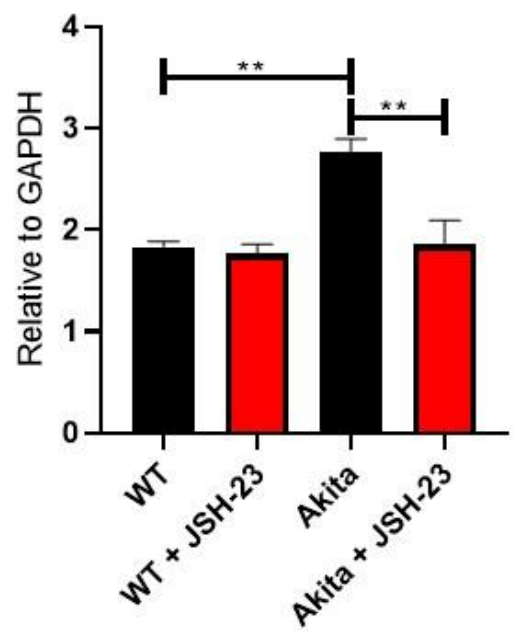


Figure 14. Pyroptosis Marker in the retinae of Akita, and C57BL/6J mice treated with JSH-23. A. Immunoblotting imaging of NLRP3. B. NLRP3 expression level was elevated in Akita mice ( $\mathrm{p}<0.018, \mathrm{n}=6$ per group). JSH-23 decreased NLRP3 expression in Akita mice ( $\mathrm{p}$ 0.0003). C. NLRP3 gene expression was increased in Akita mice ( $p<0.0025, n=6$ per group). JSH-23 decreased the gene expression level of NLRP3 in Akita mice ( $\mathrm{p}<0.0003)$. D. Casp-1 gene expression increased in Akita mice $(\mathrm{p}<0.0001$, $\mathrm{n}=6$ per group). JSH-23 decreased the gene expression of casp-1 $(\mathrm{p}<0.0001)$. E. IL-1 $\beta$ gene expression was elevated in Akita mice ( $p<0.0001, n=6$ per group). JSH-23 decreased the gene expression level of IL-1 $\beta(\mathrm{p}<0.0001)$. 
FIGURE 14

A.

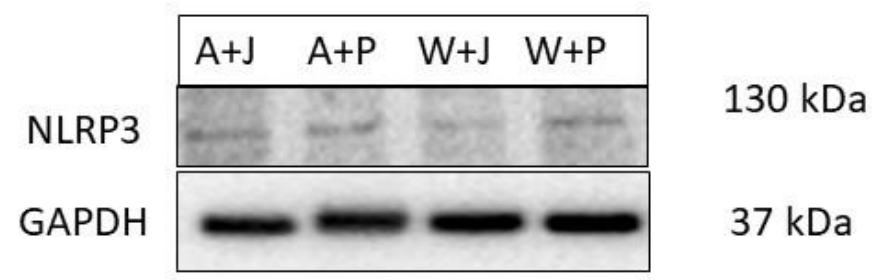

B.

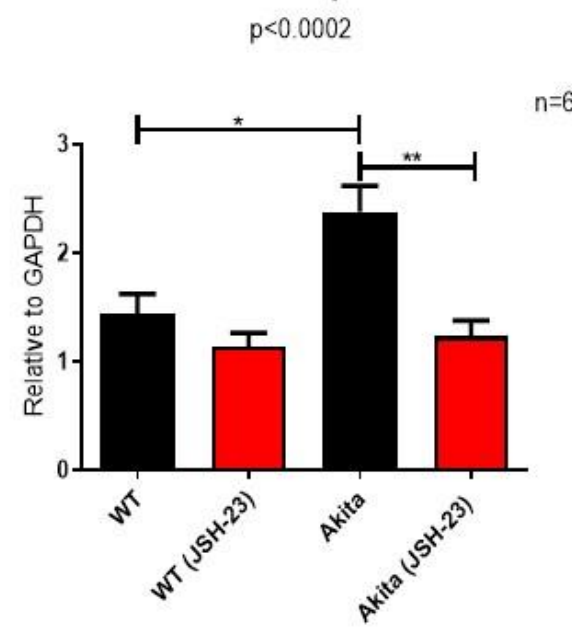

D.

Caspase-1 Gene Expression $p<0.0001$

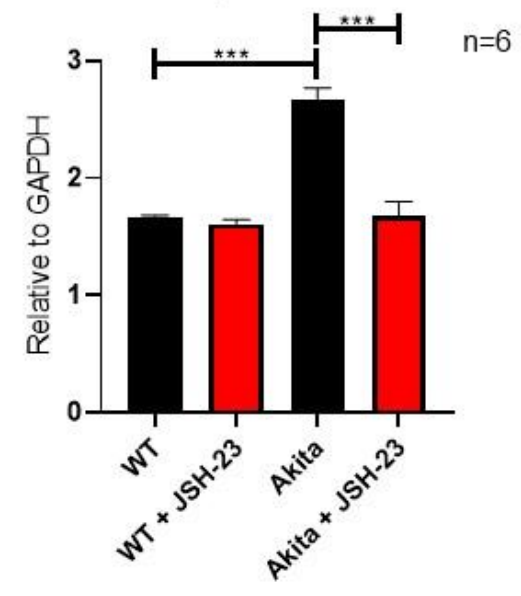

C. NLRP3 Gene Expression $p<0.0003$

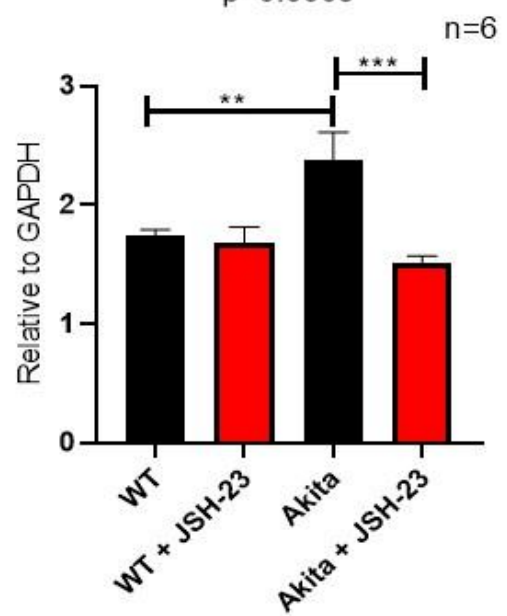

E.

IL-1及 Gene Expression $p<0.0001$ $\mathrm{n}=6$

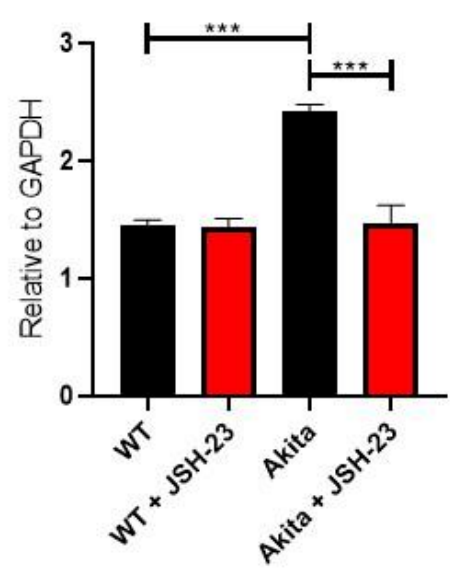


Figure 15. Expression of Junctional Molecules in the retinae of Akita, and C57BL/6J mice treated with JSH-23. A. Immunoblotting image of Cx43, and occludin. B. Cx43 expression was decreased in Akita mice ( $\mathrm{p}<0.0165, \mathrm{n}=5$ per group). JSH-23 increased the expression of $\mathrm{Cx} 43$ ( $\mathrm{p}<0.0006)$. C. Occludin expression was decreased in Akita mice ( $p<0.0068, n=5$ per group). JSH-23 decreased the expression of occludin $(p<0.0071)$. D. Cx43 gene expression was decreased in Akita mice ( $<<0.003, n=5$ per group). JSH-23 increased the gene expression in Akita $(\mathrm{p}<0.0237)$. E. Occludin gene expression was decreased in Akita mice ( $\mathrm{p}<0.0073, \mathrm{n}=5$ per group). JSH-23 increased the gene expression of occludin $(\mathrm{p}<0.006)$. 
FIGURE 15

A.

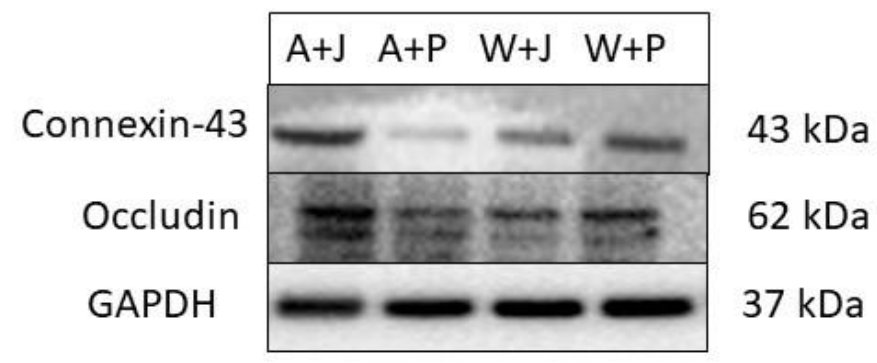

B.

Connexin-43 Expression

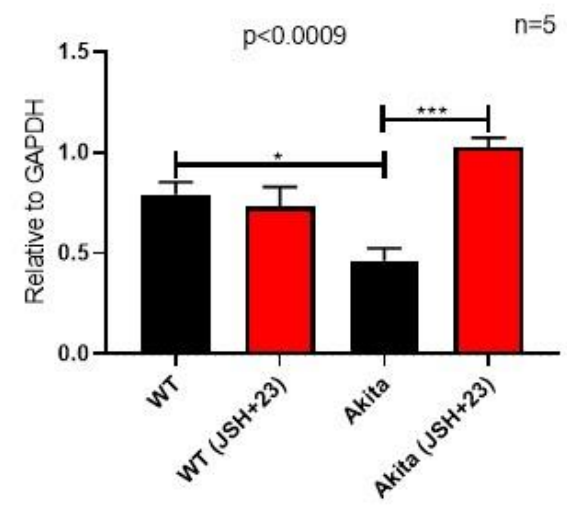

D.
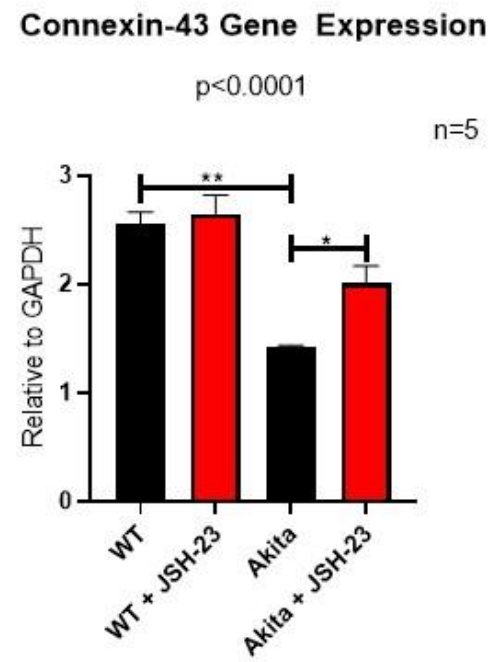

C. Occludin Expression $p<0.0027$

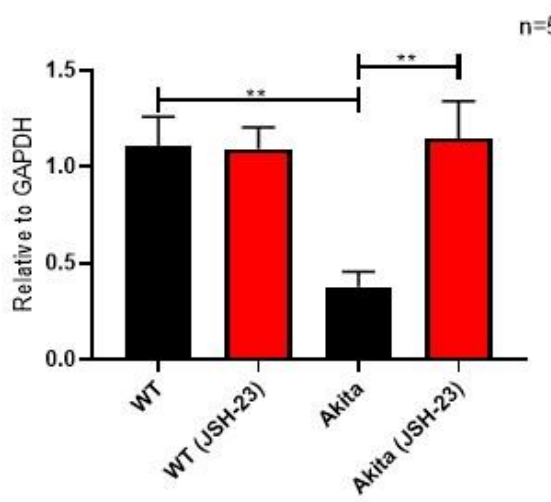

E. Occludin Gene Expression

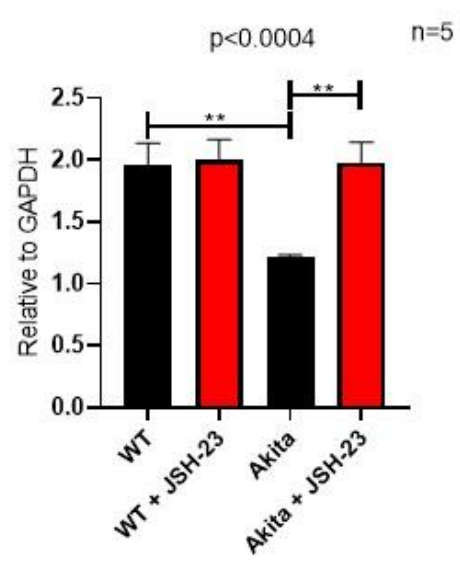


the mean $(456.2 \mathrm{mg} / \mathrm{dL}, \mathrm{p}<0.0001)$ blood glucose level in Akita mice (Fig. 10C). Akita mice have a mean body weight of $26.60 \mathrm{~g}$, substantially lower than C57BL/6J mice with a mean of 30.82g ( $<<0.0001)$. JSH-23 did not have any effect on the mean body weights of the Akita mice (Fig. 10B). Akita displayed significantly lower plasma insulin levels $(\mathrm{p}<0.0001)$ (Fig. 10D). As expected, results from IP administered glucose tolerance test (ipGTT) showed high basal glucose levels in Akita in comparison to C57BL/6J mice. Furthermore, ipGGT also revealed that the Akita strain was unable to lower its glucose level (p<0.0090) in their blood (Fig. 10E).

JSH-23 Diminishes Key Inflammatory Molecules in the Diabetic Retinae. Western blotting and qPCR analyses were used to examine the effects of systemic inhibition of NF- $\kappa B$ in mice retinae. The total $(\mathrm{p}<0.0353)$ and phosphorylated amounts $(\mathrm{p}<0.0463)$ of

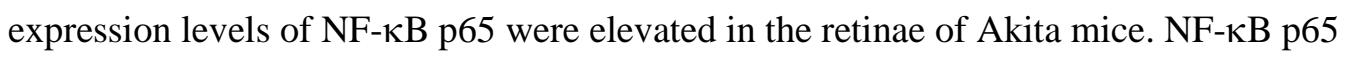
subunit gene expression $(\mathrm{p}<0.0001)$ was also elevated in the retina of Akita mice. JSH-23 decreased the total $(\mathrm{p}<0.0053)$ and phosphorylated $(\mathrm{p}<0.0254)$ and gene expression $(\mathrm{p}<0.0002)$ levels of NF-кB p65 (Fig. 11).

ICAM-1 expression level $(\mathrm{p}<0.0218)$ and the gene expression $(\mathrm{p}<0.0003)$ were elevated in the retinae of Akita mice. JSH-23 decreased the expression level $(\mathrm{p}<0.0028)$ and gene expression $(\mathrm{p}<0.0001)$ of ICAM-1 in the retinae of Akita mice. The iNOS expression level $(\mathrm{p}<0.0001)$ and gene expression $(\mathrm{p}<0.0012)$ were increased in the retinae of Akita mice. JSH-23 decreased the expression $(\mathrm{p}<0.0001)$ and gene expression $(p<0.0031)$ levels of iNOS in the retinae of Akita mice. COX-2 expression $(p<0.0001)$ and gene expression levels $(\mathrm{p}<0.0004)$ were increased in the retinae of Akita mice. JSH23 decreased expression level 
$(\mathrm{p}<0.0001)$ and gene expression levels $(\mathrm{p}<0.0001)$ of COX-2 in the retinae of Akita mice (Fig. $12 \& 13)$.

JSH-23 Decreases Expression of Pyroptosis Markers in the Diabetic Retinae. NLRP3 expression $(\mathrm{p}<0.0180)$ and gene expression levels $(\mathrm{p}<0.0025)$ were increased in the retinae of Akita mice. JSH-23 decreased expression ( $\mathrm{p}<0.0003)$ and gene expression levels $(\mathrm{p}<0.0003)$ of NLRP3 in the retinae of Akita mice. The gene expressions levels of casp-1 $(\mathrm{p}<0.0001)$ and IL-1 $\beta(\mathrm{p}<0.0001)$ were increased in the retinae of Akita mice.

JSH-23 decreased gene expression levels of casp-1 (p<0.0001) and IL-1 $\beta(p<0.0001)$ in the retinae of Akita mice (Fig. 14).

JSH-23 Augments Integrity of the Tight and Gap Junctions Proteins in the Diabetic Retinae. Cx43 expression $(\mathrm{p}<0.0165)$ and gene expression levels $(\mathrm{p}<0.0003)$ were elevated in the retinae of Akita mice. JSH-23 increased expression $(\mathrm{p}<0.0006)$ and gene expression levels $(\mathrm{p}<0.0237)$ in the retinae of Akita mice. Occludin expression $(\mathrm{p}<0.0068)$ and gene expression levels $(\mathrm{p}<0.0073)$ in the retinae of Akita mice were also modulated as can be seen that JSH-23 increased the expression $(\mathrm{p}<0.0071)$ and gene expression levels $(\mathrm{p}<0.0060)$ of occludin in the retinae of Akita mice (Fig. 15).

\section{$\underline{\text { Discussion }}$}

There are several mouse models of T1D induced DR that vary in etiology, severity, mode of inheritance, progression, and overall disease pathology. Akita strain of mouse becomes diabetic due to a mutation in the insulin 2 (Ins2) gene that results in improper folding of the insulin protein, thus causing a toxic injury to $\beta$-cells of the 
pancreas. This structural alteration in the insulin molecule impairs insulin secretion, OS, cell death, and an impairs glucose-stimulated insulin release. This also produces toxic byproducts, leading to a severe inflammatory changes in the diabetic retinae causing the retinovascular permeability, and leukostasis [144, 216-218, 243]. NF- $\kappa \mathrm{B}$ is the first

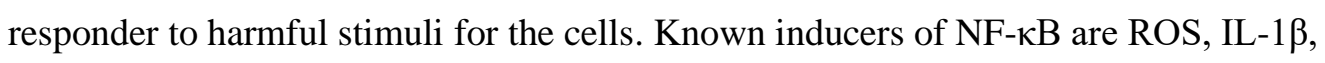
bacterial LPS, and ionizing radiation mediated DNA damage [244-248]. NF- $\kappa$ B is a family of transcription factors, RelA (p65), that hetero/homodimerize, translocate to the nucleus to augment NF-кB directed genes' expression, particularly the inflammatory mediators [121].

Inflammatory mediators such as iNOS, COX-2, and ICAM-1 are elevated in the retinae of DR, associated with iBRB breakdown, thus increasing the retinal vascular permeability. Increased leukostasis mediated by ICAM-1 is associated with an increase in the vascular permeability [234]. HgA induces leukostasis in retinal vessels in rodents that leads to endothelial apoptosis [249-251]. Leukostasis impairs vision via two proposed mechanisms: (a) iBRB breakdown due to cellular apoptosis in the endothelium and (b) endothelial apoptosis that leads to avascular capillaries; thus, nonperfusion or hypoperfusion which in turn results into neovascularization [251]. NF- $\kappa \mathrm{B}$ plays an essential role in inflammation and leukostasis via ICAM-1.

Inflammation of the retinal vasculature was significantly diminished as demonstrated by expression analyses of the critical inflammatory mediators such as ICAM-1, COX-2, and iNOS in the retinae of Akita mice. Also, the total NF- $\mathrm{kB}$ p65, and pNF- $\kappa$ B p65 activities were significantly reduced, indicating a clear readout of the specific inhibition of the critical transcription factor that is responsible for mounting 
immune response in the diabetic retinae. In diabetes, leukocyte adhesion to retinal endothelium is the primary mechanism of leukostasis. This adhesion is mediated by the upregulation of ICAM-1 due to NF- $\mathrm{BB}$ activation, which increases ICAM-1 expression. Increased leukostasis is associated with enhanced vascular permeability [166-168]. Furthermore, inhibition of ICAM-1 has shown to reduce the leakage and leukocytes adhesion along with a decrease in leukocytes adherence in diabetic rats [169]. Prominent inflammatory mediators like iNOS, COX-2, and ICAM-1 were elevated in the diabetic retinas, as shown in this study. These molecules are associated with iBRB breakdown leading to an increase in the retinal vascular permeability during diabetes because of the chronic inflammation that potentially contributes to iBRB breakdown. It was reported that inhibition of NF- $\kappa \mathrm{B}$ activation by calcium dobesilate prevented degradation of occludin in part by decreasing the expression of ICAM-1 [58].

Similarly, the $\mathrm{HgA}$ induced downregulation of Cx43 severely affected the GJIC in the blood vessels and that has again been shown to contribute to iBRB integrity during DR pathogenesis [252]. Low expression of Cx43 was concurrently associated with other companion junctional proteins such as occludin and ZO-1 that were also found to be downregulated [195]. Therefore, we analyzed retinal cell lysates for occludin, and Cx43, employing Western blotting and qPCR assays. Their expression levels in JSH-23-treated Akita mice were increased significantly. JSH-23 was shown to be a protective agent by attenuating the loss of Cx43 during the hypoxic environments [253]. Furthermore, others have shown that specific inhibition of NF- $\mathrm{kB}$ by JSH-23 attenuated the pathological sprouting of the lymphatic vessels [254]. NF- $\mathrm{kB}$ activation also activated the assembly of the NLRP3 inflammasome. NLRP3 has been shown to be active during inflammation, and activation of inflammasome in the retinae [242, 255, 256]. 
Pyroptosis, and inflammatory cell death both activate via the assembly of the NLRP3 inflammasome that further enables casp-1, which then cleaves the IL-1 $\beta$. Retinal vascular cell death during $\mathrm{HgA}$ causes the breakdown of iBRB. $\mathrm{HgA}$ induced activation of casp-1, and IL-1 $\beta$ has been reported in causing Müller cell death [193]. This study showed an increase in NLRP3 expression level and the gene expression of casp-1, and IL-1 $\beta$ in the retinae of Akita mice. JSH-23 significantly decreased NLRP3 expression levels and the gene expression of both casp-1 and IL-1 $\beta$ in the retinae of Akita mice.

The incidence of T1D is rising, and glycemic variability is common among young children these days. This has long-term implications for health and well-being for the diabetics. Research has identified several potential options to cure T1D, but none of them have shown any concrete outcome till today. Thus, targeted interventions are needed to reduce the risk of long-term T1D-related complications, and improve the immediate quality of life in patients. The NF- $\mathrm{B}$ molecule is a critical player in the inflammatory process; thus, strategies inhibiting NF- $\mathrm{KB}$ has potential therapeutic applications in the fight against diabetes. The result of this study showed that the sustained long-term inhibition of NF- $\mathrm{KB}$ activity could significantly diminish the degradation of cell-junctional molecules in the retinae of Akita mice.

Conclusion: Inflammatory mediators such as ICAM-1, INOS, and COX-2 expression were elevated in the retinae of Akita mice. That upregulation of inflammatory mediators was associated with the activation of NF- $\kappa \mathrm{B}$ p65. Elevated levels of inflammatory mediators are linked with the degradation of junctional molecules, thus impairing the iBRB. JSH-23 decreased NF- $\mathrm{KB}$ p65 expression levels in the retinae of Akita mice along with inflammatory mediators (ICAM1, INOS, and COX-2) expression in the retinae of 
Akita mice. JSH-23 treatment reduced NLRP3 and other pyroptosis mediators (e.g. casp1, and IL-1 $\beta$ ). Inhibition of NF- $\mathrm{B}$ p65 also upregulated the expression of $\mathrm{Cx} 43$, and occludin in the retinae of Akita mice. Inhibition of NF-kB p65 also decreases blood glucose level. That decrease could be due to an increase in insulin sensitivity in the Akita mice. 


\section{CHAPTER IV}

\section{EFFECT OF JSH-23 ON VISION IN AKITA MICE}

\section{Introduction}

T1D predisposes patients to long-term complications like kidney failure, neuropathy, and blindness. Lately, the incidence of T1D is rising, and glycemic variability is becoming more common in the younger population. Although T1D is considered an autoimmune disease, it is not clear what exactly causes the immune system to attack the beta cells in the pancreas. Up to 90 percent of T1D patients can develop retinopathy post-diagnosis; as a result, it is becoming a severe medical problem globally. DR is the leading cause of blindness in the working-age adults [250]. Unfortunately, there is no cure for DR.

HgA causes endothelial damage and capillary nonperfusion, ultimately leading to retinal hypoxia. This prompts the growth of abnormal blood vessels in the eye. Early detection and timely intervention can reduce the risk, but vision loss is irreversible. Research in the past has identified several options to treat T1D but not all benefit the majority of patients. Thus, more study needed to address the vascular pathology that occurs in the retinae.

$\mathrm{HgA}$ is known to cause sustained ROS generation, ATP depletion, ER stress, and, finally, inflammation as a complication of DR pathogenesis. This eventually leads to microvascular damage, basement membrane thickening, iBRB breakdown, capillary cell 
death, acellular capillary, neovascularization, and sometimes the detachment of the retina itself.

Inflammatory mediators such as iNOS, COX-2, and ICAM-1 are elevated in the retinae of DR, and are associated with iBRB breakdown, thus increasing the retinal vascular permeability. Increased leukostasis is related to an increase in vascular permeability too [234]. HgA induces leukocytes adhesion in rodents retinal vessels that leads to endothelial apoptosis [249-251]. NF- $\kappa B$ plays an essential role in inflammation, and leukostasis via ICAM-1.

iBRB breakdown is strongly associated with the release of proinflammatory factors such as iNOS, and elevated levels of inflammatory markers that play a definitive role in raising IOP. Additionally, IOP elevation linked with the upregulation of the hypoxia-inducible factor-1 alpha (HIP-1 $\alpha$ ), interleukins, and VEGF [257]. Inflammation contributes to BRB breakdown and thus increases the intraocular pressure (IOP).

In this study, we decided to inhibit NF- $\mathrm{BB}$, the first responder during the inflammation, employing a T1D mouse model and demonstrate that specific targeting of the NF- $\kappa \mathrm{B}$ activity could help prevent chronic inflammation that is responsible for the degenerative changes in the retinae. Our findings highlight the significance of targeted intervention in reducing the long-term diabetic complications and thus improving the underlying constant inflammatory milieu that is propagated by chronic metabolic dysfunction in the diabetic patients.

\section{$\underline{\text { Methods }}$}

Systemic Blood Pressure (BP) and Intraocular Pressure. The systemic blood pressure 
was measured with CODA noninvasive blood pressure instrument (Kent Scientific, Torrington, CT). The IOP was recorded by a Tonometer (iCare, Tonolab). Both pressure were measured before and after the JSH-23 treatment in mice [258].

Fluorescein Angiography. Mice injected by IP with $100 \mu$ l of AK-FLUOR ${ }^{\circledR}$ (NDC 17478-253-10, Akorn, Inc, Lake Forest, IL) after induction of anesthesia with $300 \mathrm{cc}$ of 2x tribromoethanol (TBE). The fundus was visualized by Micron IV microscope (Phoenix Technology Group, Pleasonton, CA). Images were analyzed via ImageJ for the presence of fluorescence outside of the retinal capillaries [259] .

In vivo Electroretinography (ERG), and Optical Coherence Tomography (OCT). Electroretinograms (ERGs) were performed on C57BL/6J and Akita age-matched mice. Briefly, mice were dark-adapted overnight, and anesthetized by IP using TBE. After pupils were dilated, full-field scotopic ERGs were recorded using the Tucker-Davis System Workstation (Tucker-Davis Technologies, Alachua, FL) for the real-time visualization of the averaged a- and b-waves. The BioSigRZ system was used for the quantification, and further analysis. OCT was performed to measure the anatomical differences in the retinal layers before and after treatment with JSH-23, employing the Image-Guided OCT2 equipment (Phoenix Technology Group, Pleasonton, CA)

Light-dark Box Chamber Test. The animals were subjected individually one by one for the light-dark box test into the light chamber with the light close. Then, PACS Shuttle Box Version 3.40 was set up with Experiment Mode as "Passive Avoidance", UCS Grid Intensity (Amperes): 0, Exploration duration: 30 
seconds, Maximal Trial Duration: 5 minutes, CS Light Intensity: 10 volts, UCS Grid Duration: 2 seconds. After 30 seconds of exploration, the light flickered on. Then the time it took the mice to transfer from the light chamber to the dark was measured [260].

Statistical Analyses. All the values are reported as mean \pm SEM. One-way ANOVA was used to analyze the difference between the groups, including a Tukey's post hoc analysis for groups' comparisons. The tests were performed with $\mathrm{p}<0.05$ and a total number of mice $(n)=5-20$ were subjected to experimentations from each group. GraphPad Prism (Ver 8, GraphPad Software) was used during the subsequent analyses.

\section{$\underline{\text { Results }}$}

Monitoring of Systemic Blood Pressure and Intraocular Pressure. We next evaluated systemic and IOP before and after JSH-23 treatment. It is known that JSH-23 increases blood pressure in hypertriglyceridemic (HTG) rats [261], therefore; we sought to determine whether JSH-23 did any alteration to the mice systemic blood pressure. To find that out, we subjected treated and untreated mice to a noninvasive tail-cuff method for recording blood pressure. None of the mice acquired showed any statistically significant change in their blood pressures. For example, the mean blood pressure in Akita mice was 117.15 mmHg, and for C57BL/6J strain it was $90.17 \mathrm{mmHg}$. JSH-23 did not have any effect on the treated Akita mice with a mean of $102.7 \mathrm{mmHg}$ (Fig. 16A). The mean IOP of the Akita mice was $25.33 \mathrm{mmHg}$ vs. $14.55 \mathrm{mmHg}$ for C57BL/6J $(\mathrm{p}<0.0001, \mathrm{n}=12$ per group). However, JSH-23 did decrease the IOP in Akita mice, $16.02 \mathrm{mmHg}(\mathrm{p}<0.0001)$ (Fig 16B). 
Figure 16. Systemic Blood Pressure and Intraocular Pressure (IOP) in Akita and C57BL/6J mice strains. A. JSH-23 does not affect the systemic blood pressure ( $\mathrm{n}=8$ per group). B. IOP was elevated in Akita mice ( $\mathrm{p}<0.0001, \mathrm{n}=12$ per group) and JSH-23 treatment decreased IOP in the Akita mice $(\mathrm{p}<0.0001)$. 
FIGURE 16

Blood Pressure Measurement for C57BL6/J and

A. Akita Mice Treated with JSH-23

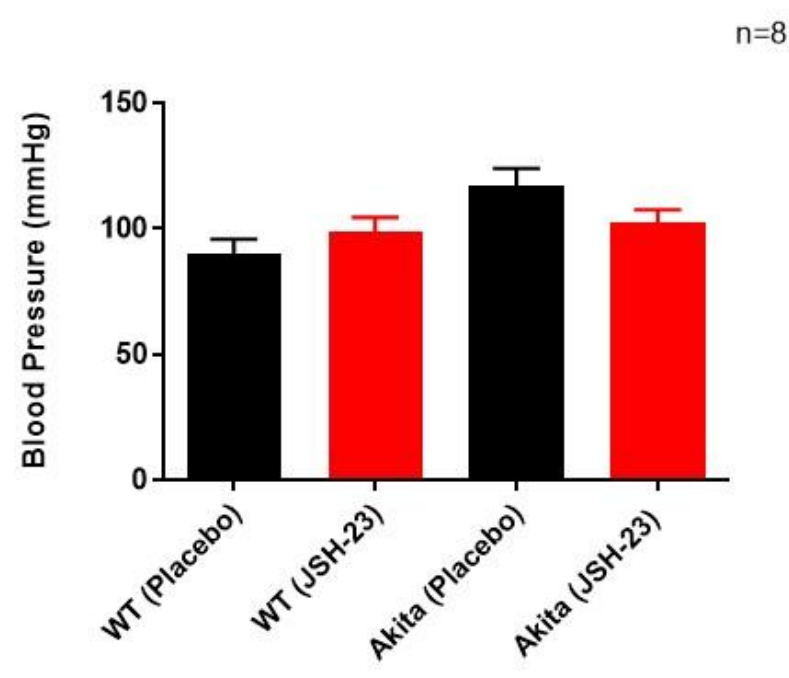

B.

Intraocular Pressure for C57BL6/J and Akita Treated wih JSH-23

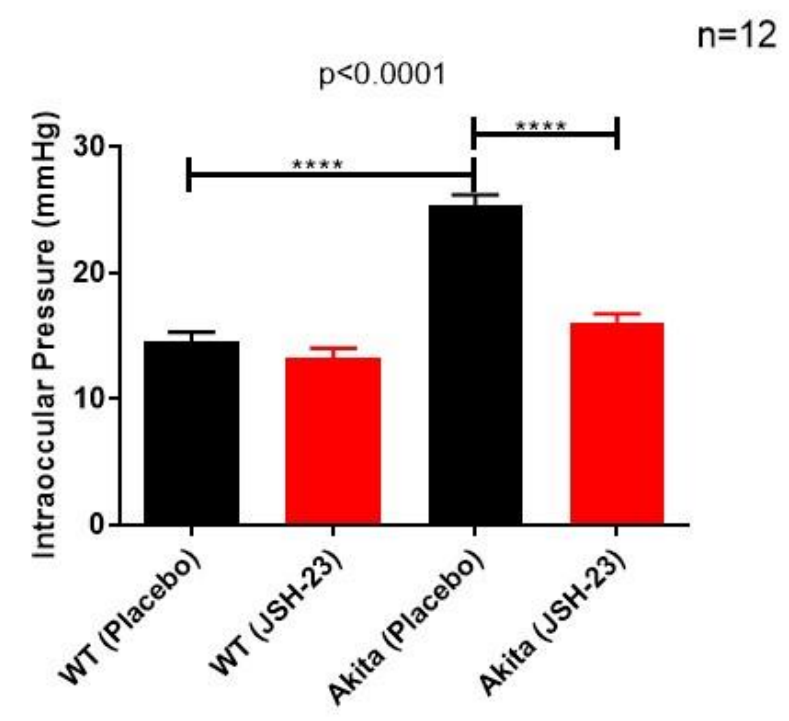


Figure 17. Fundus imaging of Akita, and C57BL/6J treated with JSH-23. The retinae of Akita mice depicted derailment in their vasculature network and the treatment with JSH-23 could repair these vasculature derailments in the affected retinae. 


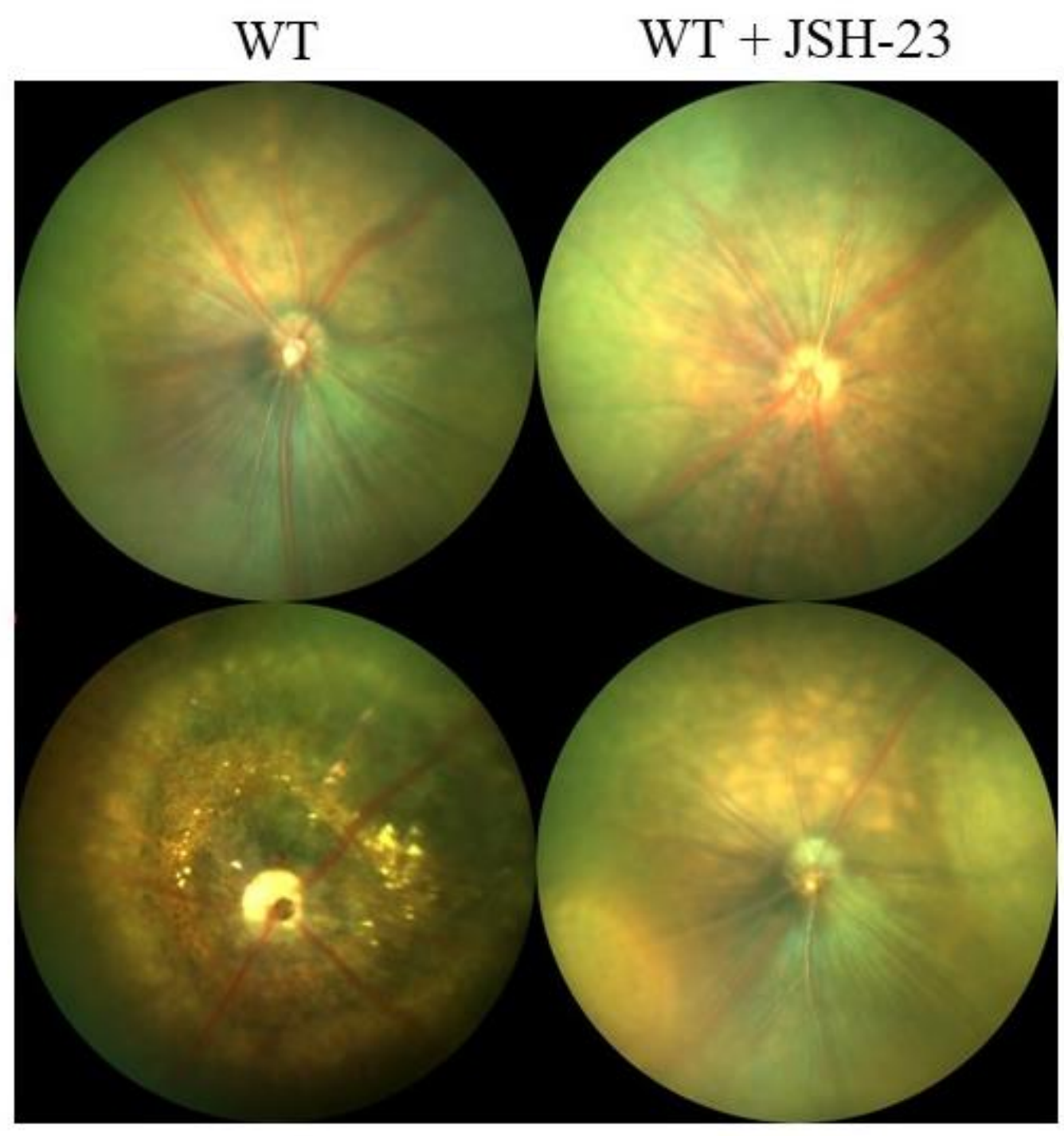

Akita

Akita + JSH-23 
Figure 18. Fluorescence Angiography in Akita, and C57BL/6J strains treated with

JSH-23. The retinae vasculature of Akita mice showed an increased vascular

permeability ( $\mathrm{p}<0.0001, \mathrm{n}=6$ per group). And treatment with JSH-23 decreased the vascular permeability in Akita mice strain $(\mathrm{p}<0.0001)$. 


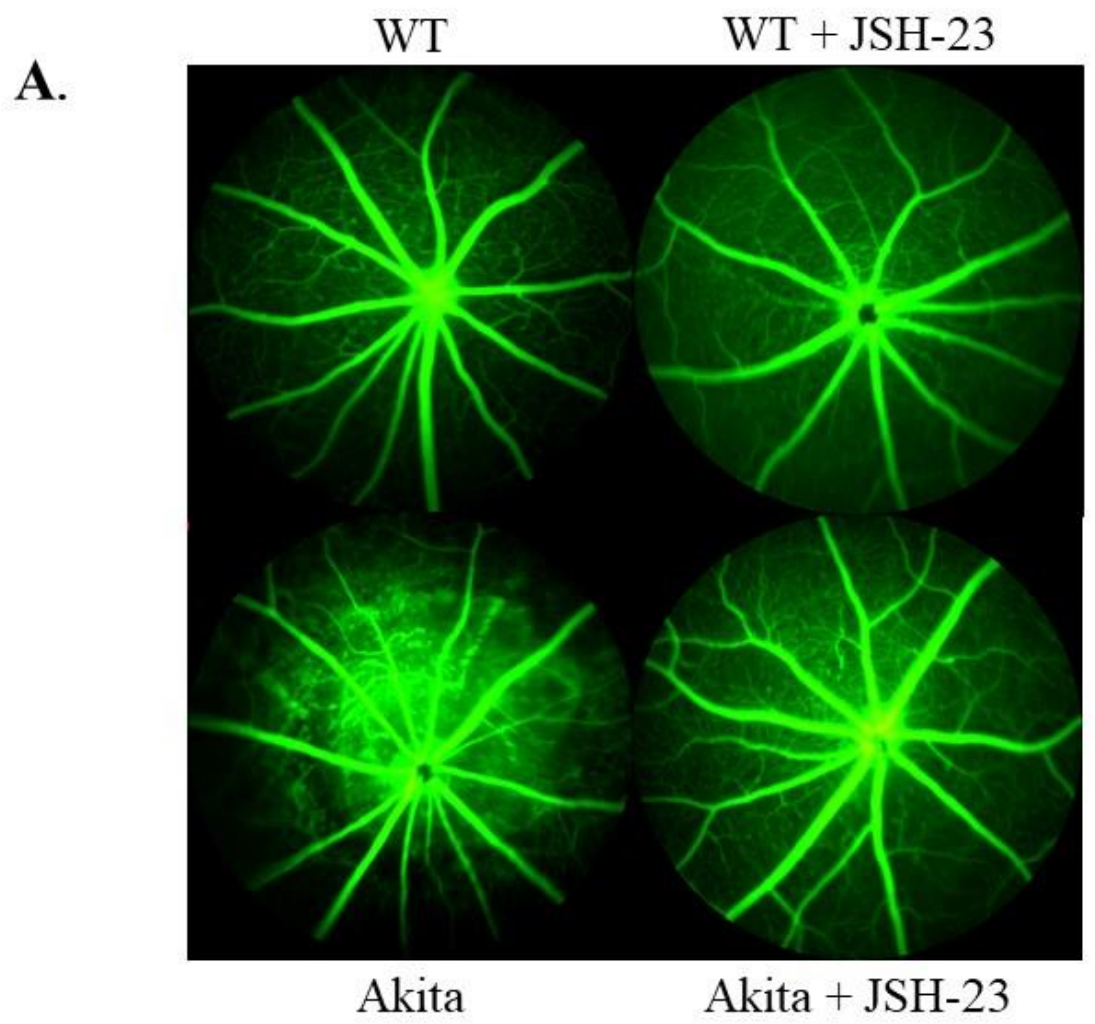

B.

Fluorescence Angiography for C57BL/6J and Akita Mice treated with JSH-23

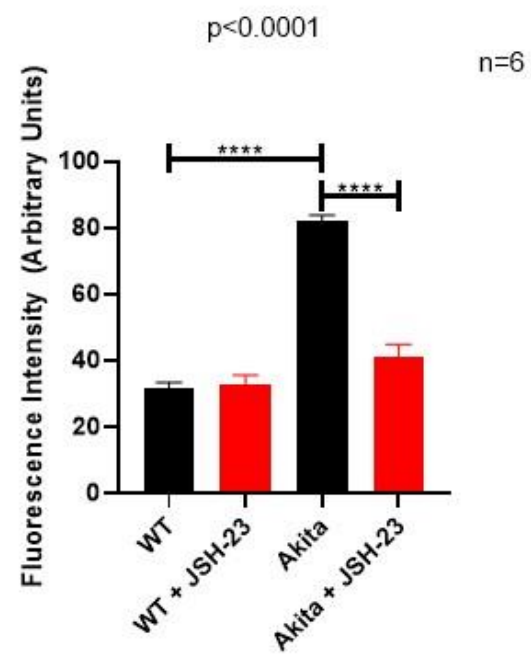


Figure 19: Optical Coherence Tomography in Akita, and C57BL/6J treated with

JSH-23. The retinal layer's thickness decreased in Akita mice $(\mathrm{p}<0.0001, \mathrm{n}=5$ per group) and the treatment with JSH-23 prevented the retinal thickening $(\mathrm{p}<0.0001)$. 


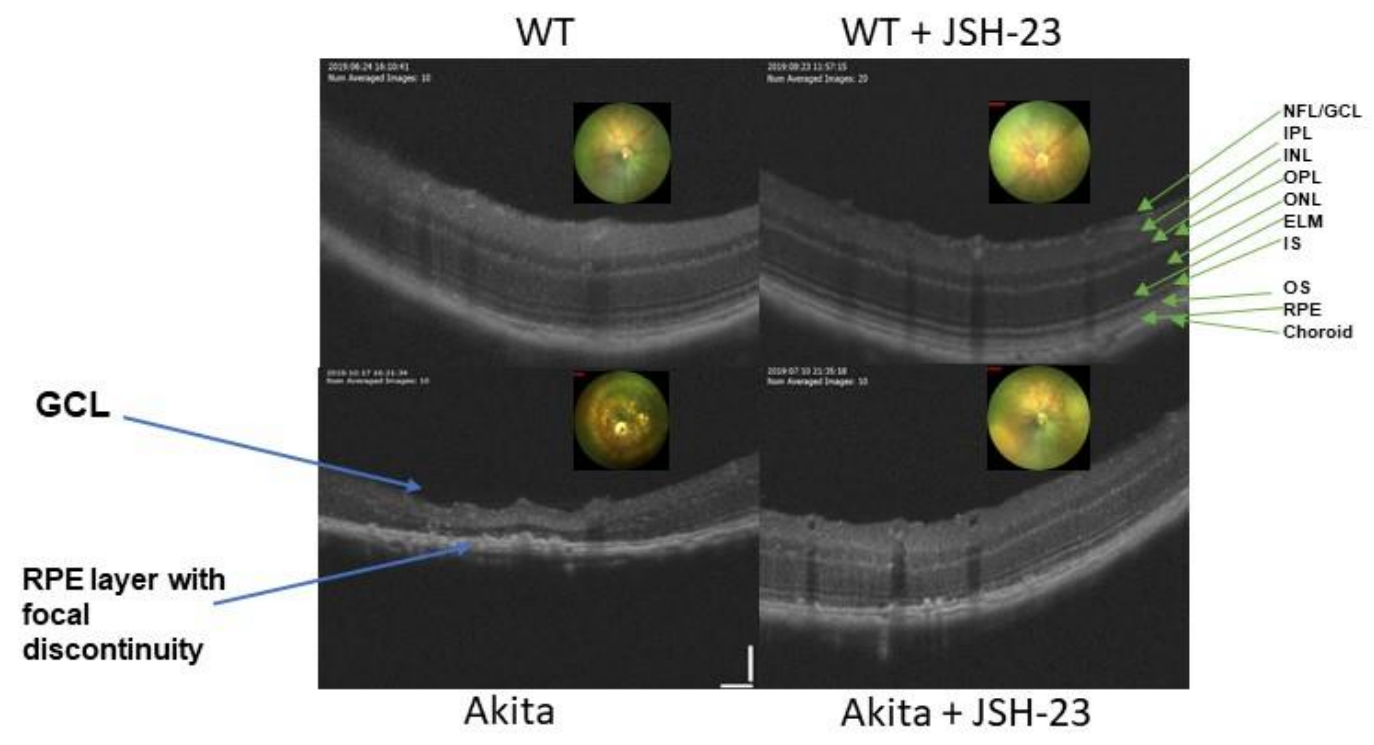

$p<0.0001$

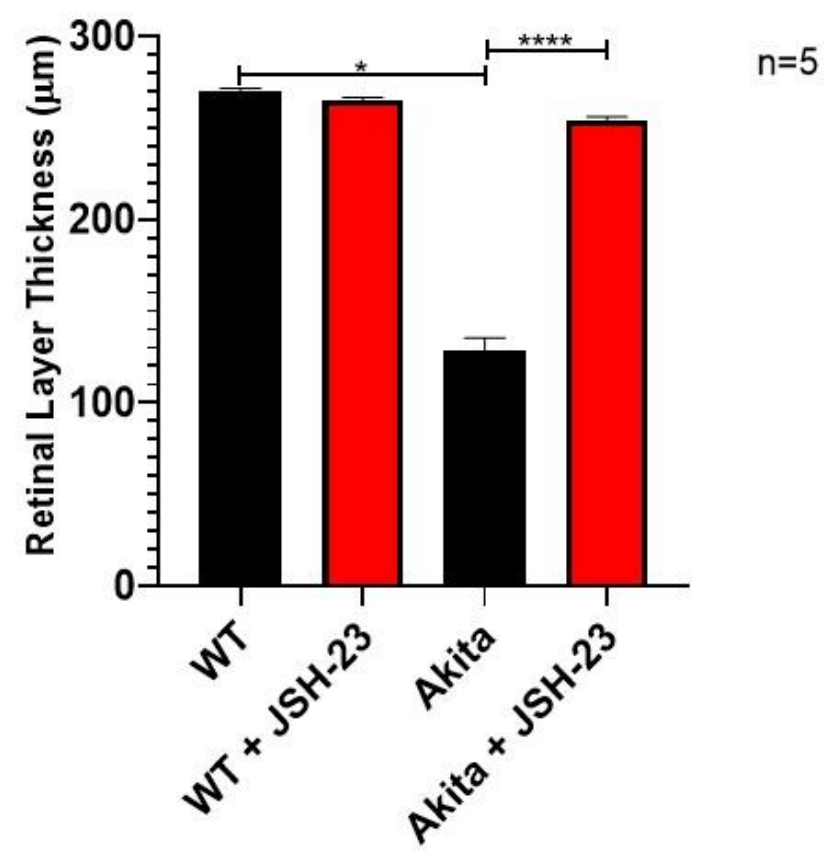


Figure 20: Electroretinogram of Akita, and C57BL/6J mice strains treated with

JSH-23. A. Electroretinograms of C57BL/6J, and Akita mice treated and non-treated with JSH23. B. Electroretinograms superimposed on top of each other on excel spreadsheet $\mathbf{C}$. Amplitude of A-wave in the retinae of Akita was found to be decreased $(\mathrm{p}<0.0001, \mathrm{n}=6$ per group) and the treatment with JSH-23 prevented this decrease in the A-wave amplitude in Akita ( $\mathrm{p}<0.0001)$. D. The amplitude of B-wave in Akita mice was also decreased ( $\mathrm{p}<0.0001, \mathrm{n}=6$ per group) aand treatment with $\mathrm{JSH}-23$ could prevent this decrease in B-wave amplitude in the Akita mice $(\mathrm{p}<0.0001)$. 
FIGURE 20

A.
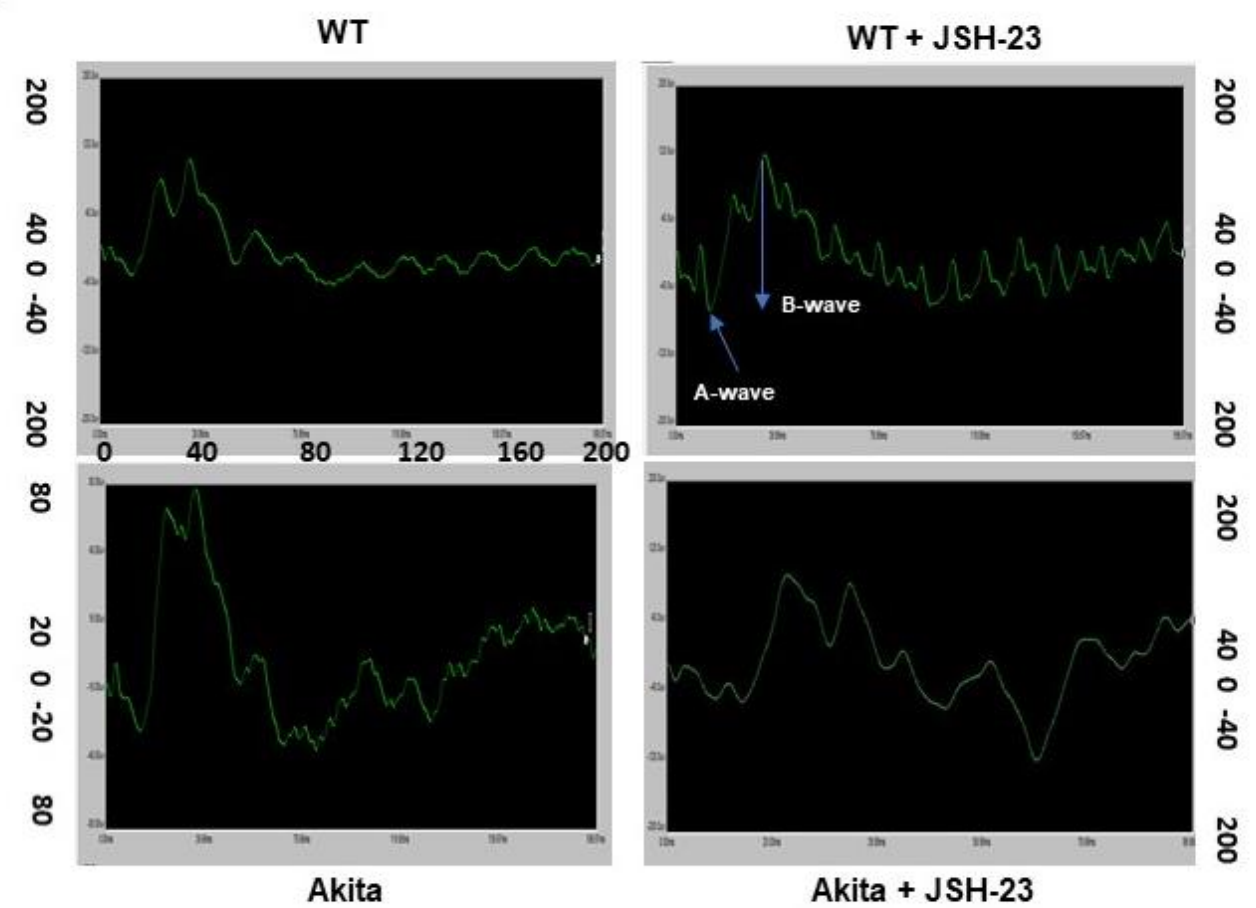

B.

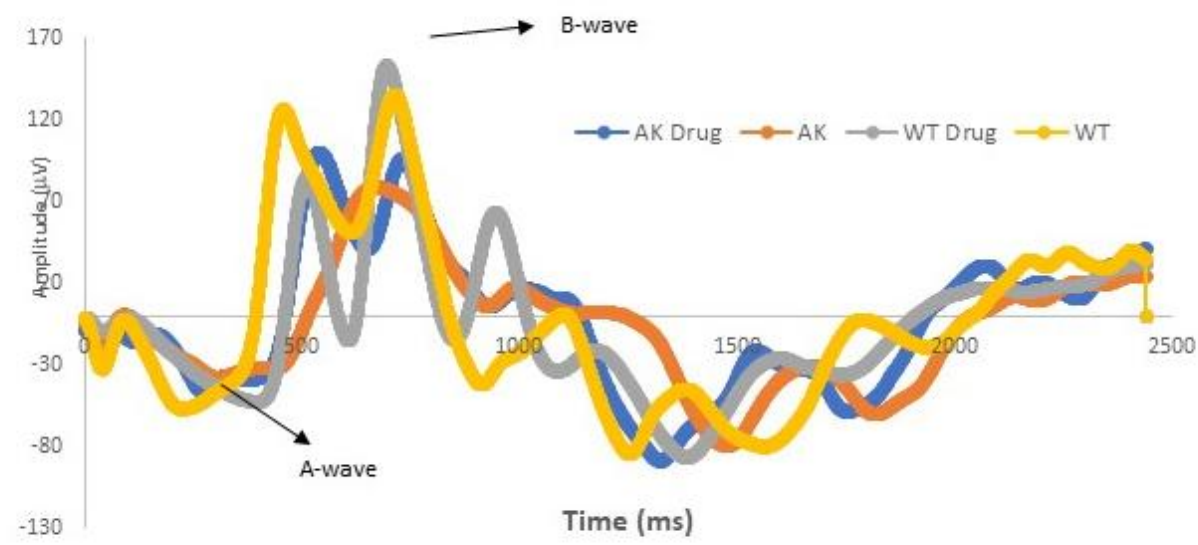




\section{A-wave}

C.

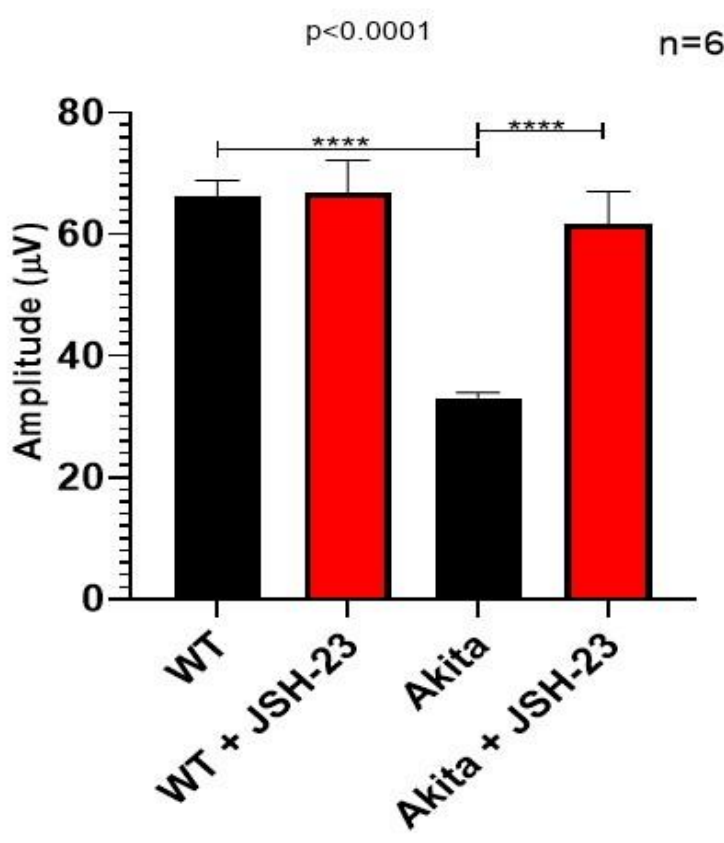

D.

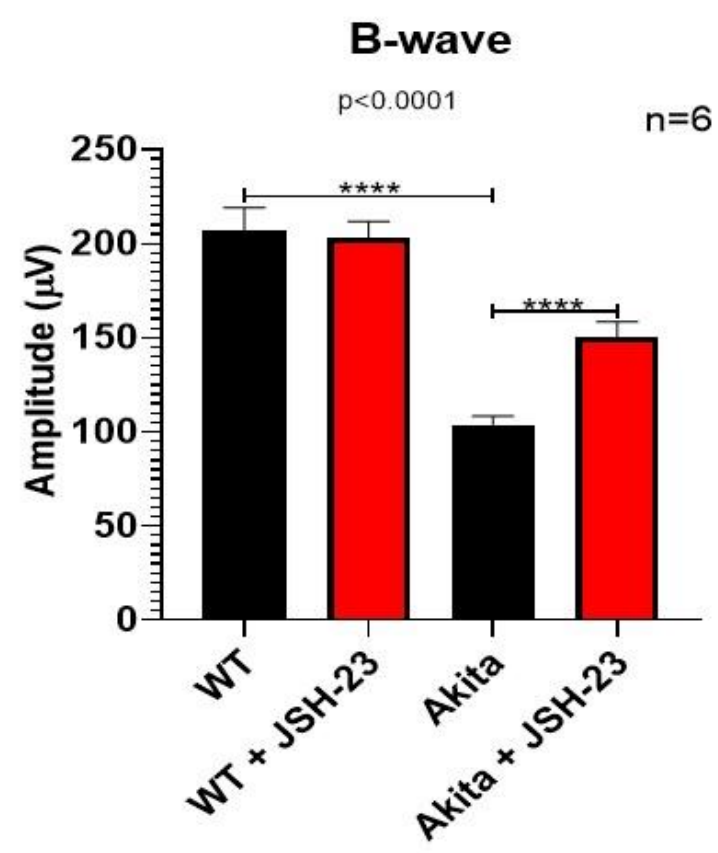


Figure 21: The light-dark chamber movement analysis of Akita and C57BL/6J mice treated with JSH-23. A. Assessment of vision-guided behavior employing a light-dark chamber, it took Akita mice significantly longer to move from the dark to the light chamber $(\mathrm{p}<0.0001, \mathrm{n}=8$ per group) relative to $\mathrm{C} 57 \mathrm{BL} / \mathrm{J} 6$. Akita treated with $\mathrm{NF}-\mathrm{kB}$ inhibitor demonstrated significantly decrease time taken by them to move from light chamber to the dark chamber ( $\mathrm{p}<0.0477, \mathrm{n}=10$ per group). 
FIGURE 21

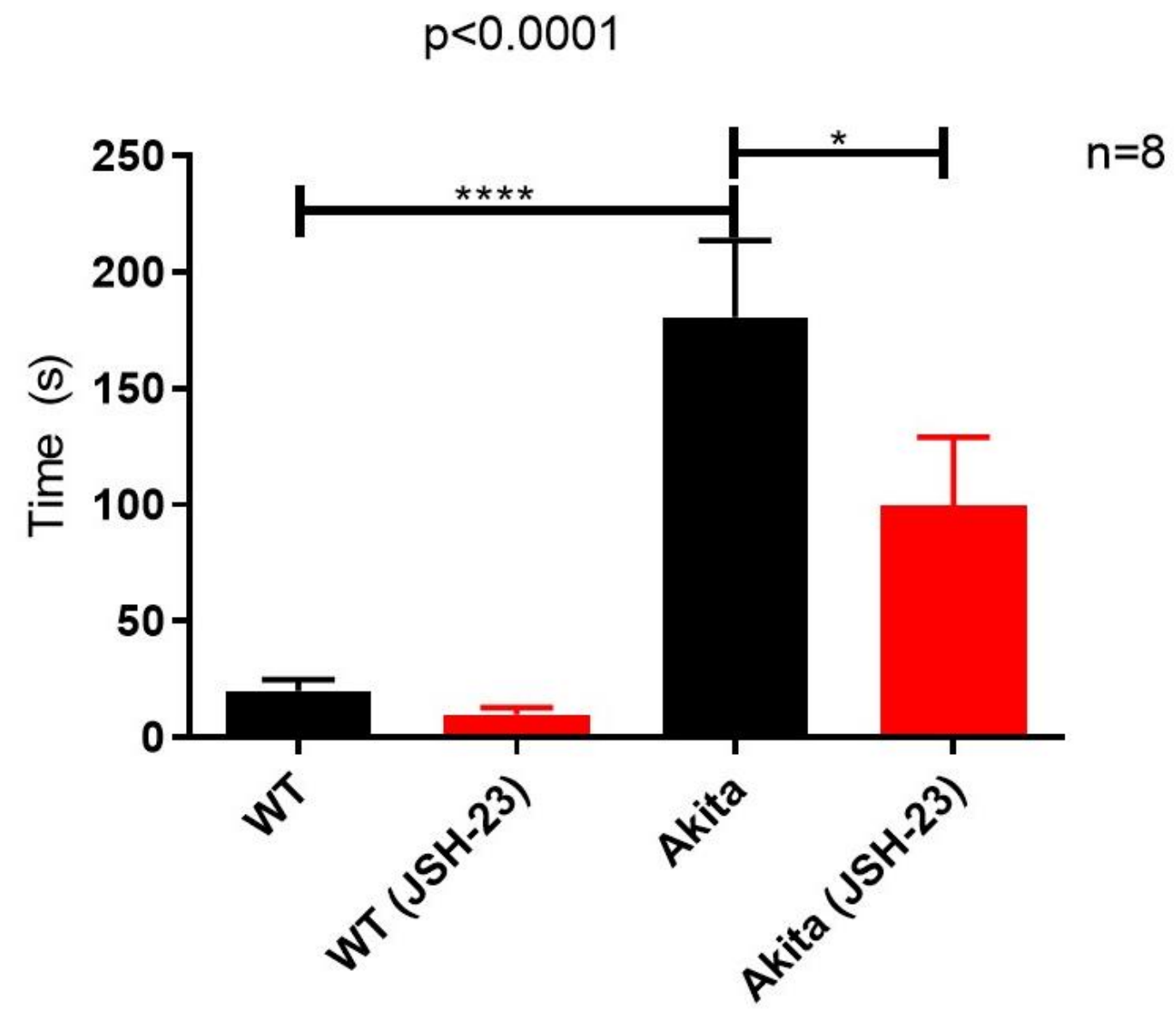


Assessment of Retinal Fundus. The retinal fundus images of Akita mice depicted the degeneration of the retinal blood vessels along with yellow spots that appeared to be cellular debris like structure and the treatment with JSH-23 seemed to prevent the degeneration of these inflamed retinal blood vessels in Akita mice post treatment (Fig. 17).

Assessment of Retinal Vasculature by Fluorescein Angiography (FA) and Fundoscopy. Retinal complications such as vascular damage is consistent with T1D. We know that HgA-led inflammation causes retinal vascular leakage, and microaneurysm formation. We studied the anti-inflammatory effects of JSH-23 on the retinal vasculature employing in vivo FA [218]. The results showed diminished retinal permeability in the JSH-23 treated mice ( $\mathrm{p}<0.0001, \mathrm{n}=6$ per group) (Fig. 18). Interestingly, a decrease in perfusion time (time is taken by fluorescein isothiocyanate; FITC dye to perfuse the retinal vasculature completely) in Akita mice of about 2 minutes was observed after an IP injection of the dye. There was also an increase in microaneurysm formation in the Akita mice as expected (Fig. 18).

In vivo Electroretinography and Optical Coherence Tomography (OCT). Functional changes in the retinae was evaluated by full-field scotopic electroretinograms (ERGs) on C57BL/6J, and Akita mice employing the BioSigRZ system. Akita mice demonstrated widened and truncated A and B waves in contrast to the sharp A, and B waves in C57BL/6J mice strain. ERGs of treated, and non-treated of Akita and C57BL/6J showed in Fig 20A and Fig.20B. Also, the A-wave was significantly reduced in Akita mice compared to WT ( $<<0.0001 \mathrm{n}=6$ per group). The average amplitude for Akita mice was $32.88 \mu \mathrm{V}$ vs. 
$66.18 \mu \mathrm{V}$ of thw $\mathrm{C} 57 \mathrm{BL} / 6 \mathrm{~J}$ mice. JSH-23 did increase the magnitude of the A-wave in Akita mice, as shown by mean value of $61.75 \mathrm{mV}(\mathrm{p}<0.0001)$ (Fig. 20C). On the other hand, the B-wave amplitude showed a significant difference between Akita, and C57BL/6J strains e.g. $103.78 \mu \mathrm{V}$ vs. $207.53 \mu \mathrm{V}$ ( $\mathrm{p}<0.0001, \mathrm{n}=6$ per group). JSH-23 treatment increased the amplitude, and mean of $150.2 \mathrm{mmHg}(\mathrm{p}<0.0001)$ (Fig. 20D). Retinal structural integrity was evaluated employing real-time, image-guided OCT in Akita strain that displayed hyporeflective retinal lucency (blue arrows) along with abnormal thickening of the membrana limitans interna, inner nervous stratum opticum, and GCL. The retinal thickness layer was reduced in the Akita strain with a mean of $128.58 \mu \mathrm{m}$, and $254.25 \mu \mathrm{M}$ C57BL/6J mice ( $<<0.0001, \mathrm{n}=5$ per group). JSH-23 prevented degradation of the retinal thickness layer in Akita mice, as reflected by the mean value of 254.25 ( $\mathrm{p}<0.0001)$ (Fig. 19C).

\section{Evaluation of Vision Guided Behavior in JSH-23 Treated Mice}

Finally, the mice were evaluated for their vision-guided behavior employing a light-dark chamber analysis. It took Akita mice significantly longer to move from the dark to the light chamber $(\mathrm{p}<0.0001, \mathrm{n}=8$ per group) relative to $\mathrm{C} 57 \mathrm{BL} / \mathrm{J} 6$. The results revealed that Akita mice treated with JSH-23 demonstrated significantly decreased time taken by them to move from the light chamber to the dark chamber post treatment $(\mathrm{p}<0.0477, \mathrm{n}=8$ per group).

\section{$\underline{\text { Discussion }}$}

We hypothesized that activation of NF- $\kappa \mathrm{B}$, and its nuclear translocation could be 
separated from other biological processes, thus giving us an opportunity to test the potential strategy of targeting specifically NF- $\mathrm{kB}$ activity for a longer duration on a sustained basis, and study its beneficial effect(s) in a well-characterized T1D mouse model. The model exhibits degenerative changes in the retinal architecture, including its blood vessels leading to the development of symptoms mimicking DR pathology [262]. By this account, treatment with inflammatory inhibitor such as JSH-23 should in principle, prevent the development of DR phenotype. To test this hypothesis, C57BL/6J and Ins ${ }^{2 \text { Akita }}$ (Akita) strain of mice were treated with JSH-23 or without for a total period of four weeks continuously. Several disease indicators, such as IOP, blood pressure, visual function, were evaluated systematically one by one. For assessing the structural, and functional aspects of the retinae methods such as FA, OCT, and ERG with or without JSH-23 treatment were employed. Our findings revealed that JSH-23 significantly decreased the retinal vasculopathy in the diabetic retinae, and retinal structure was successfully protected as evidenced by OCT, and a concurrent decrease in the vascular leakage as shown by fundus photography and FA analyses. Further, the data indicated that visual function were affected in the Akita mouse and is consistent with previously described results [218]. Similar changes in the mouse models of hypertension, and retinal neovascularization depicted severe capillary non-perfusion, vessel constriction, beading, neovascularization, fibrosis, and edema that have been reported in the literature [263]. These changes are associated with inflammation and activation of $\mathrm{NF}-\kappa \mathrm{B}$. Our findings indicate that mitigation of DR severity and its pathology are possible via timely inhibition of inflammation on a sustained basis using a selective inhibitor of inflammation.

Chronic inflammation during diabetes is associated with iBRB breakdown that leads to an increased retinal vascular permeability, and thus elevate IOP, thereby 
decreasing vascular permeability. In our study the IOP also improved, as did visual function which were revealed by the ERG analyses when inflammation was successfully arrested. Notably, the inflammatory response to injury has also been shown to be effectively attenuated by the JSH-23 treatment in another model system, as well [264]. In a nutshell, this study advances our understanding of the role of inflammation in DR, and sheds important light on one of the approaches to further reduce the inflammatory insults in a privileged organ-like the eye. However, additional studies are needed on how best to deliver the JSH-23 therapeutically in a clinical setting or its more potent versions directly into the eye in a longer-acting fashion. The results did show diminished retinal permeability in the JSH-23 treated mice, again confirming that inhibition of inflammation via NF- $\mathrm{B}$ inhibition could help protect the retinal vasculature in the diseased eyes. Therefore, the results from the present work indicate that mitigation of DR severity, in fact, is possible via inhibition of inflammation using a selective inhibitor.

Conclusions. Treatment with JSH-23 successfully decreased IOP in Akita mouse strain without change in systemic BP noticed. One of the significant findings that came out of this work is that the inhibition of inflammation perhaps helped improve the vision in Akita mice thus indicating that controlling inflammation could potentially decrease retinal inflammatory insults, and therefore improve the structural, as well as, functional attributes of the diabetic retinae in a chronic disease such as diabetes. 


\section{CHAPTER V CONCLUDING DISCUSSION}

T1D or insulin-dependent diabetes is a chronic illness that is usually diagnosed during childhood [220-222]. Clinically, diabetes management has proven challenging for a variety of reasons including physiological factors such as increased insulin sensitivity, especially in children [223]. T1D leads to the degeneration of microvascular network. DR costs the US government 1/2 a billion dollar in medical cost every year [265]. According to the National Eye Institutes (NEI), in 2010 there were approximately 7.7 million individuals living with DR, and that number is projected to double by 2050. Although more Caucasians are affected by the disease, it is more common in African-Americans and Hispanics communities [266]. DR affects both type I and type II DM patients, however DR is twice more common in T1D [225].

DR is the leading microvascular damage in Diabetes. It is defined by leakage of the blood and other body fluids into the retinae from nearby microvessels followed by abnormal angiogenesis, increase in permeability, micro aneurysms, loss of pericytes, and thickening of the basement membrane [226]. DR starts as NPDR, gradually progresses to DME and or PDR [224]. NPDR is characterized by the presence of hemorrhage, microaneurysms, abnormality in the retinal microvessels, and the cotton wool spots (fluffy white patches in the retina). On the other hand, PDR is characterized as an abnormal growth of blood vessels in the retina [267]. Untreated DR could develop into DME (fluid accumulation into the macula) or PDR (meovascularization). DME not 
PDR is more prevalent in type II diabetes [268]. Other complications of DR include retinal detachment. The development of vessels' growth into the area that drains fluid from the eye raises IOP to the point that can damage the optic nerve. If left untreated, PDR causes severe vision loss or even blindness.

Treatment of DR depends on the stage of the disease itself since the goal remains to slow or stop further disease progression. Many times, laser (photocoagulation) is used to create burns in the retina to seal the leaks in order to avoid further leakage. Injections of drugs (anti-vascular endothelial growth factor) in the eye are aimed at stopping the vascular leakage and new vessel formation. These approaches, along with tight bloodglucose control and dietary measures, may help slow down disease progression in some people [225, 226]. Current interventions do not adequately address the "retino-vascular" signature pathology that underlies the initiation, progression, and maintenance of the DR phenotype. Furthermore, they fail to restore vision in the majority of patients. The etiology of DR is not fully understood despite an abundance of literature describing the impact of the polyol flux, hexosamine pathways, AGEs, and OS. However, recently, DR is regarded as a stand-alone inflammatory disease due to the presence of various inflammatory mediators that have been repeatedly found in the vitreous and retinas of both diabetic animals and humans [227]. Inflammation is a response of the immune system after an injury had occurred or to a foreign entity. The resolution of inflammation involves cytokines, which upregulate pro-inflammatory proteins [269]. There is a consistent presence of a chronic inflammatory environment in the diabetics individuals, which could be mediated by dysregulation of the master regulator i.e. NF- $\kappa \mathrm{B}$.

Interestingly, a substantial increase in the expression of inflammatory markers/molecules is directly associated with NF- $\kappa B$ [120], a dynamic transcription factor that orchestrates complex biological processes, including the inflammatory 
response itself [228]. Owing to its upstream role in cell-signaling, NF- $\kappa \mathrm{B}$ is considered as a central component in the inflammatory response [121, 209, 229, 230]. Dysregulations of NF- $\kappa \mathrm{B}$ induces overexpression of inflammatory mediators (iNOS, ICAM-1, COX-2) in the retinas of diabetic animal models and patients [231]. It induces activation of pyroptosis process (NLRP3, IL-1 $\beta$ ) [194]. This sustained inflammation could easily lead to degradation of the iBRB in many susceptible individuals leading to a substantial decrease in the expression of junctional molecules such as Cx43, and occludin [233]. Furthermore, iBRB impairments also contributes to fluid accumulation in the retina [232].

There is an increase in inflammatory mediators (NF-kB p65, COX-2, INOS, and ICAM-1) in the retina of T1D mice. These mediators are associated with decreasing the expression of junctional molecules (occludin, and $\mathrm{Cx} 43$ ) leading to iBRB impairment, increased retinal vascular permeability, and increase in the ocular pressure. The objective of this study was to investigate whether treatment with JSH-23 mitigates this vision loss and retinal vascular permeability, thus potentially preventing the development of DR. We therefore hypothesized that pre-empting inflammation by systemically inhibiting NK- $\kappa \mathrm{B}$ activity with, JSH-23 could mitigate microvascular alterations in the diabetic retinae.

Findings from this study suggest that decreasing the inflammation alone could protect the diabetic retinae and its vascular network highlighting the fact that regulating NK-кB may have broad implications in treating chronic inflammatory diseases, including diabetes and its devastating complications. This study showed a decrease in the blood glucose of Akita mice after treatment with JSH-23. This decreased in blood glucose level could be due to increase in insulin sensitivity, byproduct of suppressing inflammation. JSH-23 decreased the inflammatory mediators (NF-кB p65, ICAM-1, iNOS, COX-2) in 
the retinae of Akita mice. It also reduced pyroptosis markers (NLRP3, Casp-1, and IL$1 \beta$ ) in the retinae of Akita mice. More importantly, JSH-23 also reduced the degradation of junctional molecules in the retina of Akita mice (occludin, and $\mathrm{Cx} 43$ ). Not only it also decreased retinal vascular permeability, IOP, in Akita mice but also increased A-wave and B-wave in Akita mice.

In this study we conclude that during T1D, vision loss is due to retinal vascular leakage by an increase in inflammatory mediators (NF-kB p65, COX-2, INOS, and ICAM-1), which leads to an increase in retinal vascular permeability, IOP, and the vision-loss. Treatment with an inflammatory inhibitor (JSH-23) most likely helped improve vision in Akita as scored via the vision-guided behavioral test. 
Figure 22. Summary. Inhibitor of inflammation (employing the JSH-23) improved visual function by decreasing the retinal vascular permeability, intraocular pressure, and retinal inflammation in the T1D Akita mouse model successfully. 
FIGURE 22

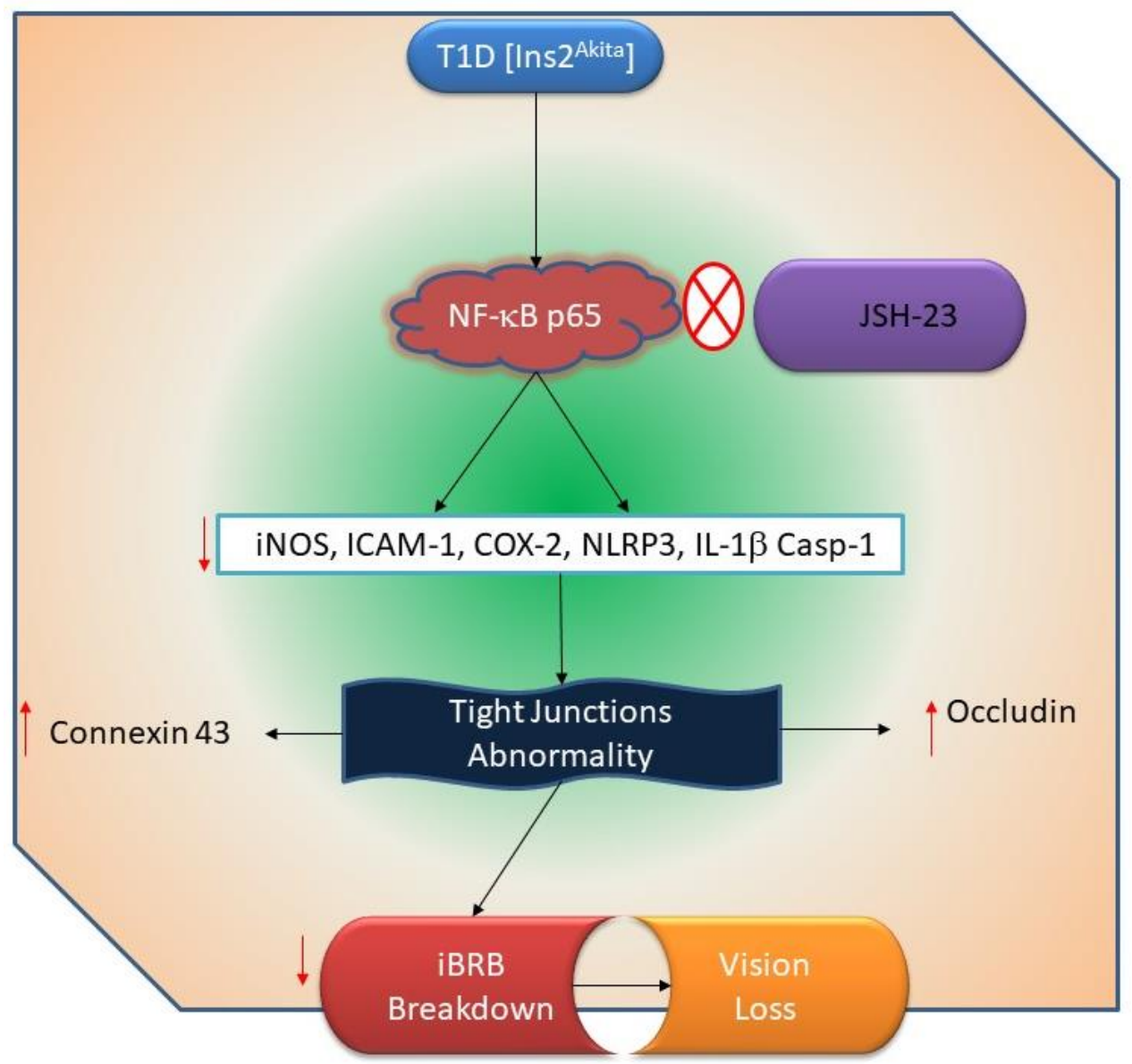




\section{$\underline{\text { Future Directions }}$}

The resident immune cells of the retina are called microglia. They help stabilized or maintain the homeostasis of the retinal environment. They reside in multiple cell layers include the IPL, OPL, and the GCL [59]. Microglia exists physiologically into two states: activated or surveying. It contains receptors for many different neuromodulators or neurotransmitters such as glutamate, dopamine, bradykinin, and norepinephrine. Microglia also secretes many substances in responses to injury, inflammation, or constitutively; NO, ROS, cytokines, and chemokines [59].

Microglial activation is due to extracellular signals, including cell death, neurodegeneration, nucleic acids, which are recognized via TLRs, which then activate the pro-inflammatory pathway of NF- $\mathrm{B}$, followed by upregulation of inflammatory mediators [270]. Microglia are enabled in DR, although the mechanism is still at large. Some studies in diabetic rats showed that $\mathrm{HgA}$ does not change the density of microglia, but more of them are activated. In human DR patients, the number of microglia significantly increases, and they migrate towards injured areas such as micro-aneurysms. Thus, it is still yet to be clear whether microglia in DR in part are protective [270]. Upon activation, microglia function in presentation of antigen, producing inflammatory markers, and phagocytoses. Active microglia could also become self-destructive via inducing the death of retinal cells [271].

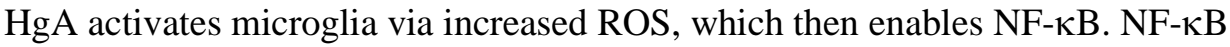
increases the expression of its pro-inflammatory genes, including IL-1 $\beta$, and ICAM-1 [270]. Hui-yang Zeng et al. reported microglia were activated around the retinal vessels in the retina of diabetic patients. Activated microglia released IL-1 $\beta$ and other 
proinflammatory mediators, which further impaired the retinal vasculature [272], mainly via activation of NF-кB [273]. In STZ induced rats, Xiaofei Chen et al. found to be a redistribution of microglia cells in the retinal layers, with the GCL and the NFL depicting an increase in the microglia populations. In contrast, the IPL has the opposite effect, which induced retinal thickening [274]. Anti-inflammatory agents, minocycline, was shown to prevent retinal neuronal cell death in STZ-induced rats by inhibiting the activation and proliferation of microglial cells [275].

Literature reported on JSH-23 effect focused on immune cells (Macrophages RAW 264.7). JSH-23 effect on microglial activation in the retinae would be critical to study the impact on JSH-23 on retinal inflammation. Interestingly, there is no study on the effect of JSH-23 directly on retinal ECs or pericytes.

They are other factors that this study did not take into account that could also affect the increase in IOP including the thickness of the cornea and drainage of aqueous humor. 


\section{REFERENCES}

1. Deretic, D., et al., rab8 in retinal photoreceptors may participate in rhodopsin transport and in rod outer segment disk morphogenesis. J Cell Sci, 1995. 108 ( Pt 1): p. 215-24.

2. Papermaster, D.S., B.G. Schneider, and J.C. Besharse, Vesicular transport of newly synthesized opsin from the Golgi apparatus toward the rod outer segment. Ultrastructural immunocytochemical and autoradiographic evidence in Xenopus retinas. Invest Ophthalmol Vis Sci, 1985. 26(10): p. 1386-404.

3. Adler, A.J. and K.J. Martin, Retinol-binding proteins in bovine interphotoreceptor matrix. Biochem Biophys Res Commun, 1982. 108(4): p. 1601-8.

4. Chader, G.J., Interphotoreceptor retinoid-binding protein (IRBP): a model protein for molecular biological and clinically relevant studies. Friedenwald lecture. Invest Ophthalmol Vis Sci, 1989. 30(1): p. 7-22.

5. Archer, S., A. Hope, and J.C. Partridge, The molecular basis for the green-blue sensitivity shift in the rod visual pigments of the European eel. Proc Biol Sci, 1995. 262(1365): p. 289-95.

6. Kuhn, H. and U. Wilden, Deactivation of photoactivated rhodopsin by rhodopsin-kinase and arrestin. J Recept Res, 1987. 7(1-4): p. 283-98.

7. Wilden, U., S.W. Hall, and H. Kuhn, Phosphodiesterase activation by photoexcited rhodopsin is quenched when rhodopsin is phosphorylated and binds the intrinsic 48-kDa protein of rod outer segments. Proc Natl Acad Sci U S A, 1986. 83(5): p. 1174-8.

8. He, W., C.W. Cowan, and T.G. Wensel, RGS9, a GTPase accelerator for phototransduction. Neuron, 1998. 20(1): p. 95-102.

9. Cooper, N., et al., The bovine rod outer segment guanylate cyclase, ROS-GC, is present in both outer segment and synaptic layers of the retina. J Mol Neurosci, 1995. 6(3): p. 211-22.

10. Liu, X., et al., Ultrastructural localization of retinal guanylate cyclase in human and monkey retinas. Exp Eye Res, 1994. 59(6): p. 761-8. 
11. Fu, Y., Phototransduction in Rods and Cones, in Webvision: The Organization of the Retina and Visual System, H. Kolb, E. Fernandez, and R. Nelson, Editors. 1995, University of Utah Health Sciences Center

12. Stryer, L., Visual excitation and recovery. J Biol Chem, 1991. 266(17): p. 10711-4.

13. Yau, K.W., Phototransduction mechanism in retinal rods and cones. The Friedenwald Lecture. Invest Ophthalmol Vis Sci, 1994. 35(1): p. 9-32.

14. Hecht, S., S. Shlaer, and M.H. Pirenne, ENERGY, QUANTA, AND VISION. J Gen Physiol, 1942. 25(6): p. 819-40.

15. Polyak, S.L., The Retina. 1948, Chicago: University of Chicago Press.

16. Henkind, P., R.I. Hansen, and J. Szalay, Ocular circulation, in Physiology of the human eye and visual system. 1979, Harper \& Row: Hagerstown. p. 67.

17. Zhang, H.R., Scanning electron-microscopic study of corrosion casts on retinal and choroidal angioarchitecture in man and animals. Progress in Retinal and Eye Research, 1994. 13(1): p. 243270.

18. Mariani, A.P., Bipolar cells in monkey retina selective for the cones likely to be blue-sensitive. Nature, 1984. 308(5955): p. 184-6.

19. Kolb, H., K.A. Linberg, and S.K. Fisher, Neurons of the human retina: a Golgi study. J Comp Neurol, 1992. 318(2): p. 147-87.

20. Boycott, B.B. and H. Wassle, Morphological Classification of Bipolar Cells of the Primate Retina. Eur J Neurosci, 1991. 3(11): p. 1069-1088.

21. Mariani, A.P., Multiaxonal horizontal cells in the retina of the tree shrew, Tupaia glis. J Comp Neurol, 1985. 233(4): p. 553-63.

22. Werblin, F.S. and J.E. Dowling, Organization of the retina of the mudpuppy, Necturus maculosus. II. Intracellular recording. J Neurophysiol, 1969. 32(3): p. 339-55.

23. Nawy, S. and C.E. Jahr, Suppression by glutamate of cGMP-activated conductance in retinal bipolar cells. Nature, 1990. 346(6281): p. 269-71. 
24. Dhingra, A., et al., The light response of ON bipolar neurons requires G[alpha]o. J Neurosci, 2000. 20(24): p. 9053-8.

25. Baylor, D.A., M.G. Fuortes, and P.M. O'Bryan, Receptive fields of cones in the retina of the turtle. J Physiol, 1971. 214(2): p. 265-94.

26. Mariani, A.P., Amacrine cells of the rhesus monkey retina. J Comp Neurol, 1990. 301(3): p. 382400.

27. Famiglietti, E.V., Jr., 'Starburst' amacrine cells and cholinergic neurons: mirror-symmetric on and off amacrine cells of rabbit retina. Brain Res, 1983. 261(1): p. 138-44.

28. Masland, R.H., Amacrine cells. Trends Neurosci, 1988. 11(9): p. 405-10.

29. Vaney, D.I., Morphological identification of serotonin-accumulating neurons in the living retina. Science, 1986. 233(4762): p. 444-6.

30. Boycott, B.B. and H. Wassle, The morphological types of ganglion cells of the domestic cat's retina. J Physiol, 1974. 240(2): p. 397-419.

31. Kolb, H., R. Nelson, and A. Mariani, Amacrine cells, bipolar cells and ganglion cells of the cat retina: a Golgi study. Vision Res, 1981. 21(7): p. 1081-1114.

32. Fukuda, Y. and J. Stone, Retinal distribution and central projections of $Y_{-}, X$-, and $W$-cells of the cat's retina. J Neurophysiol, 1974. 37(4): p. 749-72.

33. Stone, J. and Y. Fukuda, Properties of cat retinal ganglion cells: a comparison of $W$-cells with Xand Y-cells. J Neurophysiol, 1974. 37(4): p. 722-48.

34. Famiglietti, E.V., Jr. and H. Kolb, Structural basis for ON-and OFF-center responses in retinal ganglion cells. Science, 1976. 194(4261): p. 193-5.

35. Gouras, P., The function of the midget cell system in primate color vision. Vision Res, 1971. Suppl 3: p. 397-410.

36. Nelson, R., E.V. Famiglietti, Jr., and H. Kolb, Intracellular staining reveals different levels of stratification for on- and off-center ganglion cells in cat retina. J Neurophysiol, 1978. 41(2): p. 472-83. 
37. Wassle, H., T. Voigt, and B. Patel, Morphological and immunocytochemical identification of indoleamine-accumulating neurons in the cat retina. J Neurosci, 1987. 7(5): p. 1574-85.

38. Sterling, P., M.A. Freed, and R.G. Smith, Architecture of rod and cone circuits to the on-beta ganglion cell. J Neurosci, 1988. 8(2): p. 623-42.

39. Nelson, R., H. Kolb, and M.A. Freed, OFF-alpha and OFF-beta ganglion cells in cat retina. I: Intracellular electrophysiology and HRP stains. J Comp Neurol, 1993. 329(1): p. 68-84.

40. Cleland, B.G. and W.R. Levick, Properties of rarely encountered types of ganglion cells in the cat's retina and an overall classification. J Physiol, 1974. 240(2): p. 457-92.

41. Devries, S.H. and D.A. Baylor, Mosaic arrangement of ganglion cell receptive fields in rabbit retina. J Neurophysiol, 1997. 78(4): p. 2048-60.

42. Amthor, F.R., E.S. Takahashi, and C.W. Oyster, Morphologies of rabbit retinal ganglion cells with complex receptive fields. J Comp Neurol, 1989. 280(1): p. 97-121.

43. Toda, R., et al., Comparison of drug permeabilities across the blood-retinal barrier, bloodaqueous humor barrier, and blood-brain barrier. J Pharm Sci, 2011. 100(9): p. 3904-11.

44. Taylor, A.W., Ocular immunosuppressive microenvironment. Chem Immunol, 1999. 73: p. $72-89$.

45. Nussenblatt, R.B., B. Liu, and Z. Li, Age-related macular degeneration: an immunologically driven disease. Curr Opin Investig Drugs, 2009. 10(5): p. 434-42.

46. Cunha-Vaz, J., The Blood-Retinal Barrier in Retinal Disease. European Ophtalmic Review, 2009. 3(2): p. 105-108.

47. Coca-Prados, M., The blood-aqueous barrier in health and disease. J Glaucoma, 2014. 23(8 Suppl 1): p. S36-8.

48. Cunha-Vaz, J.G., M. Shakib, and N. Ashton, Studies on the permeability of the blood-retinal barrier. I. On the existence, development, and site of a blood-retinal barrier. Br J Ophthalmol, 1966. 50(8): p. 441-53.

49. Cunha-Vaz, J., The Blood-Retinal Barrier in the Management of Retinal Disease: EURETINA Award Lecture. Ophthalmologica, 2017. 237(1): p. 1-10. 
50. Strauss, O., The Retinal Pigment Epithelium in Visual Function. Physiological Reviews, 2005. 85(3): p. $845-881$.

51. Díaz-Coránguez, M., C. Ramos, and D.A. Antonetti, The inner blood-retinal barrier: Cellular basis and development. Vision Research, 2017. 139: p. 123-137.

52. Chan, Y.H., et al., Differential Regulation of LPS-Mediated VE-Cadherin Disruption in Human Endothelial Cells and the Underlying Signaling Pathways: A Mini Review. Frontiers in Cell and Developmental Biology, 2020. 7(280).

53. Danesh-Meyer, H.V., et al., Connexin43 in retinal injury and disease. Progress in Retinal and Eye Research, 2016. 51: p. 41-68.

54. Sato, T., et al., Downregulation of Connexin 43 Expression by High Glucose Reduces Gap Junction Activity in Microvascular Endothelial Cells. Diabetes, 2002. 51(5): p. 1565.

55. Mugisho, O.O., et al., Immunohistochemical Characterization of Connexin43 Expression in a Mouse Model of Diabetic Retinopathy and in Human Donor Retinas. International journal of molecular sciences, 2017. 18(12): p. 2567.

56. SÁEZ, J.C., et al., Plasma Membrane Channels Formed by Connexins: Their Regulation and Functions. Physiological Reviews, 2003. 83(4): p. 1359-1400.

57. Hossain, M.Z., P. Ao, and A.L. Boynton, Platelet-derived growth factor-induced disruption of gap junctional communication and phosphorylation of connexin43 involves protein kinase C and mitogen-activated protein kinase. Journal of Cellular Physiology, 1998. 176(2): p. 332-341.

58. Leal, E.C., et al., Calcium dobesilate inhibits the alterations in tight junction proteins and leukocyte adhesion to retinal endothelial cells induced by diabetes. Diabetes, 2010. 59(10): p. 2637-2645.

59. Vecino, E., et al., Glia-neuron interactions in the mammalian retina. Progress in Retinal and Eye Research, 2016. 51: p. 1-40.

60. Liu, Q., et al., Fenofibrate ameliorates diabetic retinopathy by modulating Nrf2 signaling and NLRP3 inflammasome activation. Molecular and Cellular Biochemistry, 2018. 445(1): p. 105-115. 
61. Coughlin, B.A., D.J. Feenstra, and S. Mohr, Müller cells and diabetic retinopathy. Vision Research, 2017. 139: p. 93-100.

62. Ghaseminejad, F., et al., The role of Müller cell glucocorticoid signaling in diabetic retinopathy. Graefe's Archive for Clinical and Experimental Ophthalmology, 2020. 258(2): p. 221-230.

63. Kaplan, H.J. and J.Y. Niederkorn, Regional immunity and immune privilege. Chem Immunol Allergy, 2007. 92: p. 11-26.

64. Forrester, J.V., et al., Dendritic cell physiology and function in the eye. Immunol Rev, 2010. 234(1): p. 282-304.

65. Jiang, L.Q., M. Jorquera, and J.W. Streilein, Subretinal space and vitreous cavity as immunologically privileged sites for retinal allografts. Invest Ophthalmol Vis Sci, 1993. 34(12): p. 3347-54.

66. Rangasamy, S., et al., Chemokine mediated monocyte trafficking into the retina: role of inflammation in alteration of the blood-retinal barrier in diabetic retinopathy. PLoS One, 2014. 9(10): p. e108508.

67. Ogura, S., et al., Sustained inflammation after pericyte depletion induces irreversible blood-retina barrier breakdown. JCI Insight, 2017. 2(3): p. e90905.

68. Haurigot, V., et al., Increased Intraocular Insulin-like Growth Factor-I Triggers Blood-Retinal Barrier Breakdown. The Journal of Biological Chemistry, 2009. 284(34): p. 22961-22969.

69. Rangasamy, S., et al., A Potential Role for Angiopoietin 2 in the Regulation of the Blood-Retinal Barrier in Diabetic Retinopathy. Investigative Ophthalmology \& Visual Science, 2011. 52(6): p. 3784-3791.

70. Joussen, A.M., et al., Nonsteroidal anti-inflammatory drugs prevent early diabetic retinopathy via TNF-alpha suppression. Faseb j, 2002. 16(3): p. 438-40.

71. Wallow, I.H. and R.L. Engerman, Permeability and patency of retinal blood vessels in experimental diabetes. Invest Ophthalmol Vis Sci, 1977. 16(5): p. 447-61. 
72. Willard, A.L. and I.M. Herman, Vascular complications and diabetes: current therapies and future challenges. J Ophthalmol, 2012. 2012: p. 209538.

73. Cogan, D.G., D. Toussaint, and T. Kuwabara, Retinal vascular patterns. IV. Diabetic retinopathy. Arch Ophthalmol, 1961. 66: p. 366-78.

74. Kuwabara, T. and D.G. Cogan, Retinal vascular patterns. VI. Mural cells of the retinal capillaries. Arch Ophthalmol, 1963. 69: p. 492-502.

75. Cordes, F.C., The diabetic: His visual prognosis: the third john e. weeks lecture. A.M.A. Archives of Ophthalmology, 1952. 48(5): p. 531-556.

76. Barber, A.J., A new view of diabetic retinopathy: a neurodegenerative disease of the eye. Prog Neuropsychopharmacol Biol Psychiatry, 2003. 27(2): p. 283-90.

77. Lieth, E., et al., Glial reactivity and impaired glutamate metabolism in short-term experimental diabetic retinopathy. Penn State Retina Research Group. Diabetes, 1998. 47(5): p. 815-20.

78. Whitmire, W., et al., Alteration of growth factors and neuronal death in diabetic retinopathy: what we have learned so far. Molecular Vision, 2011. 17: p. 300-308.

79. Preliminary report on effects of photocoagulation therapy. The Diabetic Retinopathy Study Research Group. Am J Ophthalmol, 1976. 81(4): p. 383-96.

80. Four risk factors for severe visual loss in diabetic retinopathy. The third report from the Diabetic Retinopathy Study. The Diabetic Retinopathy Study Research Group. Arch Ophthalmol, 1979. 97(4): p. 654-5.

81. Davis, M.D., Vitreous contraction in proliferative diabetic retinopathy. Arch Ophthalmol, 1965. 74(6): p. 741-51.

82. Dobree, J.H., PROLIFERATIVE DIABETIC RETINOPATHY: EVOLUTION OF THE RETINAL LESIONS. Br J Ophthalmol, 1964. 48: p. 637-49.

83. Rand, L.I., et al., Factors influencing the development of visual loss in advanced diabetic retinopathy. Diabetic Retinopathy Study (DRS) Report No. 10. Investigative Ophthalmology \& Visual Science, 1985. 26(7): p. 983-991. 
84. Fong, D.S., A. Girach, and A. Boney, Visual side effects of successful scatter laser photocoagulation surgery for proliferative diabetic retinopathy: a literature review. Retina, 2007. 27(7): p. 816-24.

85. Seah, I., et al., Use of biomaterials for sustained delivery of anti-VEGF to treat retinal diseases. Eye, 2020.

86. Dagher, Z., et al., Studies of rat and human retinas predict a role for the polyol pathway in human diabetic retinopathy. Diabetes, 2004. 53(9): p. 2404-11.

87. Gabbay, K.H., The sorbitol pathway and the complications of diabetes. N Engl J Med, 1973. 288(16): p. 831-6.

88. Barnett, P.A., et al., The effect of oxidation on sorbitol pathway kinetics. Diabetes, 1986. 35(4): p. 426-32.

89. Lassegue, B. and R.E. Clempus, Vascular $N A D(P) H$ oxidases: specific features, expression, and regulation. Am J Physiol Regul Integr Comp Physiol, 2003. 285(2): p. R277-97.

90. Szwergold, B.S., F. Kappler, and T.R. Brown, Identification of fructose 3-phosphate in the lens of diabetic rats. Science, 1990. 247(4941): p. 451-4.

91. Gonzalez, R.G., et al., 31P NMR studies of the diabetic lens. Magn Reson Med, 1988. 6(4): p. 43544.

92. Asnaghi, V., et al., A role for the polyol pathway in the early neuroretinal apoptosis and glial changes induced by diabetes in the rat. Diabetes, 2003. 52(2): p. 506-11.

93. Lorenzi, M., The polyol pathway as a mechanism for diabetic retinopathy: attractive, elusive, and resilient. Exp Diabetes Res, 2007. 2007: p. 61038.

94. Singh, R., et al., Advanced glycation end-products: a review. Diabetologia, 2001. 44(2): p. $129-46$.

95. Hammes, H.P., et al., Differential accumulation of advanced glycation end products in the course of diabetic retinopathy. Diabetologia, 1999. 42(6): p. 728-36.

96. Newton, A.C., Regulation of the $A B C$ kinases by phosphorylation: protein kinase $C$ as a paradigm. Biochem J, 2003. 370(Pt 2): p. 361-71. 
97. Xia, P., et al., Characterization of the mechanism for the chronic activation of diacylglycerolprotein kinase C pathway in diabetes and hypergalactosemia. Diabetes, 1994. 43(9): p. 1122-9.

99. Lynch, J.J., et al., Increased endothelial albumin permeability mediated by protein kinase C activation. J Clin Invest, 1990. 85(6): p. 1991-8.

100. Wolf, B.A., et al., Diacylglycerol accumulation and microvascular abnormalities induced by elevated glucose levels. J Clin Invest, 1991. 87(1): p. 31-8.

101. Geraldes, P. and G.L. King, Activation of Protein Kinase C Isoforms \& Its Impact on Diabetic Complications. Circulation research, 2010. 106(8): p. 1319-1331.

102. Beatty, S., et al., The role of oxidative stress in the pathogenesis of age-related macular degeneration. Surv Ophthalmol, 2000. 45(2): p. 115-34.

103. Dikalov, S., Cross talk between mitochondria and NADPH oxidases. Free Radic Biol Med, 2011. 51(7): p. 1289-301.

104. Cai, J., et al., Oxidative damage and protection of the RPE. Prog Retin Eye Res, 2000. 19(2): p. 205-21.

105. Chance, B., H. Sies, and A. Boveris, Hydroperoxide metabolism in mammalian organs. Physiol Rev, 1979. 59(3): p. 527-605.

106. Giacco, F. and M. Brownlee, Oxidative stress and diabetic complications. Circ Res, 2010. 107(9): p. $1058-70$.

107. Kowluru, R.A. and P. Koppolu, Diabetes-induced activation of caspase-3 in retina: effect of antioxidant therapy. Free Radic Res, 2002. 36(9): p. 993-9.

108. Kowluru, R.A., et al., Diabetes-induced activation of nuclear transcriptional factor in the retina, and its inhibition by antioxidants. Free Radic Res, 2003. 37(11): p. 1169-80.

109. Koya, D. and G.L. King, Protein kinase Cactivation and the development of diabetic complications. Diabetes, 1998. 47(6): p. 859-66.

110. Bierhaus, A., et al., Understanding RAGE, the receptor for advanced glycation end products. J Mol Med (Berl), 2005. 83(11): p. 876-86. 
111. Kowluru, R.A. and P.S. Chan, Oxidative stress and diabetic retinopathy. Exp Diabetes Res, 2007. 2007: p. 43603.

112. Zhang, W., et al., Inflammation and diabetic retinal microvascular complications. J Cardiovasc Dis Res, 2011. 2(2): p. 96-103.

113. Medawar, P.B., Immunity to homologous grafted skin; the fate of skin homografts transplanted to the brain, to subcutaneous tissue, and to the anterior chamber of the eye. Br J Exp Pathol, 1948. 29(1): p. 58-69.

114. Janeway, C.A., Jr. and R. Medzhitov, Innate immune recognition. Annu Rev Immunol, 2002. 20: p. 197-216.

115. Davis, M.M., T cell receptor gene diversity and selection. Annu Rev Biochem, 1990. 59: p. 475-96.

116. Amsen, D., C.G. Spilianakis, and R.A. Flavell, How are $T(H) 1$ and $T(H) 2$ effector cells made? Current opinion in immunology, 2009. 21(2): p. 153-160.

117. Romagnani, S., et al., Properties and origin of human Th17 cells. Mol Immunol, 2009. 47(1): p. 37.

118. Amadi-Obi, A., et al., TH17 cells contribute to uveitis and scleritis and are expanded by IL-2 and inhibited by IL-27/STAT1. Nat Med, 2007. 13(6): p. 711-8.

119. Croft, M. and C. Dubey, Accessory molecule and costimulation requirements for CD4 T cell response. Crit Rev Immunol, 1997. 17(1): p. 89-118.

120. Liu, T., et al., NF-KB signaling in inflammation. Signal Transduction And Targeted Therapy, 2017. 2: p. 17023.

121. Hoffmann, A., G. Natoli, and G. Ghosh, Transcriptional regulation via the NF-kappaB signaling module. Oncogene, 2006. 25(51): p. 6706-16.

122. Ghosh, S. and M.S. Hayden, Celebrating 25 years of NF-kappaB research. Immunol Rev, 2012. 246(1): p. 5-13.

123. Hayden, M.S. and S. Ghosh, NF-kappaB, the first quarter-century: remarkable progress and outstanding questions. Genes Dev, 2012. 26(3): p. 203-34. 
124. Vallabhapurapu, S. and M. Karin, Regulation and function of NF-kappaB transcription factors in the immune system. Annu Rev Immunol, 2009. 27: p. 693-733.

125. Sun, S.C., Non-canonical NF-kappaB signaling pathway. Cell Res, 2011. 21(1): p. 71-85.

126. Beinke, S. and S.C. Ley, Functions of NF-kappaB1 and NF-kappaB2 in immune cell biology. Biochem J, 2004. 382(Pt 2): p. 393-409.

127. Karin, M. and M. Delhase, The I kappa B kinase (IKK) and NF-kappa B: key elements of proinflammatory signalling. Semin Immunol, 2000. 12(1): p. 85-98.

128. Hayden, M.S. and S. Ghosh, Shared principles in NF-kappaB signaling. Cell, 2008. 132(3): p. 34462.

129. Sun, S.C., The noncanonical NF-kappaB pathway. Immunol Rev, 2012. 246(1): p. 125-40.

130. Sun, S.C. and Z.G. Liu, A special issue on NF-kappaB signaling and function. Cell Res, 2011. 21(1): p. 1-2.

131. Zhang, H. and S.C. Sun, NF-kappaB in inflammation and renal diseases. Cell Biosci, 2015. 5: p. 63.

132. Colleran, A., et al., Deubiquitination of NF-kappaB by Ubiquitin-Specific Protease-7 promotes transcription. Proc Natl Acad Sci U S A, 2013. 110(2): p. 618-23.

133. Zhou, A., et al., Identification of NF-KB-regulated genes induced by TNF $\alpha$ utilizing expression profiling and RNA interference. Oncogene, 2003. 22: p. 2054.

134. Cai, Y., et al., Curcumolide reduces diabetic retinal vascular leukostasis and leakage partly via inhibition of the p38MAPK/NF-kappa B signaling. Bioorg Med Chem Lett, 2017. 27(8): p. 18351839.

135. Korhonen, R., et al., Nitric oxide production and signaling in inflammation. Curr Drug Targets Inflamm Allergy, 2005. 4(4): p. 471-9.

136. Kolios, G., V. Valatas, and S.G. Ward, Nitric oxide in inflammatory bowel disease: a universal messenger in an unsolved puzzle. Immunology, 2004. 113(4): p. 427-37. 
137. Fabio, L.M.R., P.N. Frans, and F. Gert, Nitric Oxide Synthase (NOS) as Therapeutic Target for Asthma and Chronic Obstructive Pulmonary Disease. Current Drug Targets, 2006. 7(6): p. 721735.

138. Wang, Y., X. Meng, and H. Yan, Niaspan inhibits diabetic retinopathyinduced vascular inflammation by downregulating the tumor necrosis factoralpha pathway. Mol Med Rep, 2017. 15(3): p. 1263-1271.

139. Carmo, A., et al., Nitric oxide synthase activity in retinas from non-insulin-dependent diabetic Goto-Kakizaki rats: correlation with blood-retinal barrier permeability. Nitric Oxide, 2000. 4(6): p. 590-6.

140. Du, Y., et al., Diabetes-induced nitrative stress in the retina, and correction by aminoguanidine. J Neurochem, 2002. 80(5): p. 771-9.

141. Abu El-Asrar, A.M., et al., Expression of the inducible isoform of nitric oxide synthase in the retinas of human subjects with diabetes mellitus. Am J Ophthalmol, 2001. 132(4): p. 551-6.

142. Ellis, E.A., et al., Time course of NADH oxidase, inducible nitric oxide synthase and peroxynitrite in diabetic retinopathy in the BBZ/WOR rat. Nitric Oxide, 2002. 6(3): p. 295-304.

143. Xia, Y. and J.L. Zweier, Superoxide and peroxynitrite generation from inducible nitric oxide synthase in macrophages. Proc Natl Acad Sci U S A, 1997. 94(13): p. 6954-8.

144. Barber, A.J., et al., The Ins2Akita mouse as a model of early retinal complications in diabetes. Invest Ophthalmol Vis Sci, 2005. 46(6): p. 2210-8.

145. Kern, T.S. and R.L. Engerman, Pharmacological inhibition of diabetic retinopathy: aminoguanidine and aspirin. Diabetes, 2001. 50(7): p. 1636-42.

146. Hammes, H.P., et al., Aminoguanidine treatment inhibits the development of experimental diabetic retinopathy. Proc Natl Acad Sci U S A, 1991. 88(24): p. 11555-8.

147. Kern, T.S., et al., Response of capillary cell death to aminoguanidine predicts the development of retinopathy: comparison of diabetes and galactosemia. Invest Ophthalmol Vis Sci, 2000. 41(12): p. 3972-8. 
148. Vane, J.R., Y.S. Bakhle, and R.M. Botting, Cyclooxygenases 1 and 2. Annu Rev Pharmacol Toxicol, 1998. 38: p. 97-120.

149. Dubois, R.N., et al., Cyclooxygenase in biology and disease. Faseb j, 1998. 12(12): p. 1063-73.

150. Santoro, M.G., Heat shock factors and the control of the stress response. Biochem Pharmacol, 2000. 59(1): p. 55-63.

151. Levi, G., L. Minghetti, and F. Aloisi, Regulation of prostanoid synthesis in microglial cells and effects of prostaglandin E2 on microglial functions. Biochimie, 1998. 80(11): p. 899-904.

152. Santoro, M.G., Antiviral activity of cyclopentenone prostanoids. Trends Microbiol, 1997. 5(7): p. 276-81.

153. Bazan, H.E., Corneal injury alters eicosanoid formation in the rabbit anterior segment in vivo. Invest Ophthalmol Vis Sci, 1987. 28(2): p. 314-9.

154. Bazan, N.G. and G. Allan, Signal transduction and gene expression in the eye: a contemporary view of the pro-inflammatory, anti-inflammatory and modulatory roles of prostaglandins and other bioactive lipids. Surv Ophthalmol, 1997. 41 Suppl 2: p. S23-34.

155. BenEzra, D., Neovasculogenic ability of prostaglandins, growth factors, and synthetic chemoattractants. Am J Ophthalmol, 1978. 86(4): p. 455-61.

156. Goldstein, J.B., S.M. Puopolo, and A.D. Proia, The effect of prostaglandin E2 on corneal inflammation in the rat. Exp Eye Res, 1993. 57(4): p. 499-501.

157. Funk, R.H., Blood supply of the retina. Ophthalmic Res, 1997. 29(5): p. 320-5.

158. Vinores, S.A., H. Sen, and P.A. Campochiaro, An adenosine agonist and prostaglandin E1 cause breakdown of the blood-retinal barrier by opening tight junctions between vascular endothelial cells. Invest Ophthalmol Vis Sci, 1992. 33(6): p. 1870-8.

159. Shanmugam, N., I.T. Gaw Gonzalo, and R. Natarajan, Molecular mechanisms of high glucoseinduced cyclooxygenase-2 expression in monocytes. Diabetes, 2004. 53(3): p. 795-802. 
160. Amano, H., et al., Roles of a prostaglandin E-type receptor, EP3, in upregulation of matrix metalloproteinase-9 and vascular endothelial growth factor during enhancement of tumor metastasis. Cancer Sci, 2009. 100(12): p. 2318-24.

161. Carmo, A., et al., Effect of cyclosporin-A on the blood--retinal barrier permeability in streptozotocin-induced diabetes. Mediators of inflammation, 2000. 9(5): p. 243-248.

162. Madonna, R., et al., High glucose-induced hyperosmolarity contributes to COX-2 expression and angiogenesis: implications for diabetic retinopathy. Cardiovasc Diabetol, 2016. 15: p. 18.

163. Carman, C.V., et al., Transcellular diapedesis is initiated by invasive podosomes. Immunity, 2007. 26(6): p. 784-97.

164. Staunton, D.E., et al., Primary structure of ICAM-1 demonstrates interaction between members of the immunoglobulin and integrin supergene families. Cell, 1988. 52(6): p. 925-933.

165. Carnemolla, R., V.V. Shuvaev, and V.R. Muzykantov, Targeting antioxidant and antithrombotic biotherapeutics to endothelium. Seminars in thrombosis and hemostasis, 2010. 36(3): p. 332-342.

166. Joussen, A.M., et al., A central role for inflammation in the pathogenesis of diabetic retinopathy. Faseb j, 2004. 18(12): p. 1450-2.

167. Du, M., et al., Serum retinol-binding protein-induced endothelial inflammation is mediated through the activation of toll-like receptor 4. Mol Vis, 2017. 23: p. 185-197.

168. Funatsu, H., et al., Association of vitreous inflammatory factors with diabetic macular edema. Ophthalmology, 2009. 116(1): p. 73-9.

169. Mei, X.Y., et al., Scutellaria barbata attenuates diabetic retinopathy by preventing retinal inflammation and the decreased expression of tight junction protein. Int J Ophthalmol, 2017. 10(6): p. 870-877.

170. Joussen, A.M., et al., Leukocyte-mediated endothelial cell injury and death in the diabetic retina. Am J Pathol, 2001. 158(1): p. 147-52.

171. Nakajima, A., et al., Endogenous PPAR gamma mediates anti-inflammatory activity in murine ischemia-reperfusion injury. Gastroenterology, 2001. 120(2): p. 460-9. 
172. Thylefors, B., et al., Global data on blindness. Bull World Health Organ, 1995. 73(1): p. 115-21.

173. Miyamoto, K., et al., Prevention of leukostasis and vascular leakage in streptozotocin-induced diabetic retinopathy via intercellular adhesion molecule-1 inhibition. Proc Natl Acad Sci U S A, 1999. 96(19): p. 10836-41.

174. Kumar, H., T. Kawai, and S. Akira, Pathogen recognition by the innate immune system. Int Rev Immunol, 2011. 30(1): p. 16-34.

175. Guo, H., J.B. Callaway, and J.P. Ting, Inflammasomes: mechanism of action, role in disease, and therapeutics. Nat Med, 2015. 21(7): p. 677-87.

176. Man, S.M. and T.D. Kanneganti, Regulation of inflammasome activation. Immunol Rev, 2015. 265(1): p. 6-21.

177. Vanaja, S.K., V.A. Rathinam, and K.A. Fitzgerald, Mechanisms of inflammasome activation: recent advances and novel insights. Trends Cell Biol, 2015. 25(5): p. 308-15.

178. Sutterwala, F.S., S. Haasken, and S.L. Cassel, Mechanism of NLRP3 inflammasome activation. Ann N Y Acad Sci, 2014. 1319: p. 82-95.

179. Martinon, F. and J. Tschopp, NLRs join TLRs as innate sensors of pathogens. Trends in Immunology, 2005. 26(8): p. 447-454.

180. Yerramothu, P., A.K. Vijay, and M.D.P. Willcox, Inflammasomes, the eye and anti-inflammasome therapy. Eye, 2018. 32(3): p. 491-505.

181. Martinon, F., K. Burns, and J. Tschopp, The Inflammasome: A Molecular Platform Triggering Activation of Inflammatory Caspases and Processing of prolL-6. Molecular Cell, 2002. 10(2): p. 417-426.

182. Leemans, J.C., S.L. Cassel, and F.S. Sutterwala, Sensing damage by the NLRP3 inflammasome. Immunological Reviews, 2011. 243(1): p. 152-162.

183. Strowig, T., et al., Inflammasomes in health and disease. Nature, 2012. 481: p. 278.

184. de Alba, E., Structure and interdomain dynamics of apoptosis-associated speck-like protein containing a CARD (ASC). J Biol Chem, 2009. 284(47): p. 32932-41. 
185. Gross, O., et al., The inflammasome: an integrated view. Immunological Reviews, 2011. 243(1): p. $136-151$.

186. Gross, O., et al., The inflammasome: an integrated view. Immunol Rev, 2011. 243(1): p. $136-51$.

187. Chen, H., et al., Enhanced Expression of NLRP3 Inflammasome-Related Inflammation in Diabetic Retinopathy. Investigative Ophthalmology \& Visual Science, 2018. 59(2): p. 978-985.

188. Vincent, J.A. and S. Mohr, Inhibition of Caspase-1/Interleukin-16 Signaling Prevents Degeneration of Retinal Capillaries in Diabetes and Galactosemia. Diabetes, 2007. 56(1): p. $224-$ 230.

189. Mendiola, A.S. and A.E. Cardona, The IL-16 phenomena in neuroinflammatory diseases. Journal of Neural Transmission, 2018. 125(5): p. 781-795.

190. Kowluru, R.A. and S. Odenbach, Role of Interleukin-16 in the Development of Retinopathy in Rats: Effect of Antioxidants. Investigative Ophthalmology \& Visual Science, 2004. 45(11): p. 41614166.

191. Vallejo, S., et al., The interleukin-1 receptor antagonist anakinra improves endothelial dysfunction in streptozotocin-induced diabetic rats. Cardiovascular Diabetology, 2014. 13(1): p. 158.

192. Yego, E.C.K., et al., Differential Regulation of High Glucose-Induced Glyceraldehyde-3-Phosphate Dehydrogenase Nuclear Accumulation in Müller Cells by IL-16 and IL-6. Investigative Ophthalmology \& Visual Science, 2009. 50(4): p. 1920-1928.

193. Mohr, S., et al., Caspase Activation in Retinas of Diabetic and Galactosemic Mice and Diabetic Patients. Diabetes, 2002. 51(4): p. 1172-1179.

194. Feenstra, D.J., E.C. Yego, and S. Mohr, Modes of Retinal Cell Death in Diabetic Retinopathy. Journal of clinical \& experimental ophthalmology, 2013. 4(5): p. 298-298.

195. Roy, S., D. Kim, and R. Lim, Cell-cell communication in diabetic retinopathy. Vision Res, 2017. 
196. Trudeau, K., T. Muto, and S. Roy, Downregulation of Mitochondrial Connexin 43 by High Glucose Triggers Mitochondrial Shape Change and Cytochrome c Release in Retinal Endothelial Cells. Investigative Ophthalmology \& Visual Science, 2012. 53(10): p. 6675-6681.

197. Tien, T., et al., Downregulation of Connexin 43 promotes vascular cell loss and excess permeability associated with the development of vascular lesions in the diabetic retina. Molecular vision, 2014. 20: p. 732-741.

198. Zhao, Y., et al., The TLR3 ligand polyl: C downregulates connexin 43 expression and function in astrocytes by a mechanism involving the NF-kappaB and PI3 kinase pathways. Glia, 2006. 54(8): p. $775-785$.

199. Nagasawa, K., et al., Possible involvement of gap junctions in the barrier function of tight junctions of brain and lung endothelial cells. Journal of Cellular Physiology, 2006. 208(1): p. 123132.

200. Tien, T., et al., Effects of high glucose-induced $\mathrm{CX}_{x} 43$ downregulation on occludin and $\mathrm{ZO}-1$ expression and tight junction barrier function in retinal endothelial cells. Investigative ophthalmology \& visual science, 2013. 54(10): p. 6518-6525.

201. Leal, E.C., et al., Inducible Nitric Oxide Synthase Isoform Is a Key Mediator of Leukostasis and Blood-Retinal Barrier Breakdown in Diabetic Retinopathy. Investigative Ophthalmology \& Visual Science, 2007. 48(11): p. 5257-5265.

202. Tang, Y., et al., Epithelial NF-kappaB enhances transmucosal fluid movement by altering tight junction protein composition after T cell activation. The American journal of pathology, 2010. 176(1): p. 158-167.

203. Spencer, B.G., et al., Pericytes, inflammation, and diabetic retinopathy. Inflammopharmacology, 2019.

204. Shen, W., et al., Conditional Müller Cell Ablation Causes Independent Neuronal and Vascular Pathologies in a Novel Transgenic Model. The Journal of Neuroscience, 2012. 32(45): p. 1571515727. 
205. Ly, A., et al., Early Inner Retinal Astrocyte Dysfunction during Diabetes and Development of Hypoxia, Retinal Stress, and Neuronal Functional Loss. Investigative Ophthalmology \& Visual Science, 2011. 52(13): p. 9316-9326.

206. Sapra, D.K.S.A., Physiology, Aqueous Humor Circulation. StatPearls Publishing, 2020.

207. Matsuoka, M., et al., Intraocular pressure in Japanese diabetic patients. Clinical ophthalmology (Auckland, N.Z.), 2012. 6: p. 1005-1009.

208. Xu, L., et al., Ocular Hypertension and Diabetes Mellitus in the Beijing Eye Study. Journal of Glaucoma, 2009. 18(1): p. 21-25.

209. Kumar, A., G. Negi, and S.S. Sharma, JSH-23 targets nuclear factor-kappa B and reverses various deficits in experimental diabetic neuropathy: effect on neuroinflammation and antioxidant defence. Diabetes Obes Metab, 2011. 13(8): p. 750-8.

210. Kumar, A., G. Negi, and S.S. Sharma, JSH-23 targets nuclear factor-kappa B and reverses various deficits in experimental diabetic neuropathy: effect on neuroinflammation and antioxidant defence. Diabetes, Obesity and Metabolism, 2011. 13(8): p. 750-758.

211. Wang, Q., et al., JSH-23 prevents depressive-like behaviors in mice subjected to chronic mild stress: Effects on inflammation and antioxidant defense in the hippocampus. Pharmacology Biochemistry and Behavior, 2018. 169: p. 59-66.

212. Zhu, S., et al., Thyroxine Affects Lipopolysaccharide-Induced Macrophage Differentiation and Myocardial Cell Apoptosis via the NF-kappaB p65 Pathway Both In Vitro and In Vivo. Mediators Inflamm, 2019. 2019: p. 2098972.

213. Ferko, M.-A. and I. Catelas, Effects of metal ions on caspase-1 activation and interleukin-16 release in murine bone marrow-derived macrophages. PLOS ONE, 2018. 13(8): p. e0199936.

214. Ozkok, A., et al., NF-kappaB transcriptional inhibition ameliorates cisplatin-induced acute kidney injury (AKI). Toxicol Lett, 2016. 240(1): p. 105-13.

215. Cho, H. and L. Sobrin, Genetics of diabetic retinopathy. Curr Diab Rep, 2014. 14(8): p. 515. 
216. Wang, J., et al., A mutation in the insulin 2 gene induces diabetes with severe pancreatic beta-cell dysfunction in the Mody mouse. J Clin Invest, 1999. 103(1): p. 27-37.

217. Izumi, T., et al., Dominant negative pathogenesis by mutant proinsulin in the Akita diabetic mouse. Diabetes, 2003. 52(2): p. 409-16.

218. Han, Z., et al., Retinal angiogenesis in the Ins2(Akita) mouse model of diabetic retinopathy. Invest Ophthalmol Vis Sci, 2013. 54(1): p. 574-84.

219. Robinson, R., et al., Update on animal models of diabetic retinopathy: from molecular approaches to mice and higher mammals. Dis Model Mech, 2012. 5(4): p. 444-56.

220. Pettitt, D.J., et al., Prevalence of diabetes in U.S. youth in 2009: the SEARCH for diabetes in youth study. Diabetes Care, 2014. 37(2): p. 402-8.

221. Dabelea, D., et al., Incidence of diabetes in youth in the United States. Jama, 2007. 297(24): p. 2716-24.

222. Vehik, K., et al., Increasing incidence of type 1 diabetes in 0- to 17-year-old Colorado youth. Diabetes Care, 2007. 30(3): p. 503-9.

223. Streisand, R. and M. Monaghan, Young children with type 1 diabetes: challenges, research, and future directions. Curr Diab Rep, 2014. 14(9): p. 520.

224. Homme, R.P., et al., Remodeling of Retinal Architecture in Diabetic Retinopathy: Disruption of Ocular Physiology and Visual Functions by Inflammatory Gene Products and Pyroptosis. Front Physiol, 2018. 9: p. 1268.

225. Vaziri, K., et al., New Therapeutic Approaches in Diabetic Retinopathy. Rev Diabet Stud, 2015. 12(1-2): p. 196-210.

226. Safi, S.Z., et al., Molecular mechanisms of diabetic retinopathy, general preventive strategies, and novel therapeutic targets. Biomed Res Int, 2014. 2014: p. 801269.

227. Miyahara, S., et al., Alteration of leukocyte-endothelial cell interaction during aging in retinal microcirculation of hypertensive rats. Jpn J Ophthalmol, 2006. 50(6): p. 509-514.

228. Baltimore, D., Discovering NF-kappaB. Cold Spring Harb Perspect Biol, 2009. 1(1): p. a000026. 
229. Shin, H.M., et al., Inhibitory action of novel aromatic diamine compound on lipopolysaccharideinduced nuclear translocation of NF-kappaB without affecting IkappaB degradation. FEBS Lett, 2004. 571(1-3): p. 50-4.

230. Shirato, K., et al., Anti-Inflammatory Effect of ETAS(R)50 by Inhibiting Nuclear Factor-kappaB p65 Nuclear Import in Ultraviolet-B-Irradiated Normal Human Dermal Fibroblasts. Evid Based Complement Alternat Med, 2018. 2018: p. 5072986.

231. Tang, J. and T.S. Kern, Inflammation in Diabetic Retinopathy. Progress in retinal and eye research, 2011. 30(5): p. 343-358.

232. Cunha-Vaz, J., R. Bernardes, and C. Lobo, Blood-retinal barrier. Eur J Ophthalmol, 2011. 21 Suppl 6: p. S3-9.

233. Rangasamy, S., P.G. McGuire, and A. Das, Diabetic retinopathy and inflammation: novel therapeutic targets. Middle East African journal of ophthalmology, 2012. 19(1): p. 52-59.

234. Funatsu, H., et al., Vitreous levels of interleukin-6 and vascular endothelial growth factor are related to diabetic macular edema. Ophthalmology, 2003. 110(9): p. 1690-6.

235. Grasemann, C., et al., Parental diabetes: the Akita mouse as a model of the effects of maternal and paternal hyperglycemia in wildtype offspring. PLoS One, 2012. 7(11): p. e50210.

236. Sun, J., et al., Cooperation of Rel family members in regulating A61-40-mediated proinflammatory cytokine secretion by retinal pigment epithelial cells. Cell Death \& Disease, 2017. 8(10): p. e3115-e3115.

237. Cummings, K.L. and R.L. Tarleton, Inducible nitric oxide synthase is not essential for control of Trypanosoma cruzi infection in mice. Infection and immunity, 2004. 72(7): p. 4081-4089.

238. He, T., et al., Interaction between iNOS and COX-2 in Hypoxia-Induced Retinal Neovascularization in Mice. Archives of Medical Research, 2007. 38(8): p. 807-815.

239. Kanczkowski, W., et al., Role of the Endothelial-Derived Endogenous Anti-Inflammatory Factor Del-1 in Inflammation-Mediated Adrenal Gland Dysfunction. Endocrinology, 2013. 154(3): p. 1181-1189. 
240. Kihara, A.H., et al., Prolonged dark adaptation changes connexin expression in the mouse retina. Journal of Neuroscience Research, 2006. 83(7): p. 1331-1341.

241. Luo, Y., et al., Differential Expression of Claudins in Retinas during Normal Development and the Angiogenesis of Oxygen-Induced Retinopathy. Investigative Ophthalmology \& Visual Science, 2011. 52(10): p. 7556-7564.

242. Chaurasia, S.S., et al., The NLRP3 Inflammasome May Contribute to Pathologic Neovascularization in the Advanced Stages of Diabetic Retinopathy. Scientific Reports, 2018. 8(1): p. 2847.

243. Yuan, Q., et al., Proinsulin atypical maturation and disposal induces extensive defects in mouse Ins2+/Akita beta-cells. PLoS One, 2012. 7(4): p. e35098.

244. Chandel, N.S., et al., Role of oxidants in NF-kappa B activation and TNF-alpha gene transcription induced by hypoxia and endotoxin. J Immunol, 2000. 165(2): p. 1013-21.

245. Fitzgerald, D.C., et al., Tumour necrosis factor-alpha (TNF-alpha) increases nuclear factor kappaB (NFkappaB) activity in and interleukin-8 (IL-8) release from bovine mammary epithelial cells. Vet Immunol Immunopathol, 2007. 116(1-2): p. 59-68.

246. Renard, P., et al., Effects of antioxidant enzyme modulations on interleukin-1-induced nuclear factor kappa B activation. Biochem Pharmacol, 1997. 53(2): p. 149-60.

247. Qin, H., et al., LPS induces CD40 gene expression through the activation of NF-kappaB and STAT1alpha in macrophages and microglia. Blood, 2005. 106(9): p. 3114-22.

248. Basu, S., et al., The DNA-dependent protein kinase participates in the activation of NF kappa B following DNA damage. Biochem Biophys Res Commun, 1998. 247(1): p. 79-83.

249. Veenstra, A.A., J. Tang, and T.S. Kern, Antagonism of CD11b with neutrophil inhibitory factor (NIF) inhibits vascular lesions in diabetic retinopathy. PLoS One, 2013. 8(10): p. e78405.

250. Tian, P., et al., Leukocytes from diabetic patients kill retinal endothelial cells: Effects of berberine. Molecular Vision, 2013. 19: p. 2092-2105. 
251. Joussen, A.M., et al., Suppression of Fas-FasL-induced endothelial cell apoptosis prevents diabetic blood-retinal barrier breakdown in a model of streptozotocin-induced diabetes. Faseb j, 2003. 17(1): p. 76-8.

252. Tien, T., et al., Effects of high glucose-induced $\mathrm{CX}_{X} 43$ downregulation on occludin and $\mathrm{ZO}-1$ expression and tight junction barrier function in retinal endothelial cells. Invest Ophthalmol Vis Sci, 2013. 54(10): p. 6518-25.

253. Wu, X., et al., Hypoxia induces connexin 43 dysregulation by modulating matrix metalloproteinases via MAPK signaling. Mol Cell Biochem, 2013. 384(1-2): p. 155-62.

254. Wong, H.L., et al., MT1-MMP sheds LYVE-1 on lymphatic endothelial cells and suppresses VEGF-C production to inhibit lymphangiogenesis. Nat Commun, 2016. 7: p. 10824.

255. Gao, J., et al., Evidence for the activation of pyroptotic and apoptotic pathways in RPE cells associated with NLRP3 inflammasome in the rodent eye. J Neuroinflammation, 2018. 15(1): p. 15.

256. Devi, T.S., et al., TXNIP links innate host defense mechanisms to oxidative stress and inflammation in retinal Muller glia under chronic hyperglycemia: implications for diabetic retinopathy. Exp Diabetes Res, 2012. 2012: p. 438238.

257. Vohra, R., J.C. Tsai, and M. Kolko, The role of inflammation in the pathogenesis of glaucoma. Surv Ophthalmol, 2013. 58(4): p. 311-20.

258. Gericke, A., et al., Elevated Intraocular Pressure Causes Abnormal Reactivity of Mouse Retinal Arterioles. Oxid Med Cell Longev, 2019. 2019: p. 9736047.

259. Asokan, P., et al., A Naturally Fluorescent Mgp Transgenic Mouse for Angiogenesis and Glaucoma Longitudinal Studies. Invest Ophthalmol Vis Sci, 2018. 59(2): p. 746-756.

260. George, A.K., et al., Effect of MMP-9 gene knockout on retinal vascular form and function. Physiological Genomics, 2019. 51(12): p. 613-622.

261. Vrankova, S., et al., The Regulatory Role of Nuclear Factor Kappa B in the Heart of Hereditary Hypertriglyceridemic Rat. Oxid Med Cell Longev, 2016. 2016: p. 9814038. 
262. Vlahopoulos, S., et al., Nuclear factor-kappaB-dependent induction of interleukin-8 gene expression by tumor necrosis factor alpha: evidence for an antioxidant sensitive activating pathway distinct from nuclear translocation. Blood, 1999. 94(6): p. 1878-89.

263. Rakoczy, E.P., et al., Characterization of a mouse model of hyperglycemia and retinal neovascularization. Am J Pathol, 2010. 177(5): p. 2659-70.

264. He, Q., et al., Inflammatory signaling regulates hematopoietic stem and progenitor cell emergence in vertebrates. Blood, 2015. 125(7): p. 1098-106.

265. Zhang, X., et al., Prevalence of diabetic retinopathy in the United States, 2005-2008. JAMA, 2010. 304(6): p. 649-56.

266. Tan, G.S., et al., Ethnic Differences in the Prevalence and Risk Factors of Diabetic Retinopathy: The Singapore Epidemiology of Eye Diseases Study. Ophthalmology, 2017.

267. Mitchell, S.L., et al., Mitochondrial Haplogroups Modify the Effect of Diabetes Duration and HbA1c on Proliferative Diabetic Retinopathy Risk in Patients With Type 2 Diabetes. Invest Ophthalmol Vis Sci, 2017. 58(14): p. 6481-6488.

268. Lee, R., T.Y. Wong, and C. Sabanayagam, Epidemiology of diabetic retinopathy, diabetic macular edema and related vision loss. Eye and vision (London, England), 2015. 2: p. 17-17.

269. Rubsam, A., S. Parikh, and P.E. Fort, Role of Inflammation in Diabetic Retinopathy. Int J Mol Sci, 2018. 19(4).

270. Altmann, C. and M.H.H. Schmidt, The Role of Microglia in Diabetic Retinopathy: Inflammation, Microvasculature Defects and Neurodegeneration. International journal of molecular sciences, 2018. 19(1): p. 110.

271. Okunuki, Y., et al., Microglia inhibit photoreceptor cell death and regulate immune cell infiltration in response to retinal detachment. Proceedings of the National Academy of Sciences of the United States of America, 2018. 115(27): p. E6264-E6273.

272. Zeng, H.-y., W.R. Green, and M.O.M. Tso, Microglial Activation in Human Diabetic Retinopathy. Archives of Ophthalmology, 2008. 126(2): p. 227-232. 
273. Mendonca, H.R., et al., Neuroinflammation and oxidative stress act in concert to promote neurodegeneration in the diabetic retina and optic nerve: galectin-3 participation. Neural regeneration research, 2020. 15(4): p. 625-635.

274. Chen, X., et al., Early spatiotemporal characterization of microglial activation in the retinas of rats with streptozotocin-induced diabetes. Graefe's Archive for Clinical and Experimental Ophthalmology, 2015. 253(4): p. 519-525.

275. Krady, J.K., et al., Minocycline Reduces Proinflammatory Cytokine Expression, Microglial Activation, and Caspase-3 Activation in a Rodent Model of Diabetic Retinopathy. Diabetes, 2005. 54(5): p. 1559-1565. 


\section{APPENDIX}

Parts of the Chapter II, and Chapter III have been submitted as journal articles and are under review currently. 


\title{
CURRICULUM VITA
}

\author{
Rubens Petit Homme
}

Professional Address:

Department of Physiology - Eye and

Vision Science Laboratory

University of Louisville School of

Medicine

323 E Chestnut St

HSC - 1204

Louisville, KY40202

Phone: 502-852-6231

Fax 502-852-6239

Email: r0peti01@Louisville.edu

Place of Birth:

La Pointe, Port-de-Paix, Haiti

Education:

Department of Physiology \&

Biophysics (Dr. Suresh C. Tyagi)

University of Louisville

M.S. in Physiology, May 2019

Department of Chemistry

Florida Southern College

B.S. in Chemistry, 2012-2016

\section{Awards and honors:}

Integrated Programs in Biomedical Sciences Doctoral Fellowship 20162018

NIHLBI Graduate Student Diversity Supplement 2019

Graduate Student Council Executive Board 2018-2019

Kentucky Chapter of the American Physiological Society, 2019 Meritorious Graduate Student Council Poster Presentation, First Place 


\section{Professional Organizations:}

American Physiological Society, Nov. 2016

American Society for Investigative Pathology, Oct. 2017

\section{Community Involvement:}

Indian Cultural Foundation - Oct. 2017

\section{Graduate Student Council}

Vice President of External Affairs - (September 2018-August 2019)

Department of Physiology Representative- (August 2018 - Present)

Kentucky State Science Fair Judge (Middle/Junior High)

\section{Abstracts:}

1. Rubens P Homme, Naira Metreveli, Sudhakar Veeranki, and Suresh Tyagi, Exercise ameliorates the development of diabetic retinopathy, FASEB, Volume 31, Apr 2017

2. Rubens P Homme, Mahavir Singh, Avisek Majumder, Akash George, Suresh Tyagi, Inhibition of Inflammation and Pyroptosis mitigate Diabetic Retinopathy via Suppressing Receptor Activated NF-kB Ligand (RANK-1), Volume 32, 01 Apr 2018

3. Akash K. George, Mahavir Singh, Rubens P Homme, Avisek Majumder, and, Suresh Tyagi, Role of Hydrogen Sulfide $\left(\mathrm{H}_{2} \mathrm{~S}\right)$ on Homocysteine Mediated Glutamate Excitotoxicity, Endoplasmic Reticulum Stress and Pyroptosis in Retina, Volume 32, Apr 2018

4. Rubens P Homme, Laha Anewesha, Avisek Majumder, Akash K. George, Mahavir Singh, and Suresh Tyagi, NF-kB p65 Subunit Inhibitor: JSH-23 mitigates Diabetic Retinopathy via Reducing Oxidative Stress, FASEB, Volume 33, April 2019

5. Avisek Majumder, Mahavir Singh, Akash K. George, Rubens $\mathbf{P}$ Homme, Naira Metreveli, Suresh Tyagi, Lactobacillus rhamnosus GG improves skeletal muscle fatigability in a mouse model of hyperhomocysteinemia, FASEB, Volume 33, April 2019 
6. Akash K. George, Mahavir Singh, Avisek Majumder, Rubens P Homme, Naira Metreveli, Sathnur B Pushpakumar, Suresh Tyagi, Hyperhomocysteinemia and the effects of Lactobacillus rhamnosus GG on cardiac functions in $\mathrm{CBS}^{+/-}$mice, FASEB, Volume 33, April 2019

7. Mahavir Singh, Akash K. George, Rubens P Homme, Avisek Majumder, Laha Anewesha, Naira Metreveli, Sathnur B Pushpakumar, Suresh Tyagi, Probiotic supplementation mitigates vascular remodeling in the Retina, FASEB, Volume 33, April 2019

\section{Manuscripts:}

1. Rubens PH, Mahavir S, Avisek M, Akash KG, Kavya N, Harpal SS, Neetu T, David L, and Suresh CT, Remodeling of Retinal Architecture in Diabetic Retinopathy: Disruption of Ocular Physiology and Visual Functions by Inflammatory Gene Products and Pyroptosis, Frontiers in Physiology, Aug 2018

2. Avisek M, Mahavir S, Akash K G, Rubens PH, Laha A., and Suresh CT, Remote ischemic conditioning as a cytoprotective strategy in vasculopathies during hyperhomocysteinemia: An emerging research perspective, Journal of Cellular Biochemistry, Sep 2018

3. Akash KG, Mahavir Singh, Rubens PH, Avisek M, Harpal SS, and Suresh CT, A hypothesis for treating inflammation and oxidative stress with hydrogen sulfide during age-related macular degeneration, International Journal of Ophthalmology, May 2018

4. Mahavir Singh, Akash KG, Rubens PH, Avisek M, Laha A., Harpal SS, and Suresh CT, Circular RNAs profiling in the cystathionine- $\beta$-synthase mutant mouse reveals novel gene targets for hyperhomocysteinemia induced ocular disorders, Experimental Eye Research, May 2018

5. Akash KG, Rubens PH, Avisek M, Suresh CT, and Mahavir S, Effect of MMP-9 gene knockout on retinal vascular function, Physiology Genomics, December 2019

6. Hardin SJ, Mahavir S, Eyob W, Molnar JC, Rubens PH, Akash KG, and Suresh CT, Diet-induced chronic syndrome, metabolically transformed trimethylamine-N-Oxide, and the cardiac dysfunctions, Reviews in Cardiovascular Medicine, September 2019 
7. Akash KG, Mahavir S, Pushpakumar S, Rubens PH,Hardin SJ, Suresh CT, Dysbiotic 1-carbon metabolism in cardiac muscle remodeling, Journal of Cell Physiology, March 2020

8. Akash KG, Avisek M, Ice H, Rubens PH, Eyob W, Suresh $\mathrm{CT}$, and Mahavir S, Genes and genetics in hyperhomocysteinemia and the "1-carbon metabolism": implications for retinal structure and eye functions, Journal of Physiology and Pharmacology, February 2020

9. Laha A, Mahavir S, Akash KG, Rubens PH, and Suresh CT, Dysregulations of 1-carbon metabolism and muscle atrophy: potential roles of forkhead box O proteins and PPARy coactivator-1a, Canadian Journal of Physiology and Pharmacology, November 2019

10. Akash KG, Rubens PH, Avisek M, Laha A, Metreveli N, Sandhu HS, and Suresh CT, Hydrogen sulfide intervention in cystathionine-b-synthase mutant mouse helps restore ocular homeostasis, International Journal of Ophthalmology, May 2019

11. Akash KG, Master K, Avisek M, Rubens PH, Laha A, Sandhu HS, Suresh CT, and Mahavir S, Circular RNAs constitute an inherent gene regulatory axis in the mammalian eye and brain, Canadian Journal of Physiology and Pharmacology, June 2019

12. Mahavir S, Akash KG, Rubens PH, Avisek M, Laha A, Sandhu HS, and Suresh CT, Expression analysis of the circular RNA molecules in the human retinal cells treated with homocysteine, Current Eye Research, March 2019

\section{Poster:}

1. Rubens Petit Homme, Naira Metreveli, Sudhakar Veeranki, and Suresh Tyagi, Exercise ameliorates the development of diabetic retinopathy, Experimental Biology, April 2017, Chicago

2. Rubens Petit Homme, Akash George,Mahavir Singh, and Suresh Tyagi, Modulation of Inflammatory Pathway mitigates Diabetic retinopathy, Kentucky Physiological Society, April 2018, Louisville

3. Rubens Petit Homme, Mahavir Singh, Avisek Majumder, Akash George, and Suresh Tyagi, Inhibition of Inflammation and Pyroptosis mitigate Diabetic Retinopathy via Suppressing Receptor Activated NF-kB Ligand (RANK-l), Experimental Biology, April 2018, San Diego

4. Rubens Petit Homme, Laha Anewesha, Sashi Papu John, Avisek Majumder, Akash George, Mahavir Singh, and Suresh Tyagi, JSH23 Mitigates Diabetic Retinopathy via Reducing Oxidative Stress, Kentucky Physiology Society, March 2019, Northern Kentucky 
5. Rubens Petit Homme, Laha Anewesha, Sashi Papu John, Avisek Majumder, Akash George, Mahavir Singh, and Suresh Tyagi, Oxidative Stress Mechanisms in Diabetic Retinopathy, Experimental Biology, April 2019, Orlando

\section{Presentation:}

1. February 2019. Spencer Symposium, Florida Southern College Department of Chemistry and Physics Lakeland FL. Stopping Inflammation Could Prevent Diabetic Retinopathy.

2. March 2019. Physiology Seminar Series, University of Louisville School of Medicine Department of Physiology, Louisville KY. Modulation of Inflammatory Pathway by Inflammation Inhibitor (JSH-23) mitigates Diabetic Retinopathy 